\title{
Contribuição para o conhecimento de Chytridiomycota da "Reserva Biológica de Paranapiacaba", Santo André, SP, Brasil
}

\author{
Carmen Lidia Amorim Pires-Zottarelli ${ }^{1,2}$ \& Alexandra Lenk Gomes ${ }^{1}$
}

Biota Neotropica $v 7$ (n3) - http://www.biotaneotropica.org.br/v7n3/pt/abstract?inventory+bn02207032007

Recebido em 27/12/06

Versão reformulada recebida em 17/09/07

Publicado em 24/09/07

${ }^{1}$ Seção de Micologia e Liquenologia, Instituto de Botânica de São Paulo, CP 3005, CEP 01061-970, São Paulo, Brasil

${ }^{2}$ Autor para correspondência: Carmen Lidia Amorim Pires-Zottarelli,e-mail: zottarelli@uol.com.br

\section{Abstract}

Pires-Zottarelli, C.L.A. \& Gomes, A.L. Contribution to the knowledge of the Chytridiomycota from the "Reserva Biológica de Paranapiacaba", Santo André, State of São Paulo, Brazil. Biota Neotrop. Sep/Dez 2007 vol. 7, no. 3 http://www.biotaneotropica.org.br/v7n3/pt/abstract?inventory+bn02207032007. ISSN 1676-0603.

The diversity study of the chytrids from soil and water from the "Reserva Biológica de Paranapiacaba", yielded 29 species, with three Blastocladiales, 23 Chytridiales, one Monoblepharidales and two Spizellomycetales. From these, $69 \%$ taxa were cited for the first time for Reserve, $14 \%$ for São Paulo State and $7 \%$ for Brazil. Rhizophydium condylosum Karling is being mentioned for the first time in Brazil.

Keywords: Brazil, diversity, zoosporic fungi, Atlantic Rainforest.

\section{Resumo}

Pires-Zottarelli, C.L.A. \& Gomes, A.L. Contribuição para o conhecimento de Chytridiomycota da "Reserva Biológica de Paranapiacaba", Santo André, estado de São Paulo, Brasil. Biota Neotrop. Sep/Dez 2007 vol. 7, no. 3 http://www.biotaneotropica.org.br/v7n3/pt/abstract?inventory+bn02207032007. ISSN 1676-0603.

Estudo da diversidade de quitridiomicetos de solo e água, na "Reserva Biológica de Paranapiacaba", resultou no isolamento de 29 espécies, com três Blastocladiales, 23 Chytridiales, uma Monoblepharidales e duas Spizellomycetales. Dos táxons isolados, $69 \%$ são citados pela primeira vez para a Reserva, $14 \%$ para o estado de São Paulo, e 7\% para o país. É a primeira menção de Rhizophydium condylosum Karling no Brasil.

Palavras-chave: Brasil, diversidade, fungos zoospóricos, Mata Atlântica. 


\section{Introdução}

O filo Chytridiomycota inclui organismos heterotróficos com paredes quitinosas, nutrição por absorção, tendo todas as espécies um estágio zoospórico no seu ciclo de vida (Barr 1990). Este filo contém somente uma classe, Chytridiomycetes, sendo a única pertencente ao reino Fungi que produz células móveis. Com exceção as poucas espécies com células poliflageladas, as células móveis (zoósporos e gametas) destes organismos possuem um único flagelo tipo chicote, posteriormente inserido (Alexopoulos et al. 1996). A classe é subdividida, principalmente, com base na ultraestrutura dos zoósporos, em cinco principais ordens, Blastocladiales, Chytridiales, Monoblepharidales, Neocallimasticales e Spizellomycetales (Hawksworth et al. 1995, Barr 2001).

Os fungos pertencentes a este filo são similares aos fungos superiores pela composição de suas paredes celulares, bioquímica celular, bem como pela análise seqüencial das subunidades ribossômicas. Sem se considerar aspectos bioquímicos ou moleculares, há espécies filamentosas entre os Chytridiomycota para justificar sua relação com os fungos superiores (Barr 1990, 1992). Outras características que possuem em comum com os outros fungos são: a estrutura cenocítica do talo e a conversão do zigoto em esporo ou esporângio de resistência, ou no desenvolvimento de talo diplóide. Possuem talo de desenvolvimento endógeno ou exógeno, holocárpico ou eucárpico, monocêntrico, policêntrico, rizoidal ou micelial; paredes celulares com quitina e glucanos; cristas mitocondriais achatadas; divisões intranucleares cêntricas; zoósporos sem mastigonemas ou escamas (flagelo tipo chicote), com um único sistema de raízes flagelares e algumas vezes rumposomos. Reprodução assexual por meio de zoósporos e, a sexual por copulação planogamética, copulação de gametângios ou somatogamia (Hawksworth et al. 1995, Alexopoulos et al. 1996).

Estes fungos estão presentes nos ecossistemas terrestres e aquáticos, vivendo saprobicamente ou parasitando algas, anfíbios, outros fungos, animais microscópicos e, plantas superiores. Olpidium brassicae (Woronin) Dang é vetor de inúmeras viroses em plantas de interesse econômico e, Synchytrium endobioticum (Schilb.) Percival é responsável pela doença conhecida como verruga preta da batata. Os representantes de Neocallimasticales são anaeróbios obrigatórios em rúmen e ceco de herbívoros (Alexopoulos et al. 1996). Batrachochytridium dendrobatidis Longcore tem merecido atenção especial por ser responsável pelo declínio da população de anfíbios nativos em várias partes do mundo, inclusive no Brasil (Carnaval et al. 2005).

No Brasil, se conhece aproximadamente somente cerca de $15 \%$ dos táxons de Chytridiomycota já registrados no mundo. Em áreas de Mata Atlântica, mesmo se considerando a importância da mesma, poucos ainda são os estudos sobre sua diversidade (Milanez et al. 1994a, Schoenlein-Crusius \& Milanez 1996, Pires-Zottarelli 1999). Na Reserva Biológica de Paranapiacaba, os estudos anteriormente realizados (Rogers et al. 1970, Schoenlein-Crusius et al. 1992, Antunes et al. 1993, Pires-Zottarelli et al. 1993, Schoenlein-Crusius \& Milanez 1998; Schoenlein-Crusius et al. 1999), contribuíram para o conhecimento da diversidade e ecologia dos fungos zoospóricos da reserva, resultando no conhecimento de 16 táxons pertencentes ao filo Chytridiomycota, com 11 ao nível específico.

O objetivo deste estudo foi o de contribuir para o conhecimento dos quitridiomicetos da Reserva Biológica de Paranapiacaba, importante fragmento de Mata Atlântica localizado no município de Santo André, estado de São Paulo.

\section{Material e Métodos}

A Reserva Biológica de Paranapiacaba (23 46' S e 46 18' W), com 336 ha, sob responsabilidade do Instituto de Botânica de São
Paulo, está situada no município de Santo André a $50 \mathrm{~km}$ da cidade de São Paulo, próxima ao complexo da Serra do Mar. A Reserva situa-se na região de transição entre a floresta tropical úmida e subtropical, coberta pela Mata Atlântica e rica em espécies arbóreas, lianas e epífitas (Domingos, 1987). O relevo é montanhoso com altitude variando de 750 a $890 \mathrm{~m}$. A umidade relativa é próxima a $100 \%$, e o elevado índice de precipitação durante todo o ano caracteriza o clima como super-úmido, sem estações secas (Funari et al 1986 apud Schoenlein-Crusius 1993). O solo é arenoso, ácido, com alto teor de húmus na camada superficial (Brasil 1960 apud De Vuono et al. 1989). Diversos riachos percorrem a reserva, os quais possuem leito arenoso, com água transparente e temperaturas variando de 9 a $20^{\circ} \mathrm{C}$, pH entre 5,0 a 7,0, teor de oxigênio dissolvido oscilando entre 5,0 a 16,0 mg.L $\mathrm{L}^{-1}$ (Schoenlein-Crusius 1993).

Para o estudo da diversidade dos quitridiomicetos, amostras de água e solo foram coletadas trimestralmente de Novembro/2003 a Novembro/2004 na Reserva, em oito pontos pré-demarcados com auxílio de GPS ("Sistema de Posicionamento Global") e, tratadas pelo método de iscagem múltipla descrito em Milanez (1989), o qual consiste na iscagem dos fungos, em laboratório e, em campo, com auxílio de "iscas" celulósicas, quitinosas e queratinosas. Para a identificação dos táxons foram utilizadas literaturas específicas, principalmente as monografias de Sparrow (1960) e Karling (1977), além de artigos contendo as descrições originais dos táxons. Os espécimes foram incorporados ao herbário do Instituto de Botânica de São Paulo (SP), em lâminas semi-permanentes montadas com resina polivinílica com glicerina e/ou lactofenol com azul de algodão, vedadas com esmalte incolor, tendo em vista a dificuldade de crescimento em meio de cultura.

\section{Resultados e Discussão}

Vinte e nove táxons de Chytridiomycota foram identificados, representando quatro ordens, Blastocladiales (três), Chytridiales (23), Monoblepharidales (um) e Spizellomycetales (dois) (Tabela 1). Os táxons são apresentados em ordem alfabética dentro das respectivas ordens e famílias.

\section{CHYTRIDIOMYCOTA \\ CHYTRIDIOMYCETES \\ BLASTOCLADIALES \\ BLASTOCLADIACEAE}

Segundo Kirk et al. (2001), a família é composta por cinco gêneros, representada por Blastocladia neste estudo.

\section{Chave para as Espécies de Blastocladia}

1. Célula basal globosa ................................. Blastocladia globosa - Célula basal cilíndrica ........................................ pringsheimii

1. Blastocladia globosa Kanouse, Am. J. Bot. 14: 298. 1927. (Figura 1)

Célula basal globosa. Zoosporângios cilíndricos, longo-clavados, 58-141 x 10-20 $\mu \mathrm{m}$, por vezes decíduos, deixando cicatrizes na célula basal. Setas presentes, não ramificadas. Sistema rizoidal pouco desenvolvido. Esporos de resistência ausentes.

Material examinado: Brasil. São Paulo: Santo André, Reserva Biológica de Paranapiacaba, fruto submerso de Malus sp. em corpo d'água (23 46' 77' S e 46 18' 56" W), 26/V/2004 e 26/VIII/2004, Pires-Zottarelli, C.L.A. SP 381568. 
Tabela 1. Táxons de Chytridiomycota isolados da Reserva Biológica de Paranapiacaba de novembro/2003 a novembro/2004. $(\mathrm{A}=$ água/ $\mathrm{S}=$ solo)

Table 1. Taxa of the Chytridiomycota isolated from the "Reserva Biológica de Paranapiacaba" from November/2003 to November/2004. $(\mathrm{A}=$ water/S = soil).

\begin{tabular}{|c|c|c|c|c|c|c|}
\hline Táxons/Meses & nov/03 & fev/04 & maio/04 & ago/04 & nov/04 & $\mathbf{F} \%$ \\
\hline \multicolumn{7}{|l|}{ Reino Fungi } \\
\hline \multicolumn{7}{|l|}{ Filo Chytridiomycota } \\
\hline \multicolumn{7}{|l|}{ Chytridiomycetes } \\
\hline \multicolumn{7}{|l|}{ Blastocladiales } \\
\hline \multicolumn{7}{|l|}{ Blastocladiaceae } \\
\hline Blastocladia globosa Kanouse* & & & A & A & & 40 \\
\hline Blastocladia pringsheimii Reinsch* & & A & & & & 20 \\
\hline \multicolumn{7}{|l|}{ Catenariaceae } \\
\hline Catenophlyctis variabilis (Karling) Karling & A & A & $\mathrm{S}$ & & & 60 \\
\hline \multicolumn{7}{|l|}{ CHYTRIDIALES } \\
\hline \multicolumn{7}{|l|}{ Chytridiaceae } \\
\hline Chytriomyces appendiculatus Karling* & $\mathrm{A} / \mathrm{S}$ & $\mathrm{A} / \mathrm{S}$ & A & A & & 80 \\
\hline Chytriomyces aureus Karling* & & A & A & A & & 60 \\
\hline Chytriomyces hyalinus Karling* & A & $\mathrm{A} / \mathrm{S}$ & A & A & A & 100 \\
\hline Chytriomyces spinosus Fay* & $\mathrm{A} / \mathrm{S}$ & $\mathrm{A} / \mathrm{S}$ & $\mathrm{A} / \mathrm{S}$ & $\mathrm{A} / \mathrm{S}$ & $\mathrm{A} / \mathrm{S}$ & 100 \\
\hline Phlyctochytrium aureliae Ajello* & & $\mathrm{S}$ & & & & 20 \\
\hline Rhizidium verrucosum Karling** & & S & S & & & 40 \\
\hline Rhizophydium condylosum Karling*** & & S & & & & 20 \\
\hline Rhizophydium coronum Hanson* & & S & & & & 20 \\
\hline Rhizophydium elyensis Sparrow & S & $\mathrm{A} / \mathrm{S}$ & $\mathrm{A} / \mathrm{S}$ & $\mathrm{S}$ & $\mathrm{S}$ & 100 \\
\hline Rhizophydium keratinophilum Karling* & & A & & & & 20 \\
\hline Rhizophydium macroporosum Karling* & & & $\mathrm{S}$ & & & 20 \\
\hline Rhizophydium sphaerotheca Zopf & $\mathrm{A} / \mathrm{S}$ & $\mathrm{A} / \mathrm{S}$ & A & $\mathrm{A} / \mathrm{S}$ & $\mathrm{A} / \mathrm{S}$ & 100 \\
\hline Rhizophydium stipitatum Sparrow & & $\mathrm{S}$ & & A & & 40 \\
\hline Septosperma rhizophydii Whiffen ex Blackw. \& Powell* & S & S & $S$ & $\mathrm{~S}$ & $\mathrm{~S}$ & 100 \\
\hline \multicolumn{7}{|l|}{ Cladochytriaceae } \\
\hline Cladochytrium replicatum Karling & S & A & A & A & & 80 \\
\hline Cladochytrium tenue Karling** & & A & & A & A & 60 \\
\hline Nowakowskiella elegans (Nowak.) Schroeter & $\mathrm{A} / \mathrm{S}$ & $\mathrm{A} / \mathrm{S}$ & A & A & A & 100 \\
\hline Nowakowskiella multispora Karling* & & & & A & & 20 \\
\hline Polychytrium aggregatum Ajello & $\mathrm{A} / \mathrm{S}$ & $\mathrm{A} / \mathrm{S}$ & $\mathrm{A} / \mathrm{S}$ & $\mathrm{S}$ & A & 100 \\
\hline Septochytrium marilandicum Karling* & $\mathrm{S}$ & & & & $\mathrm{S}$ & 40 \\
\hline \multicolumn{7}{|l|}{ Endochytriaceae } \\
\hline Diplophlyctis asteroidea Dogma* & & & A & & A & 40 \\
\hline Diplophlyctis sarcoptoides (H.E. Petersen) Dogma & & & & A & & 20 \\
\hline Entophlyctis luteolus Longcore*** & $\mathrm{A} / \mathrm{S}$ & $\mathrm{A} / \mathrm{S}$ & $\mathrm{A} / \mathrm{S}$ & $\mathrm{A} / \mathrm{S}$ & $\mathrm{A} / \mathrm{S}$ & 100 \\
\hline \multicolumn{7}{|l|}{ MONOBLEPHARIDALES } \\
\hline \multicolumn{7}{|l|}{ Gonapodyaceae } \\
\hline Gonapodya prolifera (Cornu) Fischer* & & & A & A & & 40 \\
\hline \multicolumn{7}{|l|}{ Spizellomycetales } \\
\hline \multicolumn{7}{|l|}{ Spizellomycetaceae } \\
\hline Karlingia granulata Karling* & $\mathrm{A} / \mathrm{S}$ & $\mathrm{A} / \mathrm{S}$ & $\mathrm{A} / \mathrm{S}$ & $\mathrm{A} / \mathrm{S}$ & $\mathrm{A} / \mathrm{S}$ & 100 \\
\hline Karlingia rosea (de Bary \& Woronin) Johanson & & & A & & & 20 \\
\hline Total & 13 & 21 & 19 & 18 & 12 & \\
\hline
\end{tabular}

\footnotetext{
* Primeira citação para a Reserva

** Primeira citação para o estado de São Paulo

**** Primeira citação para o Brasil

* First citation for Reserve

** First citation for São Paulo State

**** First citation for Brazil
} 
As características do espécime examinado concordam com Sparrow (1960), Karling (1977), Milanez \& Trufem (1981, 1984) e Milanez et al. (2003). É a primeira citação da espécie para a Reserva.

\section{Blastocladia pringsheimii Reinsch, Jahrb. wiss. Bot. 11:298 1878.}

(Figura 2)

Célula basal cilíndrica, parte distal expandida, formando lóbulos dilatados, dicotomicamente ramificados. Zoosporângios cilíndricos,

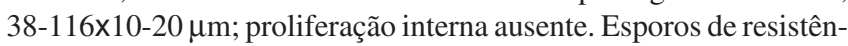
cia dispostos como os zoosporângios, esféricos ou subesféricos, truncados na base, 30-36 x 27,5-34 $\mu \mathrm{m}$; germinação não observada.

Material examinado: Brasil. São Paulo: Santo André, Reserva Biológica de Paranapiacaba, fruto submerso de Malus sp. em corpo d'água (23 46' 77' S e 46 $18^{\circ}$ '56" W), 26/II/2004, Pires-Zottarelli, C.L.A. SP 381567.

As características do espécime examinado concordam com Sparrow (1960), Karling (1977) e Milanez \& Trufem (1981, 1984). É a primeira citação da espécie para a Reserva.

\section{CATENARIACEAE}

Segundo Kirk et al. (2001), a família é composta por três gêneros, representada por Catenophlyctis neste estudo.

\section{Catenophlyctis variabilis (Karling) Karling, Am. J. Bot., 52(2): 133-138. 1965.}

Basiônimo: Phlyctorhiza variabilis Karling, Am. J. Bot., 34:27-32. 1947. (Figura 3)

Talo eucárpico, policêntrico, monocêntrico no início do desenvolvimento, intramatrical. Zoosporângios normalmente irregulares, com um a três tubos de descarga para liberação dos zoósporos; parede lisa; sistema rizoidal bastante desenvolvido a partir de vários pontos da parede do zoosporângio. Esporos de resistência não observados.

Material examinado: Brasil. São Paulo: Santo André, Reserva Biológica de Paranapiacaba, amostra de água e/ou solo, ecdise de

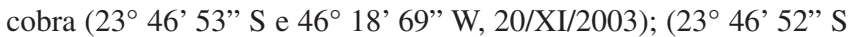
e $46^{\circ} 18^{\prime} 77^{\prime}$ 'W, $23^{\circ} 46^{\prime} 78^{\prime \prime} \mathrm{S}$ e $46^{\circ} 18^{\prime} 55^{\prime}$ ' W, 26/II/2004);

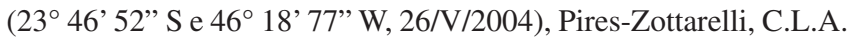
SP 381565 .

As características apresentadas pelos espécimes concordam com Karling $(1965,1977)$. A primeira citação da espécie para a Reserva é de Schoenlein-Crusius et al. (1992), de folhas de Alchornea triplinervia (Spreng.) Müll. Arg., Quercus robur L. e Ficus microcarpa L. f., em decomposição nos riachos.

\section{CHYTRIDIALES CHYTRIDIACEAE}

Segundo Kirk et al. (2001), a família é composta por 34 gêneros, dos quais apenas Chytriomyces, Phlyctochytrium, Rhizidium, Rhizophydium e Septosperma estão representados neste estudo.

\section{Chave para os Gêneros}

1. Zoosporângio operculado Chytriomyces

- Zoosporângio não operculado ... 2

2. Zoosporângio apofisado Phlyctochytrium

- Zoosporângio não apofisado. 3

3. Sistema rizoidal não ramificado .Septosperma - Sistema rizoidal ramificado.... .... 4
4. Sistema rizoidal normalmente distinto e prolongado; zoósporos, quando liberados, formam uma massa, onde permanecem agrupados por alguns minutos ou nadam imediatamente

Rhizidium

- Sistema rizoidal normalmente distinto e não prolongado; zoósporos, quando liberados, não formando uma massa ...

Rhizophydium

Os gêneros Rhizophydium e Chytriomyces foram os melhores representados.

\section{Chave para as Espécies de Chytriomyces}

1. Zoosporângios ornamentados ................ Chytriomyces spinosus - Zoosporângios não ornamentados .............................................. 2

2. Zoosporângios apendiculados......................... . appendiculatus

- Zoosporângios não apendiculados .......................................... 3

3. Zoósporos com gotícula lipídica amarelo-ouro............C. aureus

- Zoósporos com gotícula lipídica incolor.................. . hyalinus

\section{Chytriomyces appendiculatus Karling, Bull. Torrey Bot. Club. 74:335. 1947.}

(Figuras 4, 5)

Talo eucárpico, monocêntrico, extra e/ou intramatrical. Zoosporângios apendiculados, operculados, hialinos quando jovens, tornando-se amarelados e com paredes espessadas quando mais velhos, variáveis em forma e tamanho, irregularmente piriformes e/ ou reniformes, 20-62 x 17-57,5 $\mu \mathrm{m}$. Zoósporos com uma gotícula lipídica conspícua. Esporos de resistência não observados.

Material examinado: Brasil. São Paulo: Santo André, Reserva Biológica de Paranapiacaba, amostra de água e/ou solo, exoesqueleto

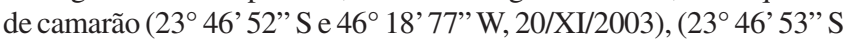
e $46^{\circ} 18^{\prime} 75^{\prime \prime} / 23^{\circ} 46^{\prime} 52^{\prime \prime} \mathrm{S}$ e $46^{\circ} 18^{\prime} 77^{\prime \prime} \mathrm{W} / 23^{\circ} 46^{\prime} 53^{\prime \prime} \mathrm{S}$ e $\left.46^{\circ} 18^{\prime} 69^{\prime \prime} \mathrm{W}, 26 / \mathrm{II} / 2004\right),\left(23^{\circ} 46^{\prime} 78^{\prime \prime} \mathrm{S}\right.$ e $46^{\circ} 18^{\prime} 55^{\prime \prime} \mathrm{W} /$

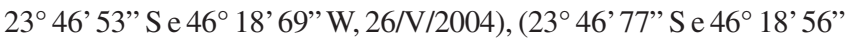
W, 26/VIII/2004), Pires-Zottarelli, C.L.A. SP 381564.

As características dos espécimes concordam com Karling (1947a, 1977). Os espécimes examinados apresentaram crescimento somente em substrato quitinoso, exoesqueleto de camarão, onde se observou abundante colonização. É a primeira citação da espécie para a Reserva.

\section{Chytriomyces aureus Karling, Am. J. Bot. 32: 363.1945.}

(Figuras 6, 7)

Talo eucárpico, monocêntrico, extra e/ou intramatrical. Zoosporângios operculados, esféricos, 21-26 $\mu \mathrm{m}$ diâm; parede lisa. Apófise sub-esporangial presente. Liberação dos zoósporos por meio de um opérculo, localizado apical ou subapicalmente nos zoosporângios. Zoósporos encistados, aproximadamente $6 \mu \mathrm{m}$ diâm., com uma gotícula lipídica amarelo-ouro. Esporos de resistência não observados.

Material examinado: Brasil. São Paulo: Santo André, Reserva Biológica de Paranapiacaba, amostra de água, exoesqueleto de camarão ( $23^{\circ} 46^{\prime} 53^{\prime \prime} \mathrm{S}$ e $46^{\circ} 18^{\prime} 75^{\prime}$ ' W, 26/II/2004), (23 46' $78^{\prime \prime} \mathrm{S}$ e $46^{\circ} 18^{\prime} 55^{\prime \prime} \mathrm{W} / 23^{\circ} 46^{\prime} 5^{\prime \prime} \mathrm{S}$ e $46^{\circ} 18^{\prime} 77^{\prime \prime} \mathrm{W} / 23^{\circ} 46^{\prime} 53^{\prime \prime} \mathrm{S}$ e $\left.46^{\circ} 18^{\prime} 75^{\prime \prime} \mathrm{W}, 26 / \mathrm{V} / 2004\right)$, (23 $46^{\prime} 78^{\prime \prime} \mathrm{S}$ e $46^{\circ} 18^{\prime} 55^{\prime \prime} \mathrm{W} /$ $23^{\circ} 46^{\prime} 52^{\prime \prime} \mathrm{S}$ e $46^{\circ} 18^{\prime} 77^{\prime \prime} \mathrm{W} / 23^{\circ} 46^{\prime} 52^{\prime \prime} \mathrm{S}$ e $46^{\circ} 18^{\prime} 77^{\prime}$ 'W, 26 / VIII/2004), Pires-Zottarelli, C.L.A. SP 381563.

As características dos espécimes examinados concordam com Karling (1945a), o qual descreveu a espécie de substratos quitinosos da cidade de Flores Nabuco, perto de Manaus (AM). É a primeira citação para a Reserva. 


\section{Chytriomyces hyalinus Karling, Am. J. Bot. 32:363.1945.}

(Figuras 8, 9)

Talo eucárpico, monocêntrico, extra e/ou intramatrical. Zoosporângios operculados, hialinos, esféricos, 20-40 $\mu \mathrm{m}$ diâm.; parede lisa. Liberação dos zoósporos por meio de opérculo, localizado apical ou subapicalmente nos zoosporângios. Zoósporos encistados, 4-5 $\mu \mathrm{m}$ diâm., com uma gotícula lipídica hialina. Esporos de resistência não observados.

Material examinado: Brasil. São Paulo: Santo André, Reserva Biológica de Paranapiacaba, amostra de água e solo, ecdise de cobra e exoesqueleto de camarão (23 $46^{\prime} 53^{\prime \prime}$ S e $46^{\circ} 18^{\prime} 75^{\prime \prime}$ W/ $23^{\circ} 46^{\prime} 52^{\prime \prime} \mathrm{S}$ e $46^{\circ} 18^{\prime} 77^{\prime \prime} \mathrm{W} / 23^{\circ} 46^{\prime} 53^{\prime \prime} \mathrm{S}$ e $46^{\circ} 18^{\prime} 69^{\prime \prime} \mathrm{W} /$ $23^{\circ} 46^{\prime} 77^{\prime \prime} \mathrm{S}$ e $\left.46^{\circ} 18^{\prime} 56^{\prime \prime} \mathrm{W}, 20 / \mathrm{XI} / 2003\right)$, (23 46' 53" S e $46^{\circ} 18^{\prime} 75^{\prime \prime} \mathrm{W} / 23^{\circ} 46^{\prime} 52^{\prime \prime} \mathrm{S}$ e $46^{\circ} 18^{\prime} 77^{\prime \prime}, 23^{\circ} 46^{\prime} 53^{\prime \prime} \mathrm{S}$ e $46^{\circ} 18^{\prime} 75^{\prime}, 23^{\circ} 46^{\prime} 78^{\prime \prime}$ S e $46^{\circ} 18^{\prime}$ 55” W, 26/II/2004), (23 46' 78" S e $\left.46^{\circ} 8^{\prime} 55^{\prime \prime} \mathrm{W}\right) / 23^{\circ} 46^{\prime} 53^{\prime \prime} \mathrm{S}$ e $46^{\circ} 18^{\prime} 75^{\prime \prime} \mathrm{W} / 23^{\circ} 46^{\prime} 52^{\prime \prime} \mathrm{S}$ e $46^{\circ} 18^{\prime} 77^{\prime \prime} \mathrm{W} / 23^{\circ} 46^{\prime} 53^{\prime \prime} \mathrm{S}$ e $46^{\circ} 18^{\prime} 69^{\prime \prime} \mathrm{W} / 23^{\circ} 46^{\prime} 77^{\prime \prime}$ $\mathrm{S}$ e $\left.46^{\circ} 18^{\prime} 56^{\prime \prime}, 26 / \mathrm{V} / 2004\right)$, (23 $46^{\prime} 52^{\prime \prime} \mathrm{S}$ e $46^{\circ} 18^{\prime} 77^{\prime \prime} \mathrm{W} /$ $23^{\circ} 46^{\prime} 52^{\prime \prime}$ S e $46^{\circ} 18^{\prime} 77^{\prime \prime} / 23^{\circ} 46^{\prime} 53^{\prime \prime} \mathrm{S}$ e $46^{\circ} 18^{\prime} 75^{\prime}$ " $/ 23^{\circ} 46^{\prime}$ ' $77^{\prime \prime} \mathrm{S}$ e $\left.46^{\circ} 18^{\prime} 56^{\prime \prime} \mathrm{W}, 26 / \mathrm{VIII} / 2004\right)$, (234 $46^{\prime} 52^{\prime \prime}$ S e $46^{\circ} 18^{\prime} 77^{\prime \prime} \mathrm{W}, 18 /$ XI/2004), Pires-Zottarelli, C.L.A. SP 381570.

As características dos espécimes concordam com Karling (1945a), que a isolou de substratos quitinosos coletados na cidade de Flores Nabuco, perto de Manaus (AM). É a primeira citação da espécie para a Reserva.

\section{Chytriomyces spinosus Fay, Mycologia 39:152. 1947.}

(Figuras 10 - 12)

Talo eucárpico, monocêntrico, extra-intramatrical. Zoosporângios operculados, hialinos, ornamentados com espinhos simples e bifurcados, esféricos, 15-42,5 $\mu \mathrm{m}$, alguns obpiriformes, 15-34 x 16-36 $\mu \mathrm{m}$. Liberação dos zoósporos por meio de opérculo delicado localizado apicalmente nos zoosporângios, de difícil visualização. Zoósporos encistados, 4-5 $\mu \mathrm{m}$ diâm., com uma gotícula lipídica conspícua. Esporos de resistência não observados.

Material examinado: Brasil. São Paulo: Santo André, Reserva Biológica de Paranapiacaba, amostra de água e solo, epiderme de cebola, palha de milho e celofane (23 $46^{\prime} 78^{\prime \prime} \mathrm{S}$ e $46^{\circ} 18^{\prime} 55^{\prime \prime} \mathrm{W} /$ $23^{\circ} 46^{\prime} 52^{\prime \prime}$ S e $46^{\circ} 18^{\prime} 77^{\prime \prime}$ W/ $23^{\circ} 46^{\prime} 53^{\prime \prime}$ S e $46^{\circ} 18^{\prime} 75^{\prime \prime} / 23^{\circ} 46^{\prime} 53^{\prime \prime} \mathrm{S}$ e $46^{\circ} 18^{\prime} 69^{\prime \prime} \mathrm{W} / 23^{\circ} 46^{\prime} 77^{\prime \prime} \mathrm{S}$ e $\left.46^{\circ} 18^{\prime} 56^{\prime \prime} \mathrm{W}, 20 / \mathrm{XI} / 2003\right)$, $\left(23^{\circ} 46^{\prime} 78^{\prime \prime} \mathrm{S}\right.$ e $46^{\circ} 18^{\prime} 55^{\prime \prime} \mathrm{W} / 23^{\circ} 46^{\prime} 52^{\prime \prime} \mathrm{S}$ e $46^{\circ} 18^{\prime} 77^{\prime \prime} \mathrm{W} /$ $23^{\circ} 46^{\prime} 53^{\prime \prime} \mathrm{S}$ e $46^{\circ} 18^{\prime} 75^{\prime \prime} / 23^{\circ} 46^{\prime} 77^{\prime \prime} \mathrm{S}$ e $46^{\circ} 18^{\prime} 56^{\prime \prime} \mathrm{W}, 26 /$

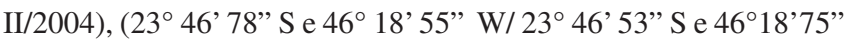
$\mathrm{W} / 23^{\circ} 46^{\prime} 52^{\prime \prime} \mathrm{S}$ e $46^{\circ} 18^{\prime} 77^{\prime \prime} \mathrm{W} / 23^{\circ} 46^{\prime} 53^{\prime \prime} \mathrm{S}$ e $46^{\circ} 18^{\prime} 69^{\prime \prime}$ W/ $23^{\circ} 46^{\prime} 77^{\prime \prime} \mathrm{S}$ e $\left.46^{\circ} 18^{\prime} 56^{\prime \prime} \mathrm{W}, 26 / \mathrm{V} / 2004\right),\left(23^{\circ} 46^{\prime} 78^{\prime \prime} \mathrm{S}\right.$ e $46^{\circ} 18^{\prime} 55^{\prime \prime} \mathrm{W} / 23^{\circ} 46^{\prime} 53^{\prime \prime} \mathrm{S}$ e $46^{\circ} 18^{\prime} 75^{\prime \prime} \mathrm{W} / 23^{\circ} 46^{\prime} 52^{\prime \prime} \mathrm{S}$ e $46^{\circ} 18^{\prime} 77^{\prime \prime} \mathrm{W} / 23^{\circ} 46^{\prime} 53^{\prime \prime} \mathrm{S}$ e $46^{\circ} 18^{\prime} 69^{\prime \prime}$ W/ $23^{\circ} 46^{\prime} 77^{\prime}$ ' S e $\left.46^{\circ} 18^{\prime} 56^{\prime \prime} \mathrm{W}, 26 / \mathrm{VIII} / 2004\right), 23^{\circ} 46^{\prime} 78^{\prime \prime} \mathrm{S}$ e $46^{\circ} 18^{\prime} 55^{\prime \prime} \mathrm{W} /$ $23^{\circ} 46^{\prime} 53^{\prime \prime} \mathrm{S}$ e $46^{\circ} 18^{\prime} 75^{\prime \prime} \mathrm{W} / 23^{\circ} 46^{\prime} 52^{\prime \prime} \mathrm{S}$ e $46^{\circ} 18^{\prime} 77^{\prime \prime} \mathrm{W} /$ $23^{\circ} 46^{\prime} 53^{\prime \prime}$ S e $46^{\circ} 18^{\prime} 69^{\prime \prime} \mathrm{W} / 23^{\circ} 46^{\prime} 77^{\prime \prime} \mathrm{S}$ e $46^{\circ} 18^{\prime} 56^{\prime \prime} \mathrm{W}, 18 /$ XI/2004), Pires-Zottarelli, C.L.A. SP 381571.

As características apresentadas pelos espécimes concordam com Fay (1947), Sparrow (1960) e Karling (1977). A espécie é estritamente celulolítica, ocorrendo usualmente em palha de milho e epiderme de cebola, colocados com iscas. É a primeira citação da espécie para a Reserva.

\section{Phlyctochytrium aureliae Ajello, Mycologia 37:111. 1945.}

(Figura 13)

Talo eucárpico, monocêntrico, extra-intramatrical. Zoosporângios ornamentados, hialinos, apofisados, esféricos, 25-37,5 $\mu \mathrm{m}$ diâm.; apófises esféricas, compostas; ornamentações espinhosas, bifurcadas.
Zoósporos com uma única gotícula lipídica. Esporos de resistência não observados.

Material examinado: Brasil. São Paulo: Santo André, Reserva Biológica de Paranapiacaba, amostra de solo, ecdise de cobra (23 46' 52" S e 46 18' 77' W, 26/II/2004), Pires-Zottarelli, C.L.A. SP 381572.

As características apresentadas pelos espécimes examinados concordam com Ajello (1945), Sparrow (1960) e Karling (1977). Apófises compostas são geralmente observadas nas espécies do gênero, segundo Karling (1977). O táxon é muito próximo de Phlyctochytrium mucronatum Canter, entretanto, não apresentou em nenhum dos zoosporângios observados, um típico espinho piramidal apical, como relatado na literatura (Canter 1949, Sparrow 1960). Foi observada pela primeira vez no país por A.I. Milanez (dados não publicados) de amostras de solo do estado de São Paulo (Limeira, BR 147, Km 110; Pedrinhas e Riacho Grande). É a primeira citação da espécie para a Reserva.

\section{Rhizidium verrucosum Karling, Am. J. Bot. 31: 255.1944.}

(Figuras 14 - 17)

Talo eucárpico, monocêntrico, extra-intramatrical. Zoosporângios ornamentados, esféricos, 22,5-75 $\mu \mathrm{m}$ diâm.; coloração marrom a âmbar; ornamentações verrucosas. Zoósporos encistados, 6-7,5 $\mu \mathrm{m}$ diâm., com uma única gotícula lipídica. Esporos de resistência não observados.

Material examinado: Brasil. São Paulo: Santo André, Reserva Biológica de Paranapiacaba, amostra de solo, ecdise de cobra

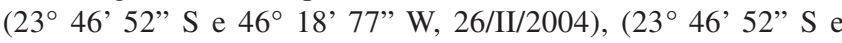
$46^{\circ} 18^{\prime} 77^{\prime}$ 'W, 26/V/2004), Pires-Zottarelli, C.L.A. SP 381569.

A descrição original é de Karling (1944) do Brasil, o qual coletou espécimes de exúvia de inseto e, substrato celulósico como epiderme de cebola e grama, de um igarapé de Rondônia. As características dos espécimes examinados concordam com o autor, entretanto, o mesmo cita zoósporos pouco menores e ovais, de 3-3,5 x 5-5,5 $\mu \mathrm{m}$. Esta é a primeira vez que o táxon é mencionado no Brasil após sua descrição original, sendo esta a primeira citação para o estado de São Paulo.

\section{Chave para as Espécies de Rhizophydium}

1. Zoosporângios com ornamentações espinhosas.. Rhizophydium keratinophilum

- Zoosporângios sem ornamentações. . .2

2. Halos concêntricos ao redor do zoosporângio R. coronum

- Halos concêntricos não formados ao redor do zoosporângio 3

3. Eixo principal rizoidal para fora do substrato............ stipitatum

Eixo principal rizoidal para dentro do substrato ..................... 4

4. Zoosporângios esféricos, com 2 poros para liberação dos zoósporos R. sphaerotheca

- Zoosporângios esféricos, normalmente com mais que 2 poros para liberação dos zoósporos ...................................................... 5

5. Zoosporângios esféricos, angulares na maturidade ..... R. elyensis

- Zoosporângios esféricos, não angulares. 6

6. Zoosporângios esféricos, 9-28,5 $\mu \mathrm{m}$ diâm.; zoósporos liberados por meio de duas a 10 papilas condilóides ..........R. condylosum

- Zoosporângios esféricos, 23-57,5 $\mu \mathrm{m}$ diâm.; zoósporos liberados por meio de duas a seis papilas não condilóides .....

R. macroporosum 


\section{Rhizophydium condylosum Karling, Archiv. Mikrobiol. 61:118-119. 1968.}

(Figura 18)

Talo eucárpico, monocêntrico, extra-intramatrical. Zoosporângios inoperculados, esféricos, (9-) 15-28,5 $\mu \mathrm{m}$ diâm., com duas a 10 papilas condilóides para liberação dos zoósporos. Zoósporos com uma única gotícula lipídica. Esporos de resistência não observados.

Material examinado: Brasil. São Paulo: Santo André, Reserva Biológica de Paranapiacaba, amostra de solo, ecdise de cobra (23 46' 52" S e 46 18' 77” W, 26/II/2004), Pires-Zottarelli, C.L.A. SP 381569 .

O espécime de fácil observação em substrato queratinoso, colonizou grande parte dele. As papilas formadas para liberação dos zoósporos dão aos zoosporângios aspecto irregular. As características apresentadas pelo espécime concordam com Karling $(1968,1977)$ e Konno (1972). É a primeira citação da espécie para o Brasil.

\section{Rhizophydium coronum Hanson, Torreya 44:31. 1944.}

\section{(Figuras 19 - 21)}

Talo eucárpico, monocêntrico, extra-intramatrical. Zoosporângios inoperculados, hialinos, esféricos, 25-35 $\mu \mathrm{m}$ diâm., algumas vezes ovóides, 34-36 × 37-41 $\mu \mathrm{m}$, com halos concêntricos, normalmente um na maturidade, o qual se deliquesce antes da liberação dos zoósporos. Zoósporos com uma única gotícula lipídica. Esporos de resistência não observados.

Material examinado: Brasil. São Paulo: Santo André, Reserva Biológica de Paranapiacaba, amostra de solo, ecdise de cobra (23 46' 53" S e 46 18 ' 75" W, 26/II/2004), Pires-Zottarelli, C.L.A. SP 381553.

Esta interessante espécie foi mencionada para o Brasil por Booth (1979) de amostras de solo de duna em Cananéia (SP). As características visualizadas concordam com Hanson $(1944,1945)$. É a primeira citação para a Reserva.

\section{Rhizophydium elyensis Sparrow, Trans. Br. mycol. Soc., 40:523-535. 1957.}

(Figuras 22, 23)

Talo eucárpico, monocêntrico, extra e intramatrical. Zoosporângios hialinos, esféricos, 15-32,5 $\mu \mathrm{m}$ diâm., angulares na maturidade, devido a formação de dois a cinco poros para liberação dos zoósporos; paredes delgadas, lisas; rizóides ramificados. Zoósporos com uma única gotícula lipídica. Esporos de resistência não observados.

Material examinado: São Paulo: Santo André, Reserva Biológica de Paranapiacaba, amostra de água e solo, ecdise de cobra e grão de pólen $\left(23^{\circ} 46^{\prime} 53^{\prime \prime} \mathrm{S}\right.$ e $46^{\circ} 18^{\prime} 75^{\prime \prime} \mathrm{W} / 23^{\circ} 46^{\prime} 52^{\prime \prime} \mathrm{S}$ e $46^{\circ} 18^{\prime} 77^{\prime \prime}$ W/ $23^{\circ} 46^{\prime} 53^{\prime \prime} \mathrm{S}$ e $46^{\circ} 18^{\prime} 69^{\prime \prime} \mathrm{W}, 20 / \mathrm{XI} / 2003$ ), $\left(23^{\circ} 46^{\prime} 78^{\prime \prime} \mathrm{S}\right.$ e $46^{\circ} 18^{\prime} 55^{\prime}$ 'W/ $23^{\circ} 46^{\prime} 53^{\prime \prime} \mathrm{S}$ e $46^{\circ} 18^{\prime} 75^{\prime \prime} \mathrm{W} /$ $23^{\circ} 46^{\prime} 52^{\prime \prime} \mathrm{S}$ e $\left.46^{\circ} 18^{\prime} 77^{\prime \prime} \mathrm{W} / 26 / \mathrm{II} / 2004\right),\left(23^{\circ} 46^{\prime} 52^{\prime \prime} \mathrm{S}\right.$ e $46^{\circ} 18^{\prime} 77^{\prime}$ 'W/ $23^{\circ} 46^{\prime} 53^{\prime \prime} \mathrm{S}$ e $46^{\circ} 18^{\prime} 75^{\prime}$ 'W, 26/V/2004), $\left(23^{\circ} 46^{\prime} 78^{\prime \prime} \mathrm{S}\right.$ e $46^{\circ} 18^{\prime} 55^{\prime \prime} \mathrm{W} / 23^{\circ} 46^{\prime} 52^{\prime \prime} \mathrm{S}$ e $46^{\circ} 18^{\prime} 77^{\prime \prime} \mathrm{W} /$ $23^{\circ} 46^{\prime} 52^{\prime \prime} \mathrm{S}$ e $46^{\circ} 18^{\prime} 77^{\prime}$ ' W/ $23^{\circ} 46^{\prime} 53^{\prime \prime} \mathrm{S}$ e $46^{\circ} 18^{\prime} 75^{\prime}$ ' W/ $23^{\circ} 46^{\prime} 53^{\prime \prime} \mathrm{S}$ e $46^{\circ} 18^{\prime} 69^{\prime \prime} \mathrm{W} / 23^{\circ} 46^{\prime} 77^{\prime}$ ' S e $46^{\circ} 18^{\prime}$ '56" W, 26/ VIII/2004), $23^{\circ} 46^{\prime} 78^{\prime \prime}$ S e $46^{\circ} 18^{\prime} 55^{\prime \prime}$ W/ $23^{\circ} 46^{\prime}$ ' 52" S e 46 $18^{\prime} 77^{\prime \prime}$ $\mathrm{W} / 23^{\circ} 46^{\prime} 53^{\prime \prime} \mathrm{S}$ e $46^{\circ} 18^{\prime} 75^{\prime \prime}$ W/ $23^{\circ} 46^{\prime} 53^{\prime \prime} \mathrm{S}$ e $46^{\circ} 18^{\prime}$ ' 69" W/ $23^{\circ} 46^{\prime} 77^{\prime}$ 'S e 46 18' 56" W, 18/XI/2004), Pires-Zottarelli, C.L.A. SP 381574 .

As características apresentadas pelos espécimes concordam com Sparrow (1957). É espécie comum em substrato queratinoso, ecdise de cobra utilizada como isca. Foi citada pela primeira vez para o Brasil por Pires-Zottarelli \& Milanez (1993) de amostras de água e solo da Represa do Lobo ("Broa"), Brotas-Itirapina (SP). Na Reserva, foi isolada por Schoenlein-Crusius et al. (1992), de folhas submersas de Alchornea triplinervia (Spreng.) Müll. Arg., Quercus robur L. e Ficus microcarpa L. f., em decomposição nos riachos.

\section{Rhizophydium keratinophilum Karling, Am. J. Bot., 33:753. 1946.}

(Figura 24)

Talo eucárpico, monocêntrico, extra-intramatrical. Zoosporângios ornamentados sésseis, hialinos, esféricos, 15-27,5 $\mu \mathrm{m}$ diâm., com uma a três papilas de descarga; ornamentações espinhosas, delicadas. Zoósporos com uma pequena gotícula lipídica. Esporos de resistência não observados.

Material examinado: Brasil. São Paulo: Santo André, Reserva Biológica de Paranapiacaba, amostra de água, cabelo (23 46' 52"' S e $46^{\circ} 18$ ' 77’ W, 26/II/2004), Pires-Zottarelli, C.L.A. SP 381562.

As características apresentadas pelos espécimes, de maneira geral, concordam com Karling (1946), Sparrow (1960), Pires-Zottarelli et al. (1996) e Pires-Zottarelli (1999). A espécie foi citada pela primeira vez para o país por Karling (1946) de substrato queratinoso de amostras de solo de Porto Velho (RO). É a primeira citação para a Reserva.

\section{Rhizophydium macroporosum Karling, Sydowia 20(1-6):74-85. 1967.}

(Figura 25)

Talo eucárpico, monocêntrico, extra-intramatrical. Zoosporângios esféricos, 23-57,5 $\mu \mathrm{m}$, com duas a seis papilas para liberação dos zoósporos; parede lisa; rizóides saindo de um eixo principal longo da base do zoosporângio. Zoósporos esféricos, com uma gotícula lipídica. Esporos de resistência não observados

Material examinado: Brasil. São Paulo: Santo André, Reserva Biológica de Paranapiacaba, amostra de solo, ecdise de cobra (234' 52" S e 46 18' 77' W, 26/V/2004), Pires-Zottarelli, C.L.A. SP 381574 .

A primeira ocorrência da espécie no Brasil é do Parque Estadual da Serra da Cantareira (Nascimento, 2007), sendo esta a primeira para a Reserva. As características apresentadas pelos espécimes concordam com Karling (1967).

\section{Rhizophydium sphaerotheca Zopf, Abhandl. Naturfors- ch. Gesell. Halle, 17:92. 1887.}

(Figuras 26, 27)

Talo eucárpico, monocêntrico, epi-endobiótico. Zoosporângios hialinos, esféricos, 15-27 $\mu \mathrm{m}$ diâm.; parede lisa, fina, dois poros para liberação dos zoósporos; sistema rizoidal delicado, constituído por um único eixo rizoidal, não prolongado. Zoósporos com uma gotícula lipídica conspícua, 2,5 $\mu \mathrm{m}$ diâm. Esporos de resistência não observados.

Material examinado: Brasil. São Paulo: Santo André, Reserva Biológica de Paranapiacaba, amostra de água e solo, ecdise de cobra (23 $46^{\prime} 53^{\prime \prime} \mathrm{S}$ e $46^{\circ} 18^{\prime} 75^{\prime \prime} \mathrm{W} / 23^{\circ} 46^{\prime} 52^{\prime \prime} \mathrm{S}$ e $46^{\circ} 18^{\prime} 77^{\prime}$ 'W/ $23^{\circ} 46^{\prime} 53^{\prime \prime} \mathrm{S}$ e $46^{\circ} 18^{\prime} 69^{\prime \prime} \mathrm{W} / 23^{\circ} 46^{\prime} 77^{\prime \prime} \mathrm{S}$ e $46^{\circ} 18^{\prime} 56^{\prime \prime} \mathrm{W}$,

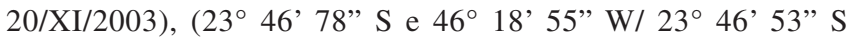
e $46^{\circ} 18^{\prime} 75^{\prime \prime} \mathrm{W} / 23^{\circ} 46^{\prime} 52^{\prime \prime} \mathrm{S}$ e $\left.46^{\circ} 18^{\prime} 77^{\prime \prime} \mathrm{W}, 26 / \mathrm{II} / 2004\right)$, $\left(23^{\circ} 46^{\prime} 78^{\prime \prime} \mathrm{S}\right.$ e $46^{\circ} 18^{\prime} 55^{\prime \prime} \mathrm{W} / 23^{\circ} 46^{\prime} 52^{\prime \prime} \mathrm{S}$ e $46^{\circ} 18^{\prime} 77^{\prime \prime} \mathrm{W} /$ $23^{\circ} 46^{\prime} 53^{\prime}$ ' S e $\left.46^{\circ} 18^{\prime} 75^{\prime \prime} \mathrm{W}, 26 / \mathrm{V} / 2004\right),\left(23^{\circ} 46^{\prime} 78^{\prime \prime} \mathrm{S}\right.$ e $46^{\circ} 18^{\prime} 55^{\prime \prime}$ W/ $23^{\circ} 46^{\prime} 53^{\prime \prime} \mathrm{S}$ e $46^{\circ} 18^{\prime} 75^{\prime}$ "W/ $23^{\circ} 46^{\prime} 52^{\prime \prime} \mathrm{S}$ e $\left.46^{\circ} 18^{\prime} 77^{\prime \prime} \mathrm{W}, 26 / \mathrm{VIII} / 2004\right),\left(23^{\circ} 46^{\prime} 78^{\prime \prime} \mathrm{S}\right.$ e $46^{\circ} 18^{\prime} 55^{\prime \prime} \mathrm{W} /$ $23^{\circ} 46^{\prime} 53^{\prime \prime} \mathrm{S}$ e $46^{\circ} 18^{\prime} 75^{\prime}$ ' W/ $23^{\circ} 46^{\prime} 53^{\prime \prime}$ S e $46^{\circ} 18^{\prime} 69^{\prime \prime} \mathrm{W}, 18 /$ XI/2004), Pires-Zottarelli, C.L.A. SP 381579.

A espécie é comum em grão de pólen de Pinus spp. utilizado como isca. As características apresentadas concordam com Sparrow (1960), Konno (1972) e Karling (1977). A primeira citação da espécie para a Reserva é de Schoenlein-Cruisus et al. (1992), de folhas submersas 
de Alchornea triplinervia (Spreng.) Müll. Arg., Quercus robur L. e Ficus microcarpa L. f.,em decomposição nos riachos.

\section{Rhizophydium stipitatum Sparrow, Trans. Br. Mycol.} Soc. 40(4): 528. 1957.

(Figuras 28, 29)

Talo eucárpico, monocêntrico, extra-intramatrical. Zoosporângios esféricos, hialinos, $17 \mu \mathrm{m}$ diâm, com o eixo principal rizoidal para fora do substrato; geralmente dois poros para liberação dos zoósporos; parede lisa. Zoósporos com uma gotícula lipídica hialina. Esporos de resistência não observados.

Material examinado: Brasil. São Paulo: Santo André, Reserva Biológica de Paranapiacaba, amostra de água e solo, ecdise de cobra e grão de pólen ( $23^{\circ} 46^{\prime} 52^{\prime}$ ' S e $46^{\circ} 18^{\prime} 77^{\prime}$ ' W, 26/II/2004), ( $23^{\circ} 46^{\prime} 52^{\prime \prime} \mathrm{S}$ e $46^{\circ} 18^{\prime} 77^{\prime}$ 'W, 26/VIII/2004), Pires-Zottarelli, C.L.A. SP 381580

As características apresentadas pelos espécimes concordam com Sparrow (1957) e Milanez (1984a). Foi primeiramente citada para a Reserva por Schoenlein-Crusius et al. (1992), de folhas submersas de Ficus microcarpa L. f. em decomposição nos riachos.

\section{Septosperma rhizophydii Whiffen ex Blackw. \& Powell, Mycotaxon 42: 45.1991}

\section{(Figura 30)}

Talo eucárpico, monocêntrico, extra-intramatrical. Zoosporângios inoperculados, piriformes, pedunculados, $12-15 \times 6-11 \mu \mathrm{m}$; parede lisa. Zoósporos com uma única gotícula lipídica. Esporos de resistência cilíndricos, 11-15 × 4-5 $\mu \mathrm{m}$, pedunculados, com a parte distal preenchida com numerosas gotículas lipídicas; germinação não observada.

Material examinado: Brasil. São Paulo: Santo André, Reserva Biológica de Paranapiacaba, amostra de solo $\left(23^{\circ} 46^{\prime} 53^{\prime \prime} \mathrm{S}\right.$ e $46^{\circ} 18^{\prime} 75^{\prime \prime} \mathrm{W} / 23^{\circ} 46^{\prime} 52^{\prime \prime} \mathrm{S}$ e $\left.46^{\circ} 18^{\prime} 77^{\prime \prime} \mathrm{W}, 20 / \mathrm{XI} / 2003\right)$, $\left(23^{\circ} 46^{\prime} 52^{\prime \prime} \mathrm{S}\right.$ e $\left.46^{\circ} 18^{\prime} 77^{\prime \prime} \mathrm{W}, 26 / \mathrm{II} / 2004\right),\left(23^{\circ} 46^{\prime} 53^{\prime \prime} \mathrm{S}\right.$ e

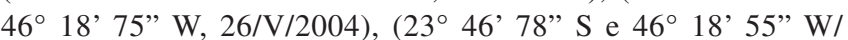
$23^{\circ} 46^{\prime} 52^{\prime \prime} \mathrm{S}$ e $46^{\circ} 18^{\prime} 77^{\prime}$ 'W/ $23^{\circ} 46^{\prime} 53^{\prime \prime} \mathrm{S}$ e $46^{\circ} 18^{\prime} 69^{\prime \prime} \mathrm{W}$, 26/VIII/2004), (23 46' $52^{\prime \prime}$ S e $46^{\circ} 18^{\prime} 77^{\prime \prime}$ W/ $23^{\circ} 46^{\prime} 53^{\prime \prime} \mathrm{S}$ e $\left.46^{\circ} 18^{\prime} 75^{\prime \prime} \mathrm{W}, 18 / \mathrm{XI} / 2004\right)$, Pires-Zottarelli, C.L.A. SP 381577.

Os espécimes ocorreram como parasitas de Rhizophydium elyensis Sparrow. As características dos mesmos concordam com Sparrow (1960), Seymour (1971), Karling (1977) e Milanez (1974). A espécie foi citada no Brasil pela primeira vez por Milanez (1974) de Rhizophydium sp, isolado de amostra de solo, da BR-128 (São Paulo-Santos). É a primeira citação para a Reserva.

\section{CLADOCHYTRIACEAE}

Segundo Kirk et al. (2001) a família é composta por 10 gêneros, dois quais, quatro estão representados neste estudo.

\section{Chave para os Gêneros}

1. Zoosporângios operculados .2

- Zoosporângios inoperculados

2. Presença de septos no rizomicélio apenas para delimitação das estruturas de reprodução Nowakowskiella

- Presença de septos e constrições no rizomicélio em intervalos regulares e também na delimitação das estruturas de reprodução Septochytrium

3. Talo delicado composto por zoosporângios individuais lisos, dilatações hifálicas e células turbinadas; zoósporos com uma única gotícula lipídica Cladochytrium
- Talo composto por agregados de zoosporângios lisos ou tuberculados; dilatações hifálicas e células turbinadas ausentes; zoósporos com várias gotículas lipídicas. Polychytrium

Segundo Kirk et al. (2001), o gênero Cladochytrium é composto por 10 espécies, sendo duas representadas no presente estudo.

\section{Chave para as Espécies de Cladochytrium}

1. Gotícula lipídica do zoósporo alaranjada. . Cladochytrium replicatum

- Gotícula lipídica do zoósporo hialina. C. tenue

\section{Cladochytrium replicatum Karling, Am. J. Bot. 18:538. 1931.}

(Figuras 31, 32)

Talo eucárpico, policêntrico, intramatrical. Zoosporângios inoperculados, geralmente terminais, não apofisados, esféricos, 10,5-17 $\mu \mathrm{m}$ diâm., ocasionalmente alongados ou piriformes, com um único tubo de descarga; parede lisa, fina. Sistema rizoidal delicado, extenso, muito ramificado, apresentando células turbinadas septadas em intervalos regulares. Zoósporos variando em número, de cinco a nove; zoósporos encistados 5-6,5 $\mu \mathrm{m}$ diâm., com um distinto glóbulo alaranjado. Esporos de resistência não observados.

Material examinado: Brasil. São Paulo: Santo André, Reserva Biológica de Paranapiacaba, amostra de água e solo, epiderme de cebola e palha de milho $\left(23^{\circ} 46^{\prime} 53^{\prime \prime} \mathrm{S}\right.$ e $46^{\circ} 18^{\prime} 75^{\prime \prime} \mathrm{W}, 20 /$ $\mathrm{XI} / 2003),\left(23^{\circ} 46^{\prime} 77^{\prime \prime} \mathrm{S}\right.$ e $\left.46^{\circ} 18^{\prime} 56^{\prime \prime} \mathrm{W}, 26 / \mathrm{II} / 2004\right),\left(23^{\circ} 46^{\prime} 52^{\prime \prime} \mathrm{S}\right.$ e $\left.46^{\circ} 18^{\prime} 77^{\prime \prime} \mathrm{W}, 26 / \mathrm{V} / 2004\right)$, (23 $46^{\prime} 77^{\prime \prime} \mathrm{S}$ e $46^{\circ} 18^{\prime} 56^{\prime \prime} \mathrm{W}, 26 /$ VIII/2004), Pires-Zottarelli, C.L.A. SP 381556.

As características dos espécimes observados concordam com Sparrow (1960) e Karling (1977). A primeira citação da espécie para o Brasil foi feita por Karling (1945b) de amostras de água coletadas nos estados do Acre, Mato Grosso, Amazonas e Ceará. A primeira citação para a Reserva é de Rogers et al (1970).

\section{Cladochytrium tenue Nowakowski, Cohn Beitr. Biol. Pflanzen, 2: 92.1876.}

(Figuras 33 - 35)

Talo eucárpico, policêntrico, extra-intramatrical. Zoosporângios delicados, terminais, piriformes, 12-16 x 11-12 $\mu \mathrm{m}$; parede lisa. Sistema rizoidal delicado, extensivo, apresentando células turbinadas septadas em duas ou mais partes. Zoósporos com uma gotícula lipídica hialina; zoósporos encistados de 5-5,5 بm diâm. Esporos de resistência esféricos, intercalares no rizomicélio, 16-20 $\mu \mathrm{m}$ diam., alguns ovais, 17-20 x 14-18 $\mu \mathrm{m}$; conteúdo hialino; apófise presente; parede lisa; germinação não observada.

Material examinado: Brasil. São Paulo: Santo André, Reserva Biológica de Paranapiacaba, amostra de água, epiderme de cebola $\left(23^{\circ} 46^{\prime} 52^{\prime \prime} \mathrm{S}\right.$ e $\left.46^{\circ} 18^{\prime} 77^{\prime} \mathrm{W}\right) / 23^{\circ} 46^{\prime} 53^{\prime \prime} \mathrm{S}$ e $46^{\circ} 18^{\prime} 75^{\prime}$ ' W,

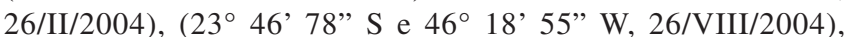
(23 46' $53^{\prime}$ ' S e $46^{\circ} 18^{\prime} 75^{\prime}$ ' W/ $23^{\circ} 46^{\prime} 52^{\prime}$ ' S e $46^{\circ} 18^{\prime} 77^{\prime}$ 'W, $18 /$ XI/2004), Pires-Zottarelli, C.L.A. SP 381581.

A espécie foi isolada pela primeira vez no país por J.S. Karling de restos vegetais em decomposição, contidos em amostras de água e solo, de Manaus (AM) e de São Carlos e Porto Velho (RO) (Karling, 1945b). As características dos espécimes examinados concordam com Sparrow (1960) e Karling (1945b, 1977). É a primeira citação da espécie para o estado de São Paulo.

O gênero Nowakowskiella, segundo Kirk et al. (2001), está composto por 15 espécies, duas delas representadas neste estudo. 


\section{Chave para as espécies de Nowakowskiella}

1. Esporos de resistência esféricos, intercalares no rizomicélio, com uma única gotícula lipídica conspícua central.

... Nowakowskiella elegans

- Esporos de resistência ovais, localizados intercalarmente no rizomicélio, com várias gotículas lipídicas............ . multispora

\section{Nowakowskiella elegans (Nowak.) Schroeter, Engler and} Prantl, Naturlichen Pfanzenfam., 1(1):82. 1892(1893).

Basiônimo: Cladochytrium elegans Nowakowski, Beitr. Biol. Pflanzen, 2:95. 1876.

(Figuras 36 - 38)

Talo eucárpico, policêntrico, extra-intramatrical. Zoosporângios operculados, hialinos, apofisados ou não, esféricos, 15-50 $\mu$ m diâm., piriformes, 39-60 x 25-37,5 $\mu \mathrm{m}$, ovais ou irregulares; quando intramatricais assumem forma alongada; parede lisa e delgada; tubo de descarga presente; proliferação interna ausente. Zoósporos encistados 5-9 $\mu \mathrm{m}$ diâm., com uma gotícula lipídica conspícua. Esporos de resistência hialinos, com uma gotícula lipídica cconspícua central, intercalares no rizomicélio, esféricos, 15-37,5 $\mu \mathrm{m}$ diâm., ocasionalmente ovais; germinação não observada.

Material examinado: Brasil. São Paulo: Santo André, Reserva Biológica de Paranapiacaba, amostra de água e solo, palha de milho e epiderme de cebola ( $23^{\circ} 46^{\prime} 53^{\prime \prime} \mathrm{S}$ e $46^{\circ} 18^{\prime} 75^{\prime \prime}$ W/ $23^{\circ} 46^{\prime} 77^{\prime \prime} \mathrm{S}$ e $\left.46^{\circ} 18^{\prime} 56^{\prime \prime} \mathrm{W}, 20 / \mathrm{XI} / 2003\right)$, (234 $46^{\prime} 52^{\prime \prime} \mathrm{S}$ e $46^{\circ} 18^{\prime} 77^{\prime \prime} \mathrm{W}, 26 /$

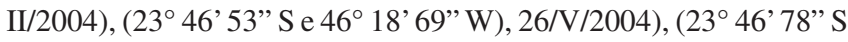
e $46^{\circ} 18^{\prime} 55^{\prime \prime}$ W/ $23^{\circ} 46^{\prime} 52^{\prime \prime} \mathrm{S}$ e $46^{\circ} 18^{\prime} 77^{\prime \prime}$ W/ $23^{\circ} 46^{\prime} 53^{\prime}$ ' S e $46^{\circ} 18^{\prime} 75^{\prime \prime} \mathrm{W}, 23^{\circ} 46^{\prime} 77^{\prime \prime} \mathrm{S}$ e $46^{\circ} 18^{\prime} 56^{\prime \prime} \mathrm{W}, 26 / \mathrm{VIII} / 2004$ ), (23 46' $52^{\prime \prime}$ S e $46^{\circ} 18^{\prime} 77^{\prime \prime}$ W/ $23^{\circ} 46^{\prime} 78^{\prime \prime}$ S e $46^{\circ} 18^{\prime} 55^{\prime \prime}$ W, $18 /$ XI/2004), Pires-Zottarelli, C.L.A. SP 381559.

Os espécimes examinados apresentaram características que concordam com Sparrow (1960) e Karling (1977). Esporos de resistência foram frequientemente verificados nos isolados. Foi observada na Reserva, pela primeira vez, em folhas submersas de Alchornea triplinervia (Spreng.) Müll. Arg., Quercus robur L. e Ficus microcarpa . f., em decomposição nos riachos, por Schoenlein-Crusius et al. (1992).

\section{Nowakowskiella multispora Karling, Sydowia 17 (1-6):314-316. 1964.}

(Figuras 39, 40)

Talo eucárpico, policêntrico, extra-intramatrical. Zoosporângios operculados, hialinos, não apofisados, obpiriformes, 21-40 x 15-20 $\mu \mathrm{m}$; parede lisa. Zoósporos com uma única gotícula lipídica. Esporos de resistência intercalarmente no rizomicélio, ovais, 15-20 x 12-15 $\mu \mathrm{m}$, apresentando diversas gotículas lipídicas.

Material examinado: Brasil. São Paulo: Santo André, Reserva Biológica de Paranapiacaba, amostra de água, celofane (23 46' 53" S e 46 18' 69”' W, 26/VIII/2004), Pires-Zottarelli, C.L.A. SP 381582.

As características apresentadas pelo espécime concordam com Karling (1964, 1977). A espécie foi citada para o Brasil, pela primeira vez, da região de Cubatão (Schoenlein-Crusius et al., 2006). É a primeira citação para a Reserva.

\section{Polychytrium aggregatum Ajello, Mycologia, 34: 443. 1942.}

(Figuras 41 - 44)

Talo eucárpico, policêntrico, extra-intramatrical. Zoosporângios inoperculados, em agregados de dois ou mais, terminais ou intercalares, não apofisados, lisos ou ornamentados, prolíferos, esféricos, 16-27 $\mu \mathrm{m}$ diâm., alguns piriformes, 19-33 x 16-25 $\mu \mathrm{m}$, com as ornamentações, as quais são tuberculadas ou papiladas. Zoósporos encistados 5-6 $\mu \mathrm{m}$ diâm., liberados através de poros, geralmente um. Esporos de resistência não observados.
Material examinado: Brasil. São Paulo: Santo André, Reserva Biológica de Paranapiacaba, amostra de água e solo, ecdise de cobra, cabelo e exoesqueleto de camarão $\left(23^{\circ} 46^{\prime} 53^{\prime \prime} \mathrm{S}\right.$ e $46^{\circ} 18^{\prime} 75^{\prime \prime} \mathrm{W} / 23^{\circ} 46^{\prime} 52^{\prime \prime} \mathrm{S}$ e $46^{\circ} 18^{\prime} 77^{\prime \prime} \mathrm{W} / 23^{\circ} 46^{\prime} 53^{\prime \prime} \mathrm{S}$ e $46^{\circ} 18^{\prime} 69^{\prime \prime} \mathrm{W} / 23^{\circ} 46^{\prime} 77^{\prime \prime} \mathrm{S}$ e $\left.46^{\circ} 18^{\prime} 56^{\prime \prime} \mathrm{W}, 20 / \mathrm{XI} / 2003\right)$, $\left(23^{\circ} 46^{\prime} 78^{\prime \prime} \mathrm{S}\right.$ e $46^{\circ} 18^{\prime} 55^{\prime \prime} \mathrm{W} / 23^{\circ} 46^{\prime} 53^{\prime \prime} \mathrm{S}$ e $46^{\circ} 18^{\prime} 75^{\prime \prime} \mathrm{W} /$ $23^{\circ} 46^{\prime} 52^{\prime \prime}$ S e $46^{\circ} 18^{\prime} 77^{\prime \prime} \mathrm{W} / 23^{\circ} 46^{\prime} 77^{\prime}$ ' S e $46^{\circ} 18^{\prime} 56^{\prime \prime} \mathrm{W}$,

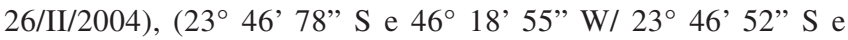
$46^{\circ} 18^{\prime} 77^{\prime \prime} \mathrm{W} / 23^{\circ} 46^{\prime} 53^{\prime \prime} \mathrm{S}$ e $46^{\circ} 18^{\prime} 75^{\prime \prime} \mathrm{W} / 23^{\circ} 46^{\prime} 53^{\prime \prime} \mathrm{S}$ e $46^{\circ} 18^{\prime} 69^{\prime \prime} \mathrm{W} / 23^{\circ} 46^{\prime} 77^{\prime \prime} \mathrm{S}$ e $46^{\circ} 18^{\prime} 56^{\prime \prime} \mathrm{W}, 26 / \mathrm{V} / 2004$ ), $\left(23^{\circ} 46^{\prime} 53^{\prime \prime} \mathrm{S}\right.$ e $46^{\circ} 18^{\prime} 75^{\prime \prime} \mathrm{W} / 23^{\circ} 46^{\prime} 53^{\prime \prime} \mathrm{S}$ e $46^{\circ} 18^{\prime} 69^{\prime \prime} \mathrm{W} /$ $23^{\circ} 46^{\prime} 77^{\prime}$ S e $\left.46^{\circ} 18^{\prime} 56^{\prime \prime} \mathrm{W}, 26 / \mathrm{VIII} / 2004\right), 23^{\circ} 46^{\prime} 78^{\prime \prime} \mathrm{S}$ e $46^{\circ} 18^{\prime} 55^{\prime \prime} \mathrm{W} / 23^{\circ} 46^{\prime} 53^{\prime \prime} \mathrm{S}$ e $46^{\circ} 18^{\prime} 75^{\prime}$ 'W/ $23^{\circ} 46^{\prime} 52^{\prime \prime} \mathrm{S}$ e $46^{\circ} 18^{\prime} 77^{\prime \prime} \mathrm{W} / 23^{\circ} 46^{\prime} 53^{\prime \prime} \mathrm{S}$ e $\left.46^{\circ} 18^{\prime} 69^{\prime \prime} \mathrm{W}, 18 / \mathrm{XI} / 2004\right)$, Pires-Zottarelli, C.L.A. SP 381558.

Foi citada pela primeira vez no Brasil por Ajello (1948) de amostras coletadas por J.S. Karling em 1943 do Amazonas. No momento, é a única espécie pertencente ao gênero. As características apresentadas concordam com Ajello (1942), Sparrow (1960) e Karling (1977).

\section{Septochytrium marilandicum Karling, Bull. Torrey Bot. Club 78: 39. 1951.}

(Figuras 45 - 48)

Talo eucárpico, policêntrico, extra-intramatrical. Rizomicélio ramificado. Zoosporângios operculados, esféricos, 30-45 $\mu \mathrm{m}$ diâm., ocasionalmente ovais e/ou irregulares; parede lisa. Zoósporos com várias gotículas lipídicas; zoósporos encistados de 5-6 $\mu \mathrm{m}$ diâm. Esporos de resistência esféricos, 13-21 $\mu$ m diâm., alguns ovais; parede espessa; coloração âmbar; germinação não observada.

Material examinado: Brasil. São Paulo: Santo André, Reserva Biológica de Paranapiacaba, amostra de água e solo, epiderme de

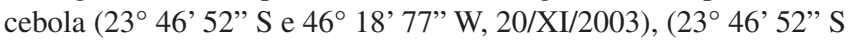
e $\left.46^{\circ} 18^{\prime} 77^{\prime \prime} \mathrm{W}, 18 / \mathrm{XI} / 2004\right)$, Pires-Zottarelli, C.L.A. SP 381560.

A espécie foi mencionada, pela primeira para o país, por Rocha \& Pires-Zottarelli (2002), de amostras de solo da Represa do Guarapiranga, São Paulo. As características apresentadas pelos espécimes examinados concordam com Karling (1951), Willoughby (1964) e Rocha \& Pires-Zottarelli (2002). É a primeira citação para a Reserva.

\section{ENDOCHYTRIACEAE}

Segundo Kirk et al. (2001), a família é composta por 10 gêneros, dos quais dois foram aqui representados, Diplophlyctis, com duas espécies, e Entophlyctis com a espécie E. luteolus Longcore descrita em Pires-Zottarelli et al. (2007).

\section{Chave para os Gêneros}

1. Zoosporângios apofisados...................................... Diplophlyctis

- Zoosporângios não apofisados ............................. Entophlyctis

\section{Chave para as Espécies de Diplophlyctis}

1. Zoosporângios sem ornamentações ..... Diplophlyctis asteroidea - Zoosporângios ornamentados...........................D. sarcoptoides

1. Diplophlyctis asteroidea Dogma, Trans. Br. mycol. Soc. 67:255. 1976.

(Figura 49)

Talo eucárpico, monocêntrico, extra-intramatrical. Zoosporângios inoperculados, apofisados, piriformes e/ou alongados, 24-60 x 14-25 $\mu \mathrm{m}$, com um tubo para liberação dos zoósporos. 
Zoósporos com uma gotícula lipídica; cisto do zoósporo persistente. Esporos de resistência ornamentados, esféricos, 17,5-25 $\mu \mathrm{m}$ diâm. ou irregulares; ornamentações papiladas e/ou tuberculadas, muitas vezes pontiagudas, apresentando gota lipídica conspícua.

Material examinado: Brasil. São Paulo: Santo André, Reserva Biológica de Paranapiacaba, amostra de água, exoesqueleto de camarão, (23 46' 77" S e 46 18' 56" W, 26/V/2004, 18/XI/2004), Pires-Zottarelli, C.L.A. SP 381578.

Foi citada pela primeira vez para o Brasil por Silva (2002) de amostras de água de igarapés de Manaus (AM). As características apresentadas pelo espécime concordam com a descrição original de Dogma (1976), entretanto, somente zoosporângios lisos foram observados e raros esporos de resistência formados. É o primeiro relato para a Reserva.

\section{Diplophlyctis sarcoptoides (H.E.Petersen) Dogma, Nova Hedwigia, 25: 122-131. 1974.}

Basiônimo: Asterophlyctis sarcoptoides H.E. Petersen, Journ. de Botanique 17:214-222. 1903.

(Figura 50)

Talo eucárpico, monocêntrico, intramatrical. Zoosporângios inoperculados, apofisados, ornamentados, esféricos, 22,5-30 $\mu$ m diâm., ocasionalmente ovais ou irregulares; ornamentações espinhosas, papiladas ou tuberculadas. Zoósporos com uma gotícula lipídica, liberados em massa por um tubo de descarga. Esporos de resistência não observados.

Material examinado: Brasil. São Paulo: Santo André, Reserva Biológica de Paranapiacaba, amostra de água, exoesqueleto de camarão, (23 46' 77' S e 46 18' 56" W, 26/VIII/2004), Pires-Zottarelli, C.L.A. SP 381578.

As características apresentadas pelos espécimes concordam com Sparrow (1960), Dogma (1974a), Pires-Zottarelli (1990) e Pires-Zottarelli et al. (1996). A primeira citação para o Brasil do gênero, como Asterophlyctis, foi feita por Karling (1945a), porém a espécie, Asterophlyctis sarcoptoides H.E. Petersen só foi referida por Antikajian (1949) a partir de espécime fornecido por J.S. Karling, isolado de amostras de solo, coletadas em São Carlos (RO) (Milanez, 1984a). Dogma (1974a) transferiu esta espécie para o gênero Diplophlyctis em virtude do desenvolvimento do talo. Foi observada, pela primeira vez na Reserva, em folhas submersas de Quercus robur L. e Ficus microcarpa L. f. em decomposição nos riachos, por Schoenlein-Crusius et al. (1992).

\section{MONOBLEPHARIDALES GONAPODYACEAE}

\section{Gonapodya prolifera (Cornu) Fischer. Rabenhorst, Kryptogamen - Fl., 1(4): 382. 1982.}

(Figuras 51 - 54)

Ocorrência em pústulas esbranquiçadas. Micélio com hifas regulares formando pseuso-septos, dividindo-as em segmentos clavados. Zoosporângios abundantes elíptico-alongados, 62,5-115 x 20-27,5 $\mu \mathrm{m}$, com proliferação interna. Zoósporos ovais, 11-12,5 x 8-9 $\mu \mathrm{m}$, alguns esféricos. Gametângios femininos e masculinos formados. Zigotos não observados.

Material examinado: Brasil. São Paulo: Santo André, Reserva Biológica de Paranapiacaba, fruto submerso de Malus sp. em corpo

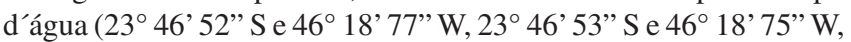
$23^{\circ} 46^{\prime} 77^{\prime \prime} \mathrm{S}$ e $\left.46^{\circ} 18^{\prime} 56^{\prime \prime} \mathrm{W}, 26 / \mathrm{V} / 2004\right)$, (23 $46^{\prime} 52^{\prime \prime} \mathrm{S}$ e $46^{\circ} 18^{\prime} 77^{\prime \prime} \mathrm{W} / 23^{\circ} 46^{\prime} 53^{\prime \prime} \mathrm{S}$ e $46^{\circ} 18^{\prime} 75^{\prime \prime}$ W/ $23^{\circ} 46^{\prime} 77^{\prime}$ ' S e $46^{\circ} 18$ ' 56” W, 26/VIII/2004), Pires-Zottarelli, C.L.A. SP 381575.

As características do espécime isolado concordam com Sparrow (1960), Karling (1977) e Milanez et al. (1994b). Os gametângios foram facilmente observados, porém a copulação de planogametas e, a formação do zigoto, não foram visualizados. É a primeira citação para a Reserva.

\section{SPIZELLOMYCETALES SPIZELLOMYCETACEAE}

Segundo Kirk et al. (2001), todas as espécies de Karlingia foram transferidas para o gênero Rhizophlyctis, entretanto, há muita polêmica nesta conceituação, pois originalmente o gênero Karlingia foi criado para acomodar quitrídias monocêntricas operculadas e, Rhizophlyctis, as inoperculadas, critério aceito por estudiosos como Karling (1977) e Dogma (1974b). O esquema classificatório utilizado para a família é o contido em Hawksworth et al. (1995).

\section{Chave para as Espécies de Karlingia}

1. Zoosporângios endoperculados e exoperculados, conteúdo cinzento; presença de rizóides constritos.... Karlingia granulata

- Zoosporângios endoperculados, conteúdo róseo; ausência de rizóides constritos. K. rosea

\section{Karlingia granulata Karling, Mycologia 39: 57-58. 1947.}

(Figuras 55 - 58)

Talo eucárpico, monocêntrico, extra-intramatrical. Sistema rizoidal extensivo, com alguns rizóides constritos. Zoosporângios exoperculados e endoperculados, esféricos, (20-)30-55 m diâm.; parede lisa, tornando-se enrugada após liberação dos zoósporos. Zoósporos esféricos, com várias gotículas lipídicas. Esporos de resistência esféricos, 15-25 ㅆm diâm; coloração âmbar.

Material examinado: Brasil. São Paulo: Santo André, Reserva Biológica de Paranapiacaba, amostra de água e solo, epiderme de cebola celofane e palha de milho, $\left(23^{\circ} 46^{\prime} 52^{\prime \prime} \mathrm{S}\right.$ e $46^{\circ} 18^{\prime} 77^{\prime \prime} \mathrm{W} /$ $23^{\circ} 46^{\prime} 53^{\prime \prime} \mathrm{S}$ e $46^{\circ} 18^{\prime} 75^{\prime \prime} \mathrm{W} / 23^{\circ} 46^{\prime} 53^{\prime \prime} \mathrm{S}$ e $46^{\circ} 18^{\prime} 69^{\prime \prime} \mathrm{W}$,

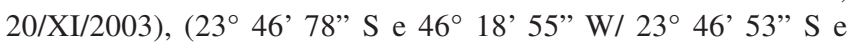
$46^{\circ} 18^{\prime} 75^{\prime \prime} \mathrm{W} / 23^{\circ} 46^{\prime} 52^{\prime \prime} \mathrm{S}$ e $46^{\circ} 18^{\prime} 77^{\prime}$ 'W/ $23^{\circ} 46^{\prime} 53^{\prime \prime} \mathrm{S}$ e $46^{\circ} 18^{\prime} 69^{\prime \prime} \mathrm{W} / 23^{\circ} 46^{\prime} 77^{\prime}$ ' S e $\left.46^{\circ} 18^{\prime} 56^{\prime \prime} \mathrm{W}, 26 / \mathrm{II} / 2004\right)$, $\left(23^{\circ} 46^{\prime} 78^{\prime \prime} \mathrm{S}\right.$ e $46^{\circ} 18^{\prime} 55^{\prime}$ 'W/ $23^{\circ} 46^{\prime} 53^{\prime \prime} \mathrm{S}$ e $46^{\circ} 18^{\prime} 75^{\prime \prime} \mathrm{W} /$ $23^{\circ} 46^{\prime} 52^{\prime \prime} \mathrm{S}$ e $46^{\circ} 18^{\prime} 77^{\prime}$ ' W/ $23^{\circ} 46^{\prime} 52^{\prime \prime} \mathrm{S}$ e $46^{\circ} 18^{\prime} 77^{\prime}$ ' W, 26/V/2004), (2346' 78' S e $46^{\circ} 18^{\prime} 55^{\prime \prime} \mathrm{W} / 23^{\circ} 46^{\prime} 53^{\prime \prime} \mathrm{S}$ e $46^{\circ} 18^{\prime} 75^{\prime \prime} \mathrm{W} / 23^{\circ} 46^{\prime} 52^{\prime \prime} \mathrm{S}$ e $46^{\circ} 18^{\prime} 77^{\prime \prime} \mathrm{W} / 23^{\circ} 46^{\prime} 53^{\prime \prime} \mathrm{S}$ e $46^{\circ} 18^{\prime} 75^{\prime \prime} \mathrm{W} / 23^{\circ} 46^{\prime} 53^{\prime \prime} \mathrm{S}$ e $46^{\circ} 18^{\prime} 69^{\prime \prime}$ W/ $23^{\circ} 46^{\prime} 77^{\prime}$ ' S e $\left.46^{\circ} 18^{\prime} 56^{\prime \prime} \mathrm{W}, 26 / \mathrm{VIII} / 2004\right),\left(23^{\circ} 46^{\prime} 78^{\prime \prime} \mathrm{S}\right.$ e $46^{\circ} 18^{\prime} 55^{\prime \prime} \mathrm{W} /$ $23^{\circ} 46^{\prime} 53^{\prime \prime} \mathrm{S}$ e $46^{\circ} 18^{\prime} 75^{\prime}$ 'W/ $23^{\circ} 46^{\prime} 52^{\prime \prime} \mathrm{S}$ e $46^{\circ} 18^{\prime} 77^{\prime \prime} \mathrm{W} /$ $23^{\circ} 46^{\prime} 52^{\prime \prime}$ S e $46^{\circ} 18^{\prime} 77^{\prime}$ 'W/ $23^{\circ} 46^{\prime} 53^{\prime \prime}$ S e $46^{\circ} 18^{\prime} 69^{\prime \prime}$ W/ $23^{\circ} 46^{\prime} 77^{\prime}$ 'S e $46^{\circ} 18^{\prime}$ 56" W, 18/XI/2004), Pires-Zottarelli, C.L.A. SP 381561.

As características apresentadas pelos espécimes estão de acordo com a descrição original de Karling (1947b). O autor descreveu como uma nova espécie do gênero Karlingia, entretanto, Sparrow (1960) cria o gênero Karlingiomyces para acomodar algumas espécies exoperculadas de Karlingia. Dogma (1974b) não concordou com a transferência, pois a espécie possui zoosporângios exoperculados e endoperculados, retendo-a no gênero Karlingia, concordando com Karling (1977). É a primeira citação para a Reserva.

\section{Karlingia rosea (de Bary \& Woronin) Johnason, Am. J. Bot. 31:399. 1944.}

Basiônimo: Chytridium roseum de Bary \& Woronin, Berichte Verh. Naturforsch. Gesell. Freiburg 2:52. 1865.

(Figuras 59 - 61)

Talo eucárpico, monocêntrico, extra-intramatrical. Zoosporângios esféricos, 30-130 m diâm., ocasionalmente ovais ou irregulares, 
com vários endopérculos; paredes espessadas e lisas, conteúdo róseo. Sistema rizoidal bastante ramificado, originando-se de vários pontos da parede do zoosporângio. Esporos de resistência não observados.

Material examinado: Brasil. São Paulo: Santo André, Reserva Biológica de Paranapiacaba, amostra de água, celofane e palha de milho, (23 46' 52" S e 46 18' 77' W, 26/V/2004), Pires-Zottarelli, C.L.A. SP 381573.

As características dos espécimes concordam com as descritas por Karling (1977) e Milanez (1984b). Foi observada pela primeira vez na Reserva, por Schoenlein-Crusius et al. (1992), em folhas submersas de Alchornea triplinervia (Spreng.) Müll. Arg., e Ficus microcarpa L. f., em decomposição nos riachos.

O presente estudo contribui para a ampliação do conhecimento dos quitridiomicetos em área de Mata Atlântica do estado de São Paulo e, no país. Dos táxons isolados, $69 \%$ são citados pela primeira

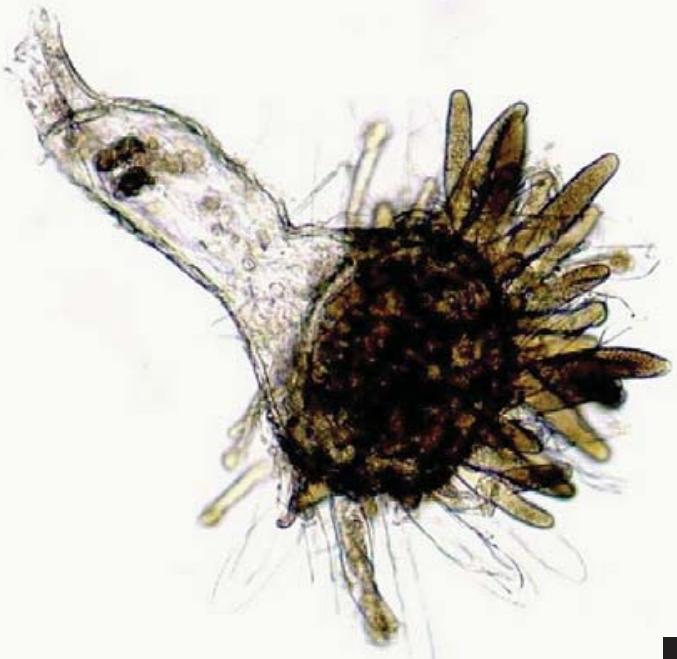

Figura 1. Blastocladia globosa. Aspecto geral do talo.

Figure 1. Blastocladia globosa. General aspect of the thallus.

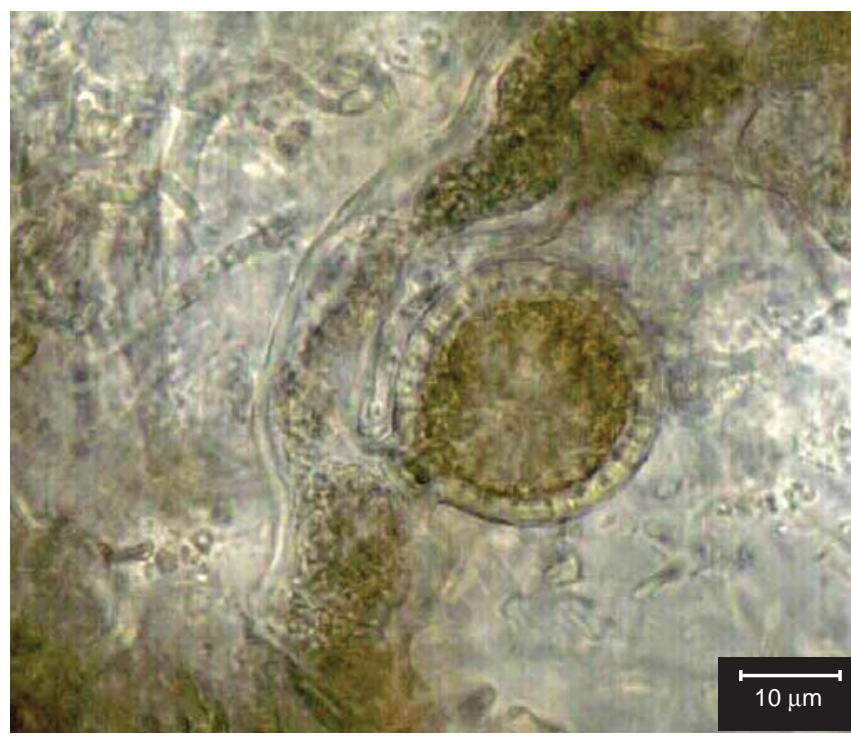

Figura 2. Blastocladia pringsheimii. Detalhe do esporo de resistência.

Figure 2. Blastocladia pringsheimii. Detail of the resting spore. vez para a Reserva, $14 \%$ para o estado de São Paulo e, $7 \%$ para o país, confirmando a distribuição cosmopolita de seus representantes.

\section{Agradecimentos}

À Fapesp pelo auxílio financeiro ao projeto (processo 03/10147-7), ao CNPq pelas bolsas concedidas aos autores e, ao Instituto de Botânica de São Paulo, pela infra-estrutura para o desenvolvimento do mesmo.

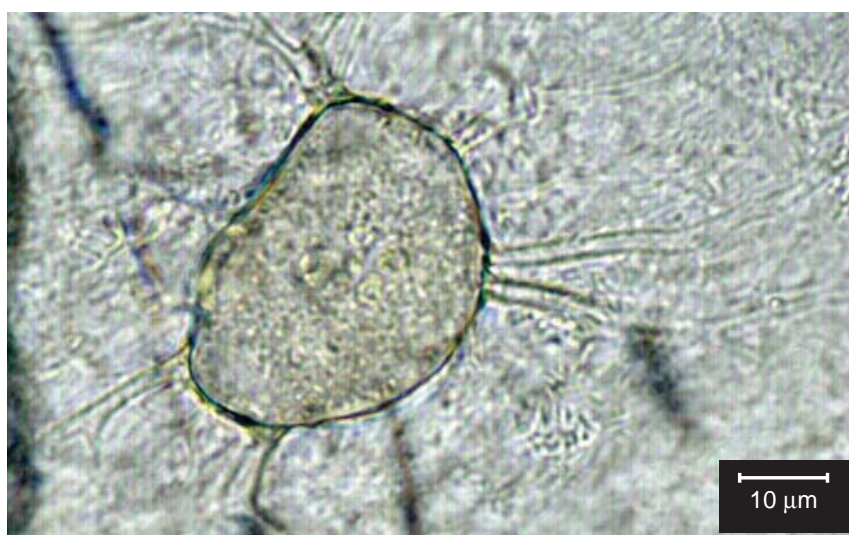

Figura 3. Catenophlyctis variabilis. Zoosporângio.

Figure 3. Catenophlyctis variabilis. Zoosporangium.

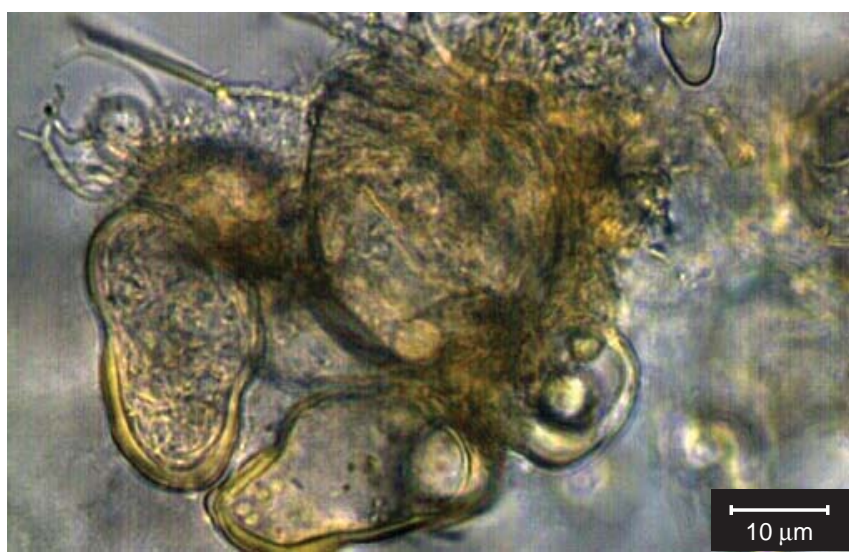

Figura 4. Chytriomyces appendiculatus. Zoosporângios agregados.

Figure 4. Chytriomyces appendiculatus. Aggregate zoosporangia.

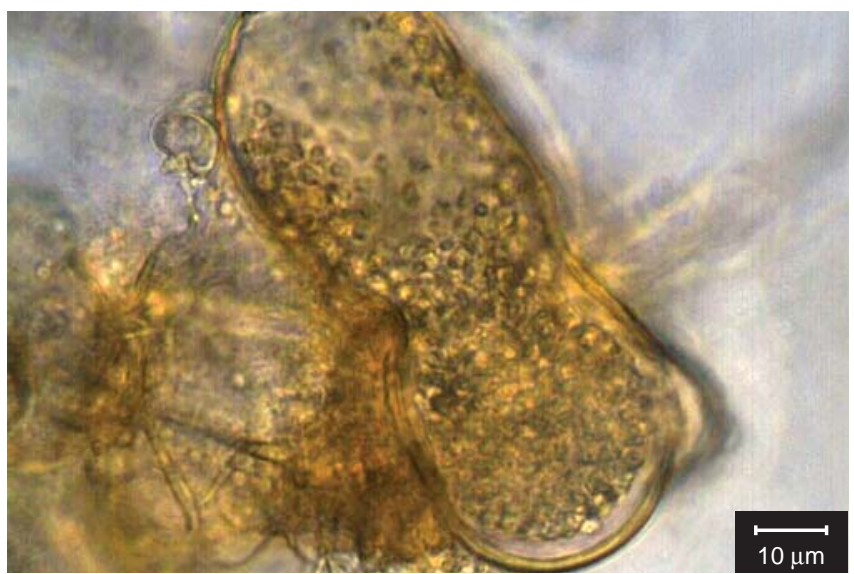

Figura 5. Chytriomyces appendiculatus. Detalhe do zoosporângio.

Figure 5. Chytriomyces appendiculatus. Detail of zoosporangium. 


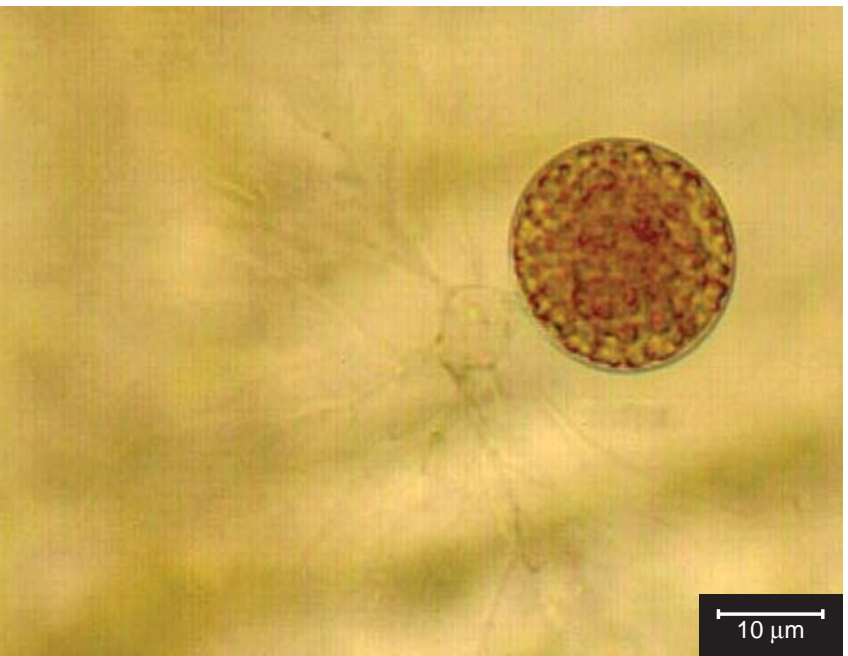

Figura 6. Chytriomyces aureus. Zoosporângio apofisado com rizóides.

Figure 6. Chytriomyces aureus. Apophysate zoosporangium with rhizoids.

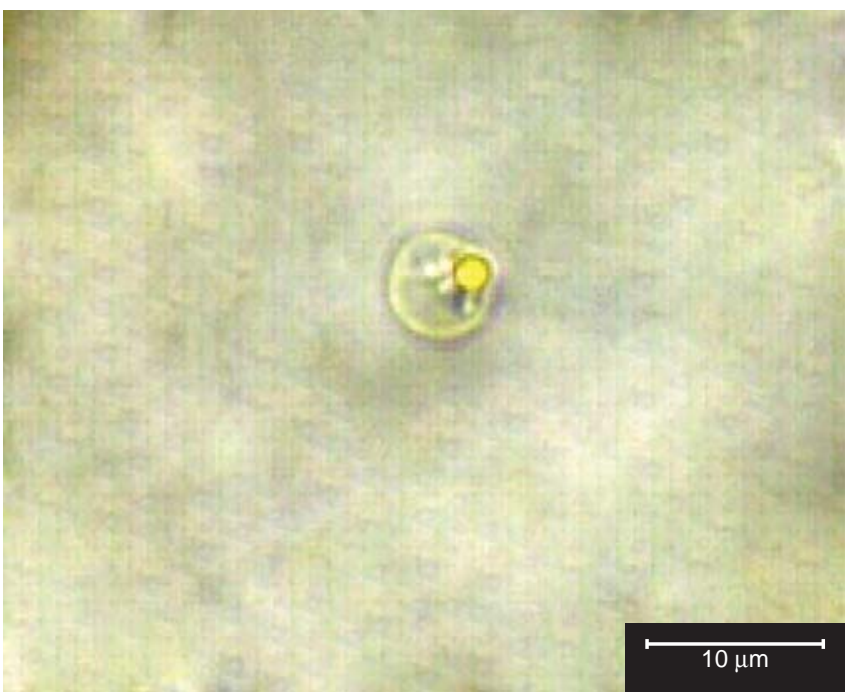

Figura 7. Chytriomyces aureus. Zoósporos.

Figure 7. Chytriomyces aureus. Zoósporos.

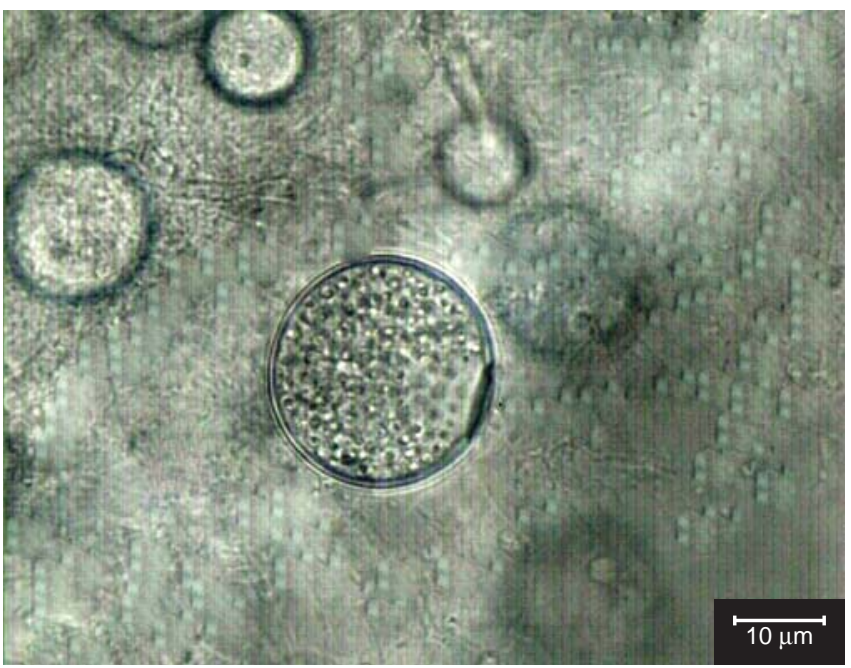

Figura 8. Chytriomyces hyalinus. Zoosporângio.

Figure 8. Chytriomyces hyalinus. Zoosporangium.

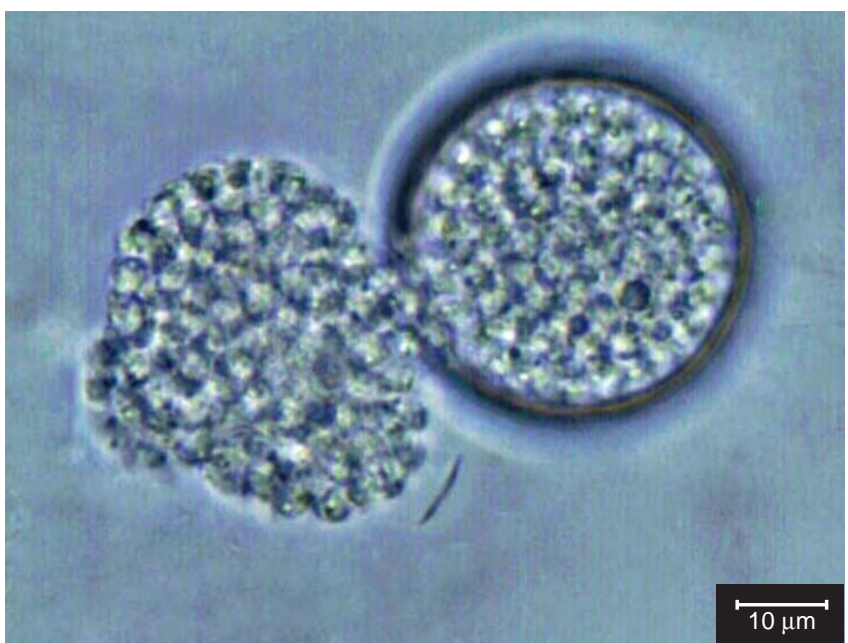

Figura 9. Chytriomyces hyalinus. Liberação de zoósporos em meio de cultura.

Figure 9. Chytriomyces hyalinus. Zoosporangium discharging in culture medium.

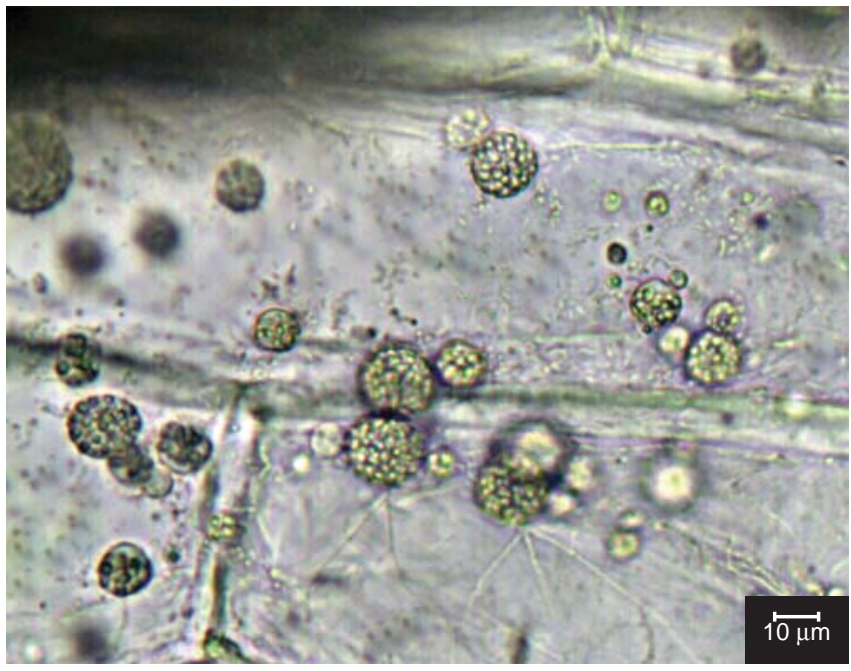

Figura 10. Chytriomyces spinosus. Zoosporângios em epiderme de cebola. Figure 10. Chytriomyces spinosus. Zoosporangia in onion skin.

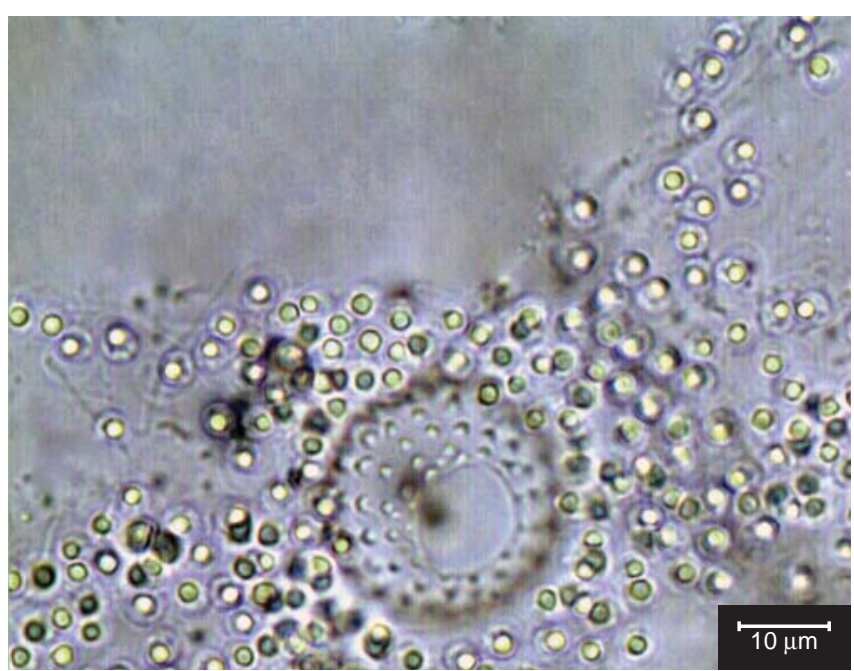

Figura 11. Chytriomyces spinosus. Liberação de zoósporos.

Figure 11. Chytriomyces spinosus. Zoosporangium discharging. 


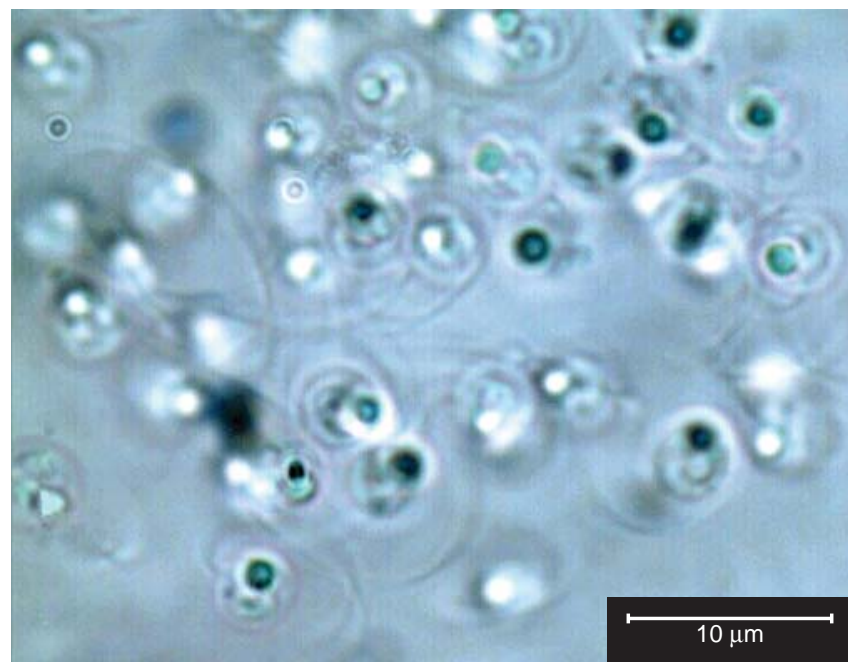

Figura 12. Chytriomyces spinosus. Zoósporos.

Figure 12. Chytriomyces spinosus. Zoospores.

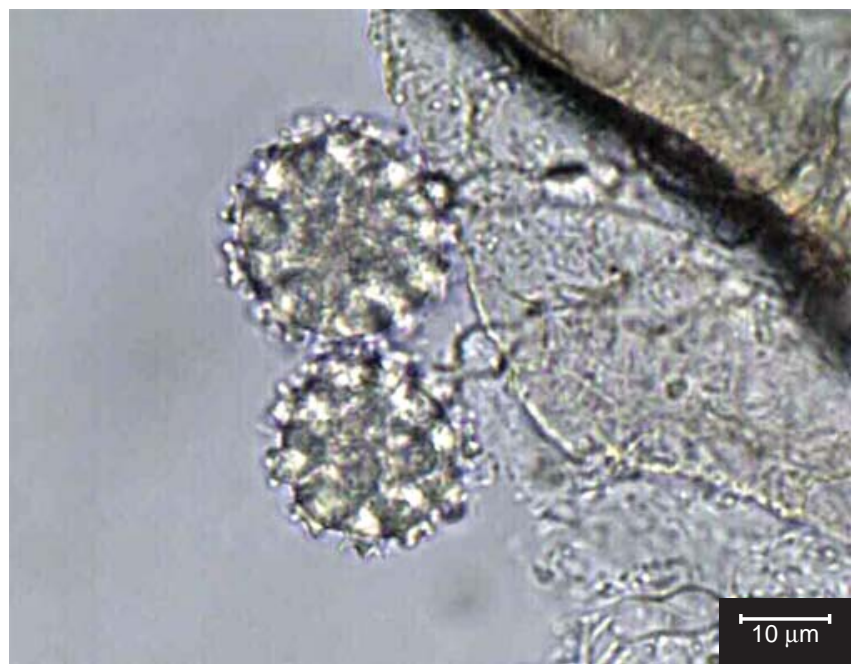

Figura 13. Phlyctochytrium aureliae. Zoosporângios em ecdise de cobra

Figure 13. Phlyctochytrium aureliae. Zoosporangia in snake skin.

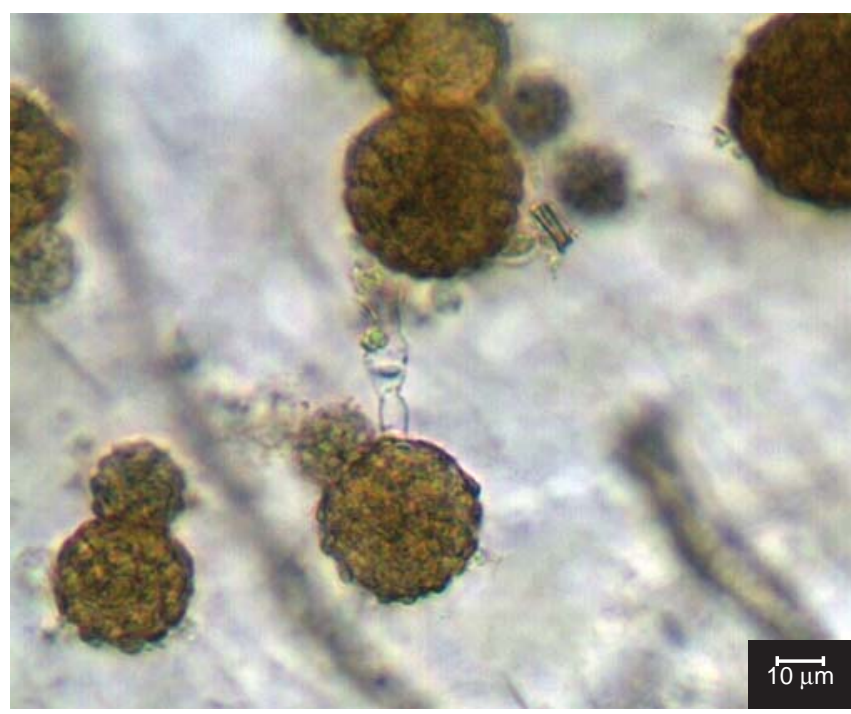

Figura 14. Rhizidium verrucosum. Zoosporângios em ecdise de cobra.

Figure 14. Rhizidium verrucosum. Zoosporangia in snake skin.

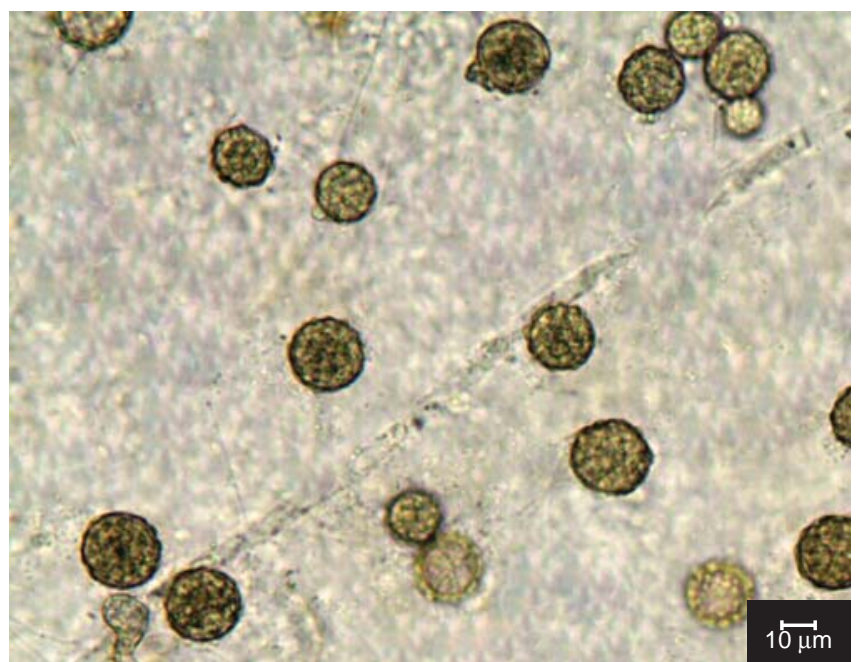

Figura 15. Rhizidium verrucosum. Zoosporângios em ecdise de cobra.

Figure 15. Rhizidium verrucosum. Zoosporangia in snake skin.

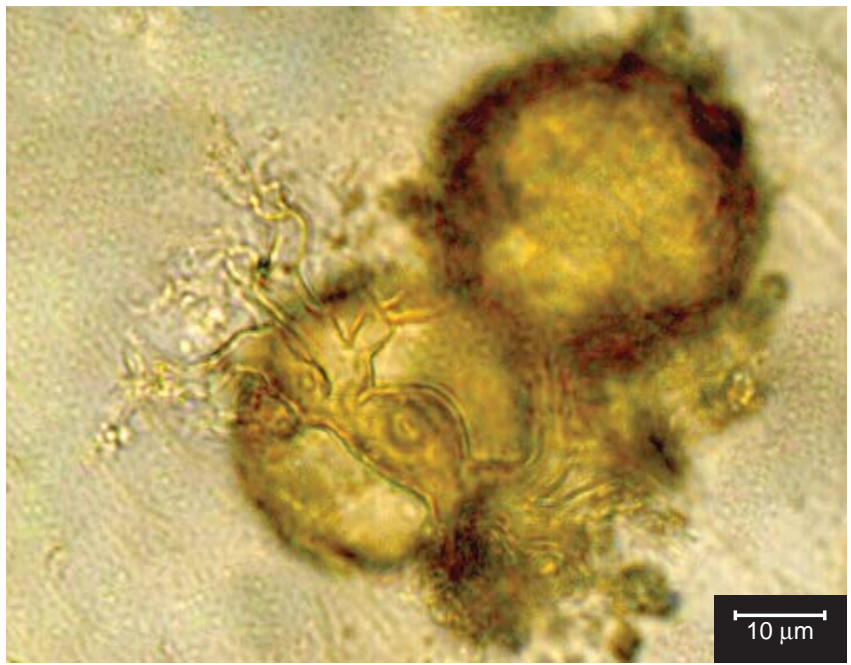

Figura 16. Rhizidium verrucosum. Rizóides.

Figure 16. Rhizidium verrucosum. Rhizoids.

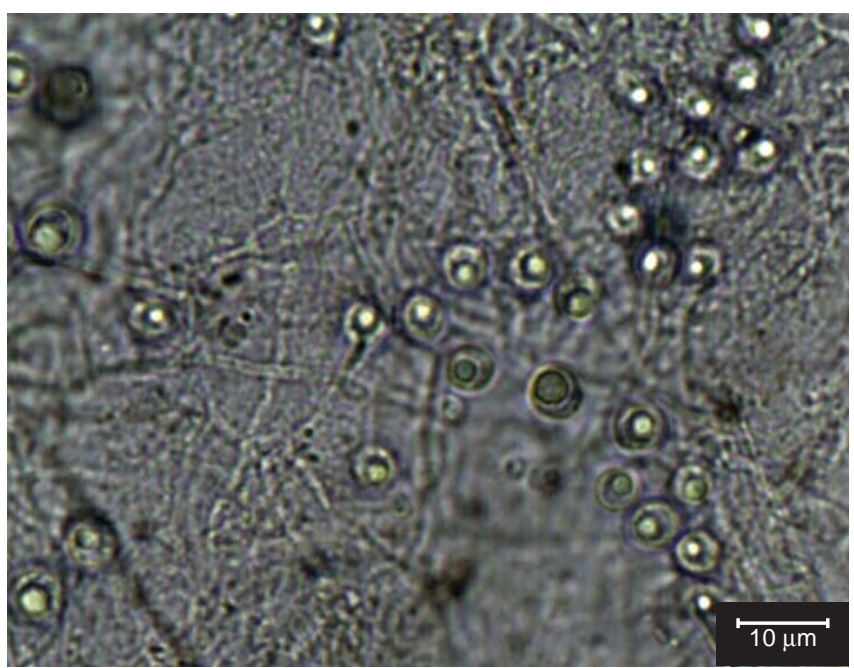

Figura 17. Rhizidium verrucosum. Zoósporos encistados.

Figure 17. Rhizidium verrucosum. Encysted zoospores. 


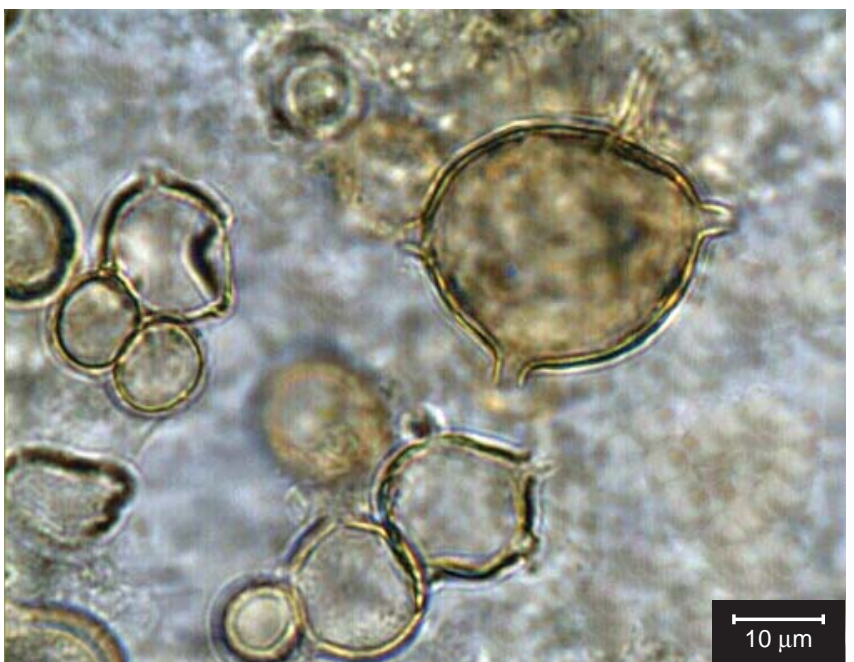

Figura 18. Rhizophydium condylosum. Zoosporângios.

Figure 18. Rhizophydium condylosum. Zoosporangia.

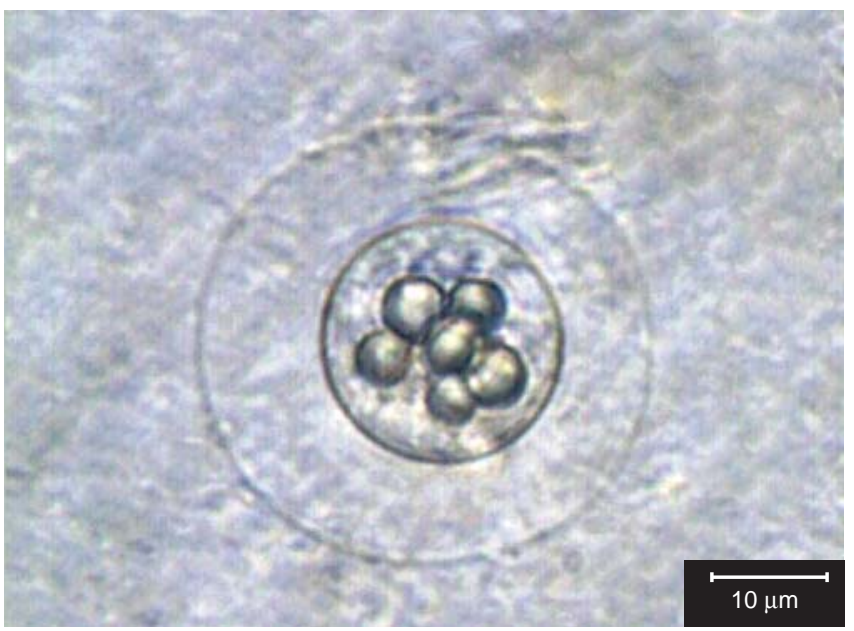

Figura 19. Rhizophydium coronum. Desenvolvimento do zoosporângio. Figure 19. Rhizophydium coronum. Development of the zoosporangium.

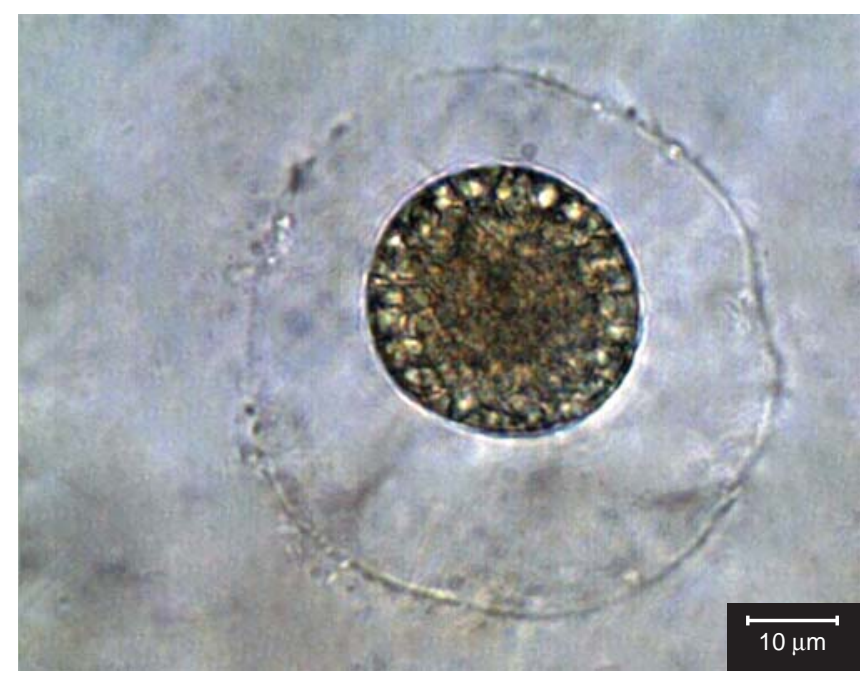

Figura 20. Rhizophydium coronum. Zoosporângio com halo evidenciado. Figure 20. Rhizophydium coronum. Zoosporangium with halo in evidence.

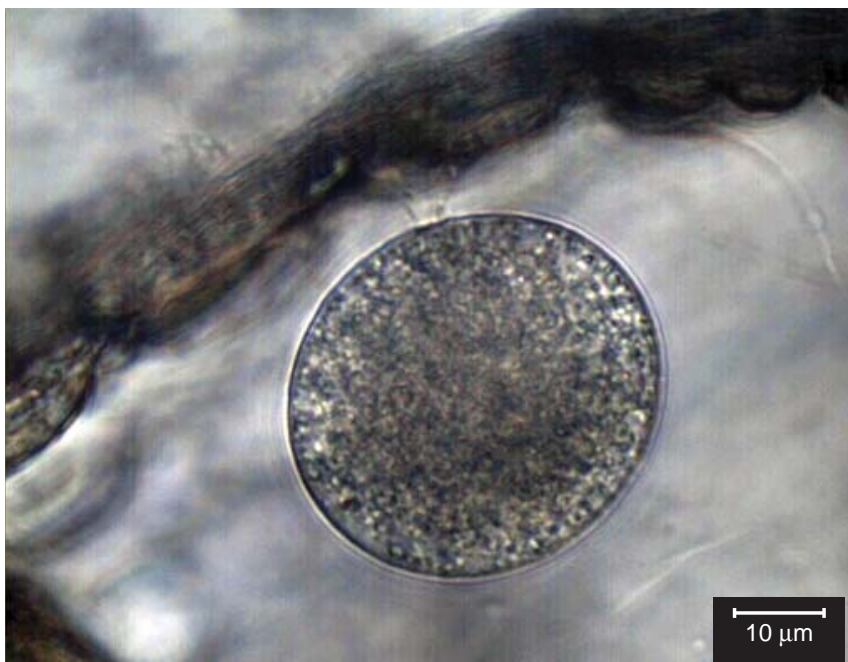

Figura 21. Rhizophydium coronum. Zoosporângio em ecdise de cobra. Figure 21. Rhizophydium coronum. Zoosporangium in snake skin.

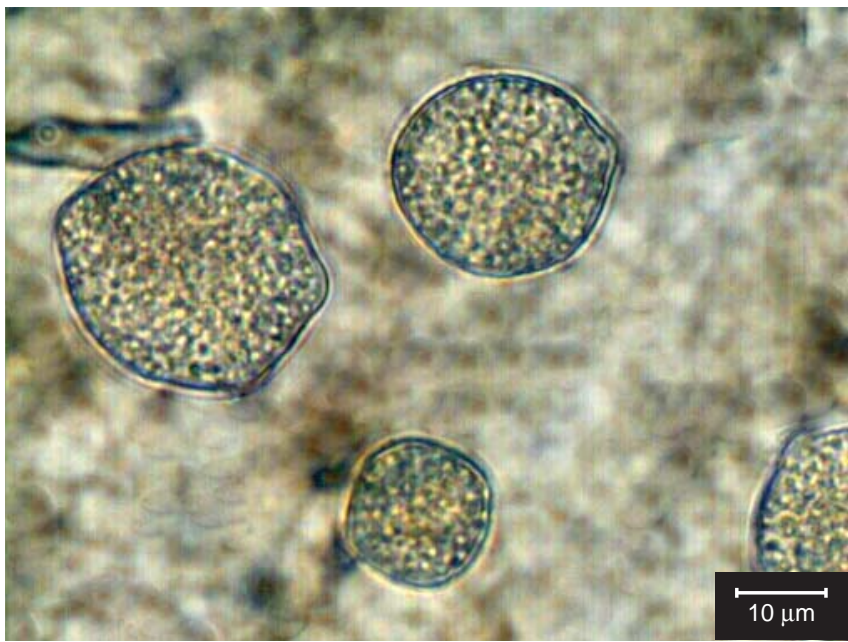

Figura 22. Rhizophydium elyensis. Zoosporângios em ecdise de cobra. Figure 22. Rhizophydium elyensis. Zoosporangia in snake skin.

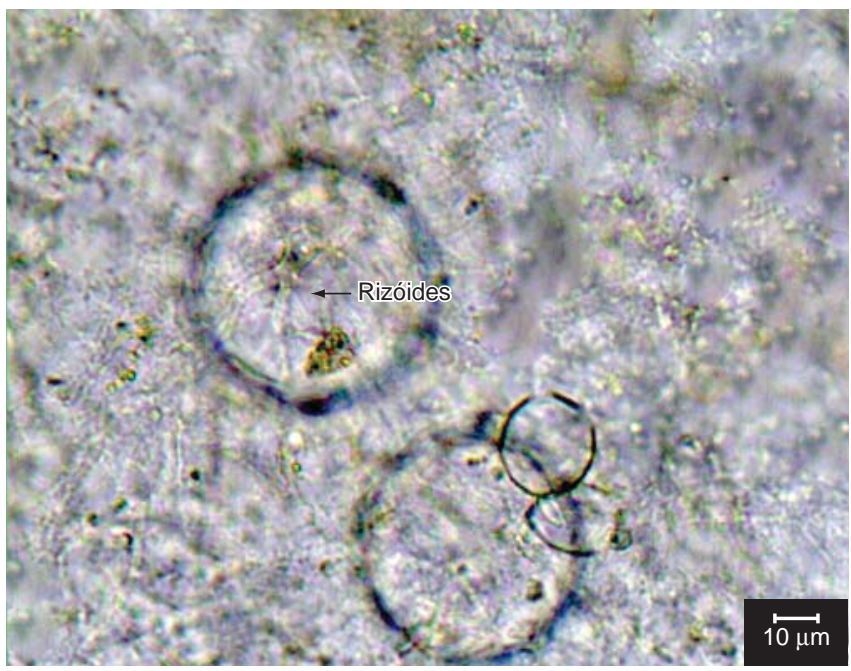

Figura 23. Rhizophydium elyensis. Rizóides.

Figura 23. Rhizophydium elyensis. Rhizoids. 


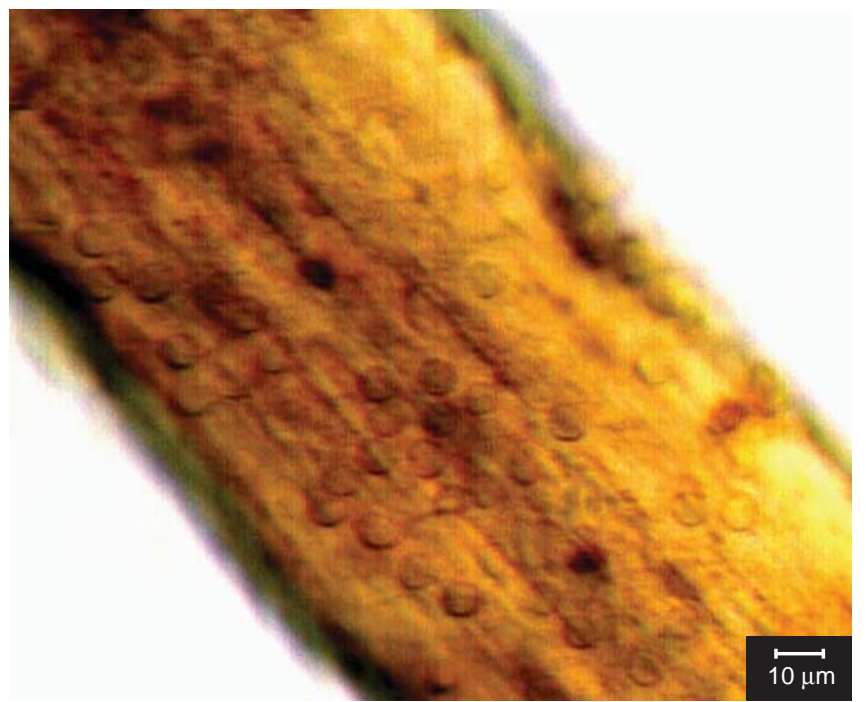

Figura 24. Rhizophydium keratinophilum. Zoosporângios em fio de cabelo.

Figure 24. Rhizophydium keratinophilum. Zoosporangia in human hair.

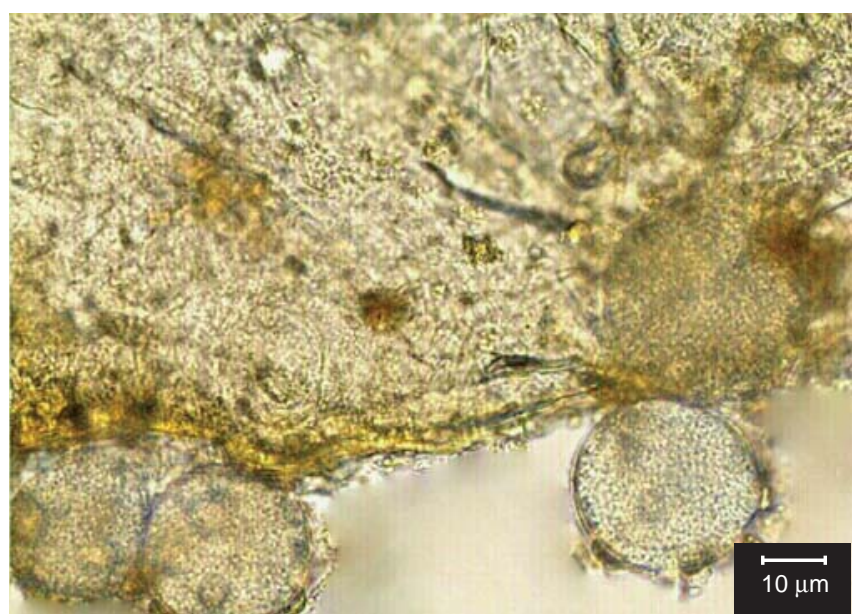

Figura 25. Rhizophydium macroporosum. Zoosporângios em ecdise de cobra.

Figure 25. Rhizophydium macroporosum. Zoosporangia in snake skin.

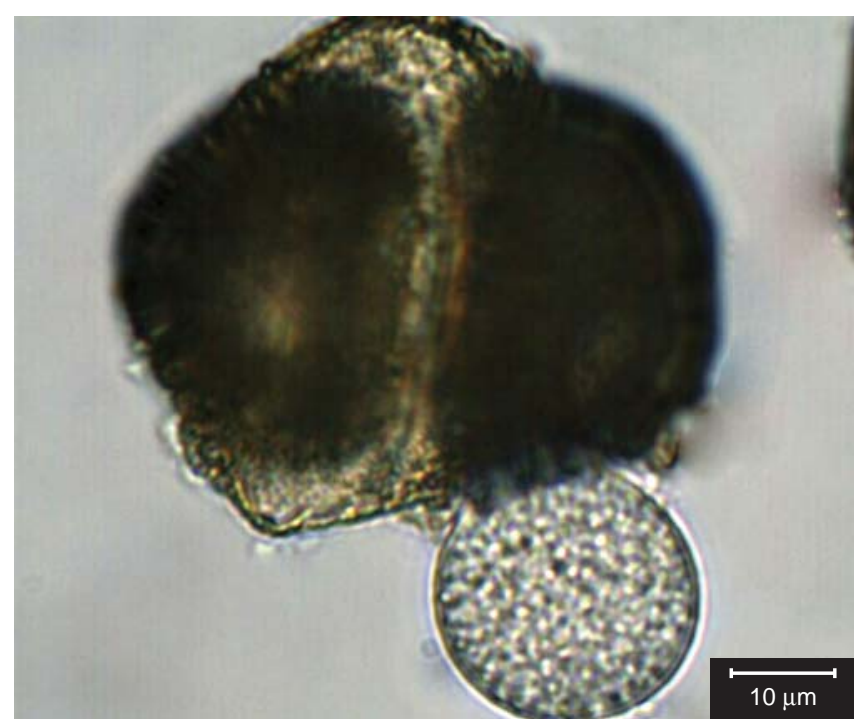

Figura 26. Rhizophydium sphaerotheca. Zoosporângio em grão de pólen. Figure 26. Rhizophydium sphaerotheca. Zoosporangium in pollen grain.

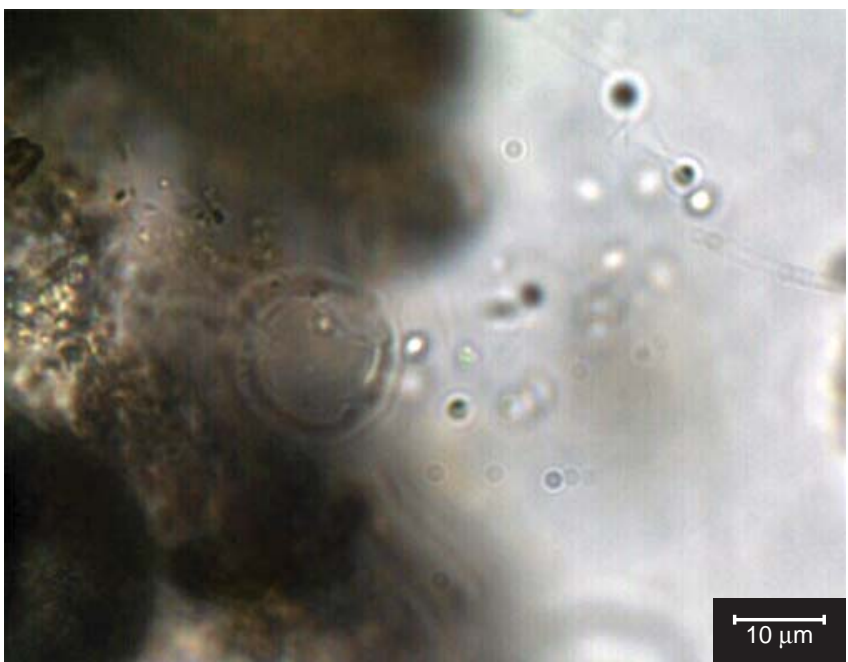

Figura 27. Rhizophydium sphaerotheca. Liberação dos zoósporos.

Figura 27. Rhizophydium sphaerotheca. Zoospore discharge.

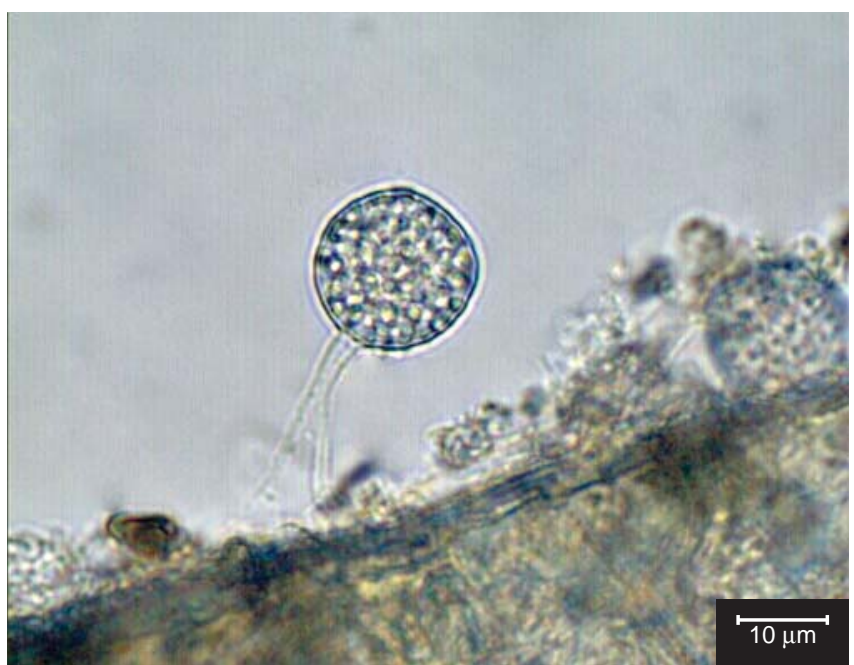

Figura 28. Rhizophydium stipitatum. Zoosporângio em ecdise de cobra. Figura 28. Rhizophydium stipitatum. Zoosporangium in the snake skin.

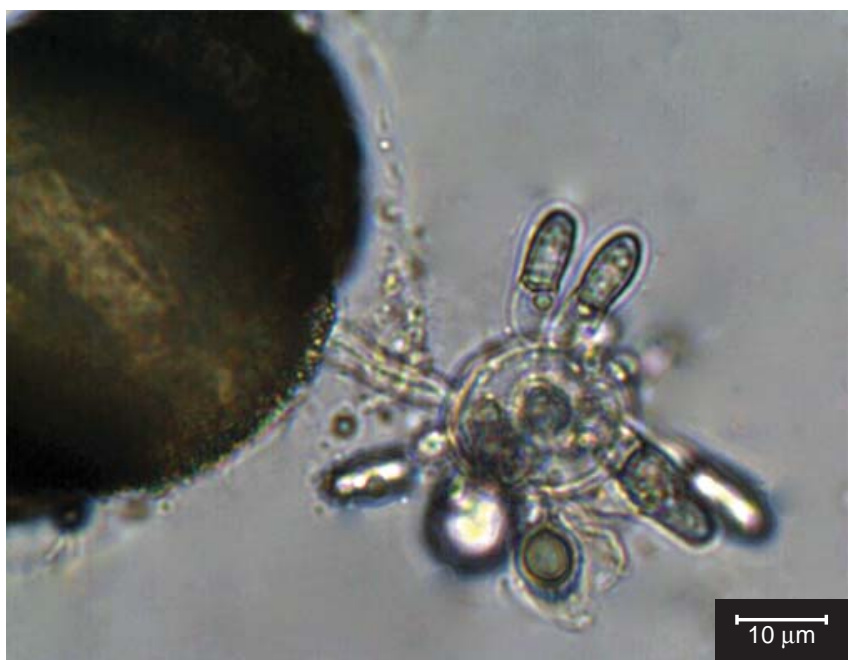

Figura 29. Rhizophydium stipitatum. Zoosporângio em ecdise de cobra parasitado por Septosperma rhizophydii.

Figure 29. Rhizophydium stipitatum. Zoosporangium in snake skin parasited by Septosperma rhizophydii. 


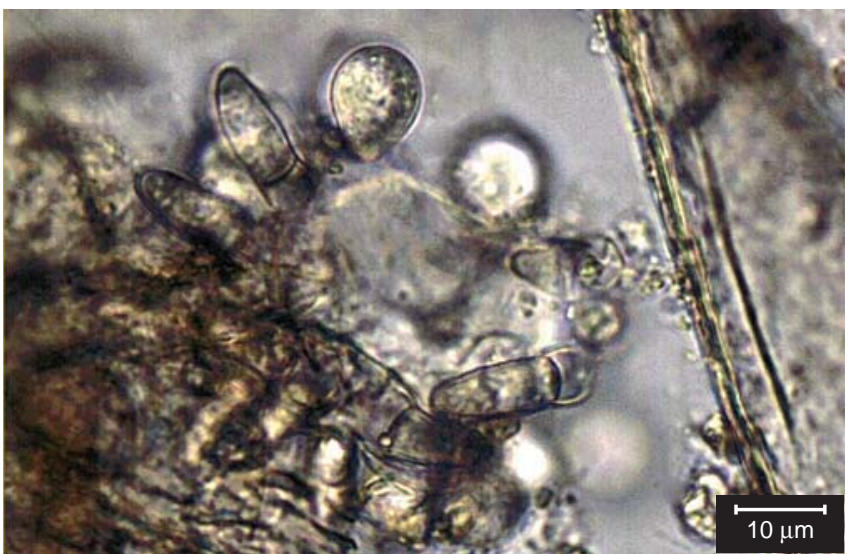

Figura 30. Septosperma rhizophydii parasitando Rhizophydium elyensis. Zoosporângio piriforme e esporos de resistência.

Figure 30. Septosperma rhizophydii parasitizing Rhizophydium elyensis. Pear-shaped zoosporangium and resting spores.

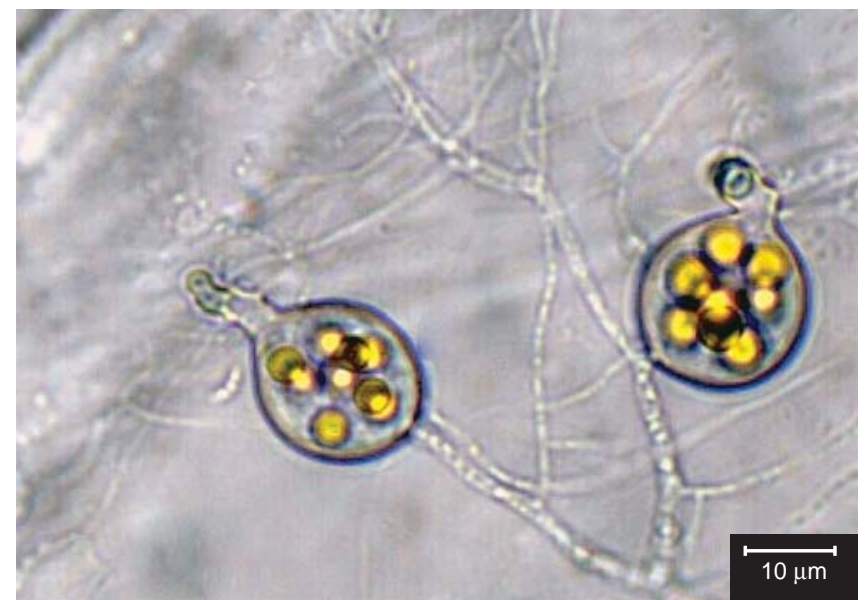

Figura 31. Cladochytrium replicatum. Zoosporângios com zoósporos.

Figure 31. Cladochytrium replicatum. Zoosporangia with zoospores.

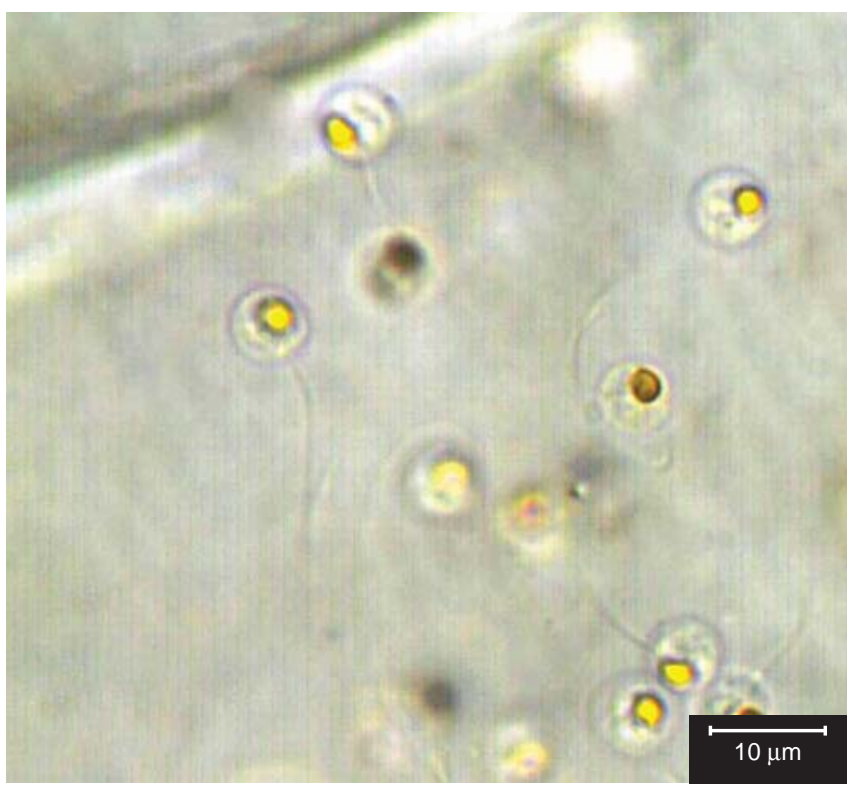

Figura 32. Cladochytrium replicatum. Zoósporos.

Figure 32. Cladochytrium replicatum. Zoospores.

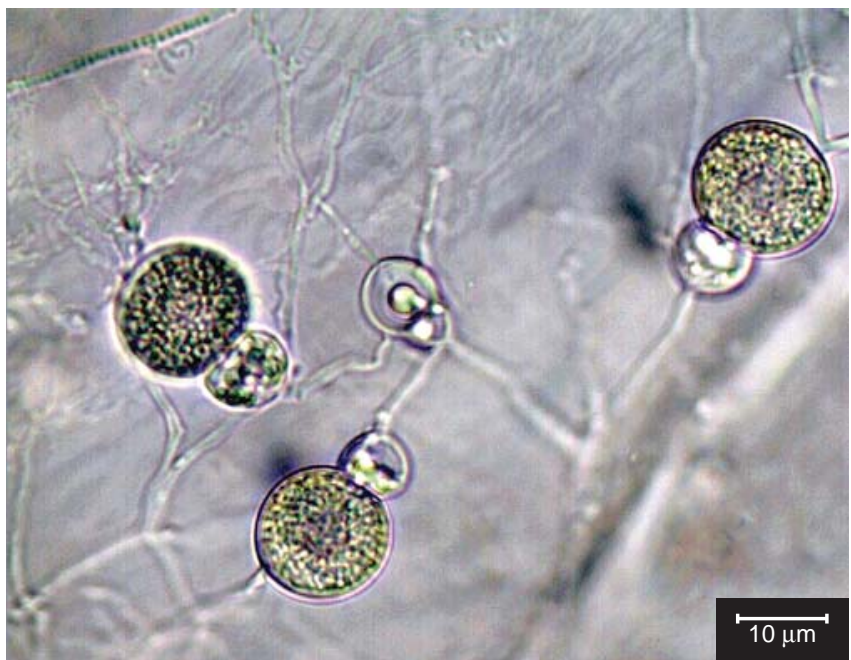

Figura 33. Cladochytrium tenue. Aspecto geral do rizomicélio.

Figure 33. Cladochytrium tenue. General aspect of the rhizomycelium.

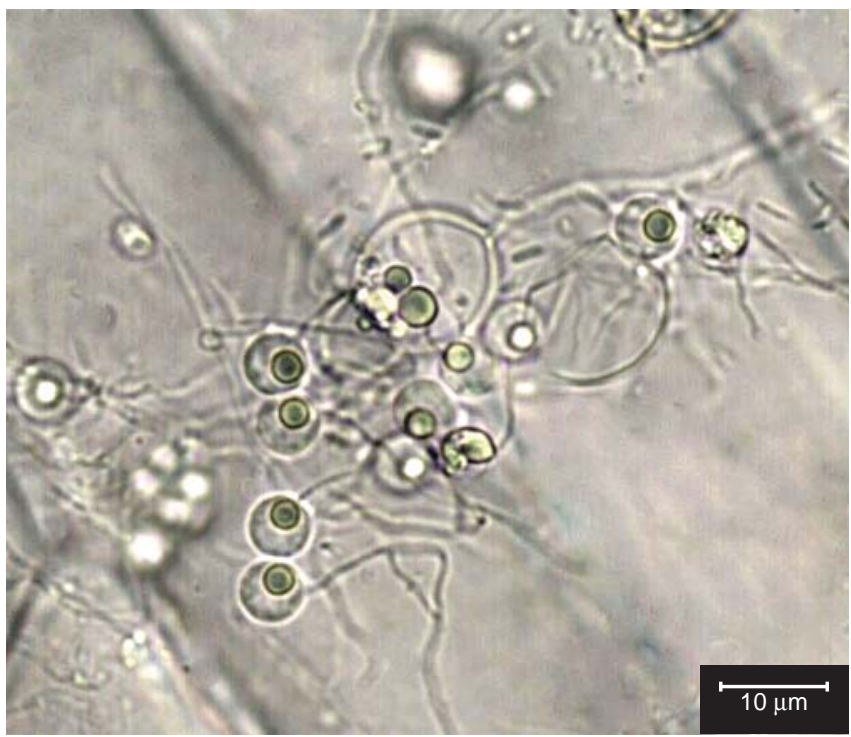

Figura 34. Cladochytrium tenue. Zoósporos liberados dos zoosporângios. Figure 34. Cladochytrium tenue. Zoospores.

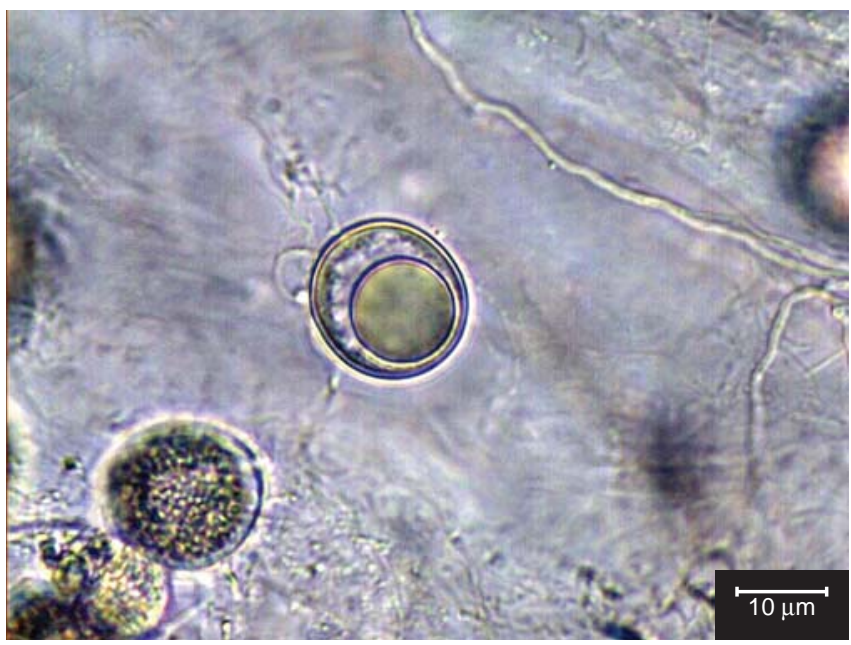

Figura 35. Cladochytrium tenue. Esporos de resistência.

Figure 35. Cladochytrium tenue. Resting spores. 


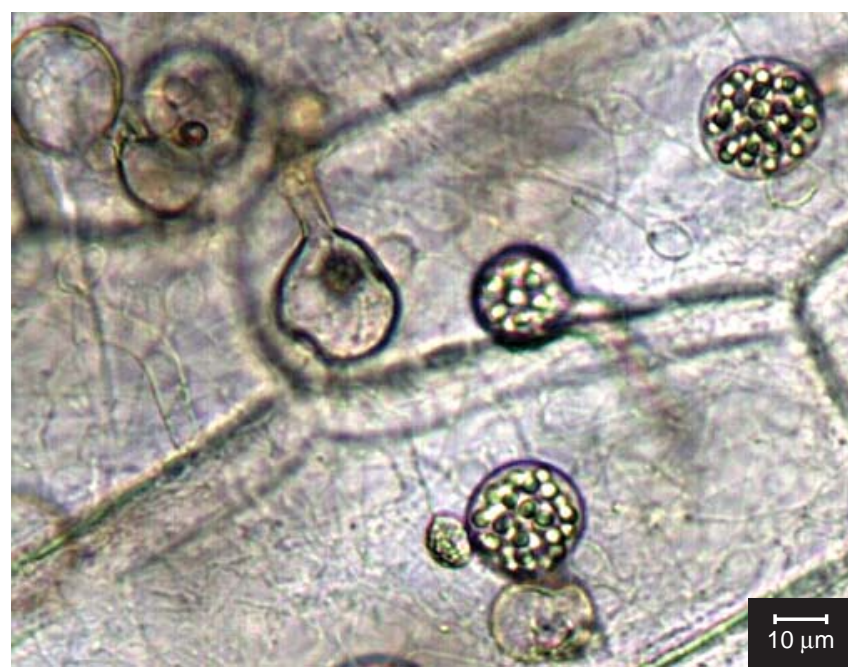

Figura 36. Nowakowskiella elegans. Aspecto geral do talo em epiderme de cebola.

Figure 36. Nowakowskiella elegans. General aspect of the thallus in onion skin.

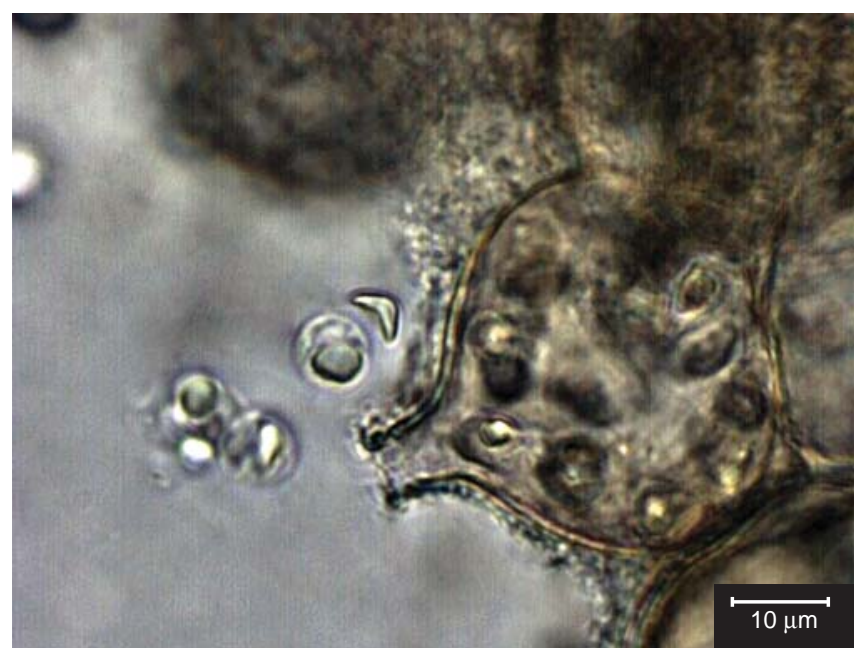

Figura 37. Nowakowskiella elegans. Liberação dos zoósporos, evidenciando o opérculo caído ao lado do zoosporângio.

Figure 37. Nowakowskiella elegans. Zoosporangium discharge with operculum nearby.

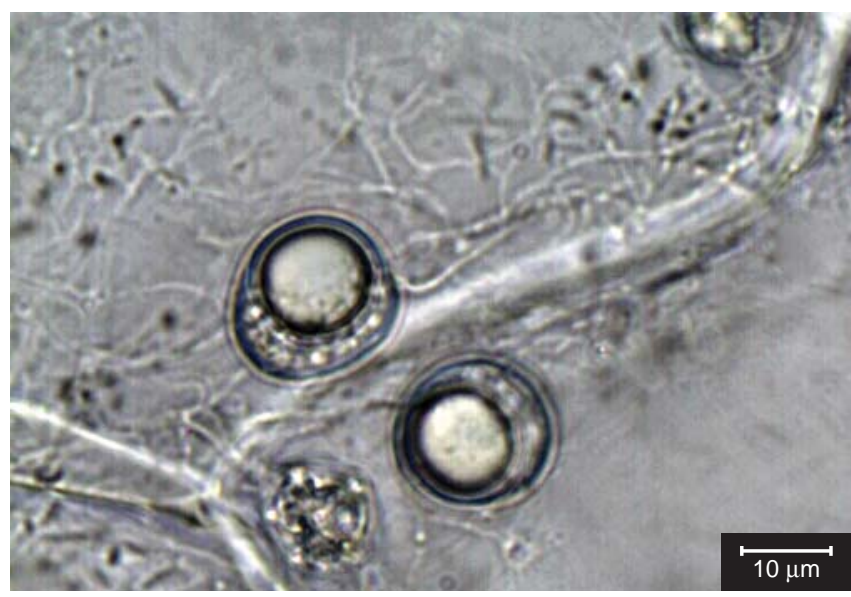

Figura 38. Nowakowskiella elegans. Esporos de resistência.

Figure 38. Nowakowskiella elegans. Resting spores.

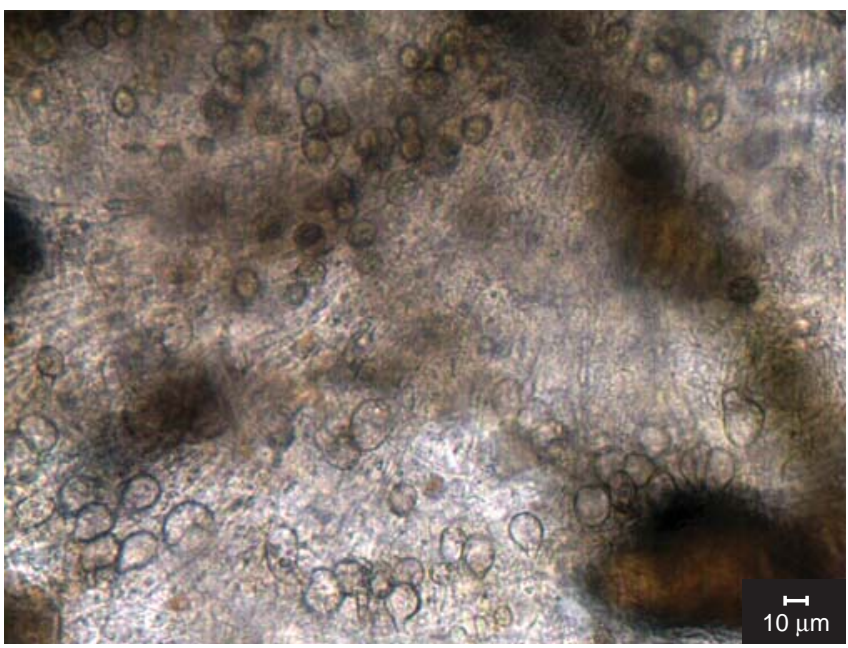

Figura 39. Nowakowskiella multispora. Aspecto geral do talo com zoosporângios e esporos de resistência intercalares ao rizomicélio.

Figure 39. Nowakowskiella multispora. General aspect of the thallus with zoosporangia and intercalary resting spores in the rhizomycelium.

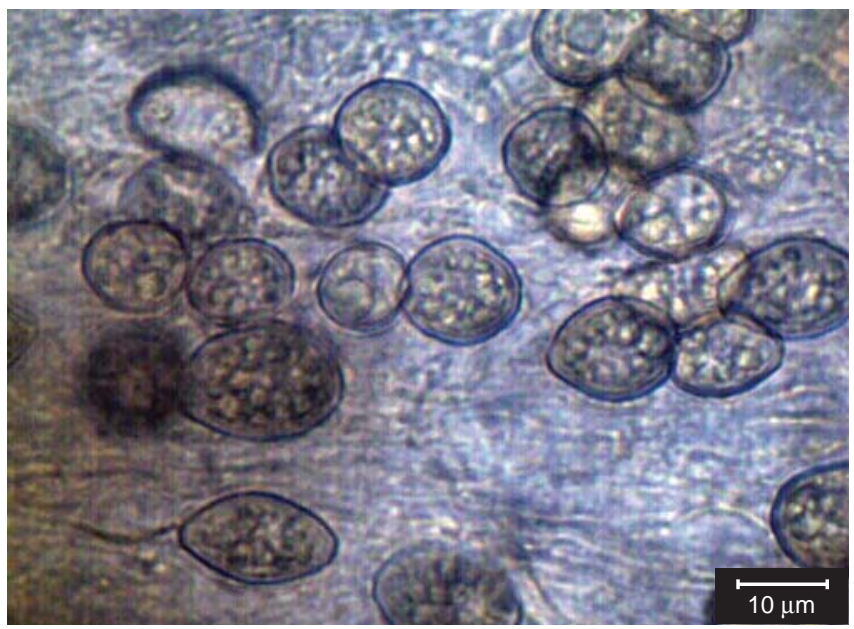

Figura 40. Nowakowskiella multispora. Detalhe dos esporos de resistência. Figure 40. Nowakowskiella multispora. Detail of resting spores.

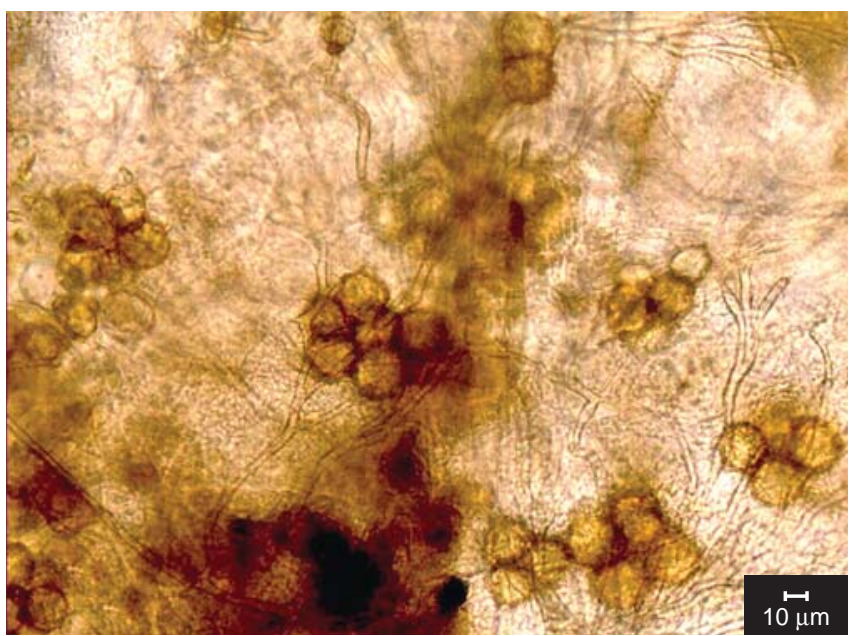

Figura 41. Polychytrium aggregatum. Aspecto geral do talo em ecdise de cobra.

Figure 41. Polychytrium aggregatum. General aspect of the thallus in snake skin. 


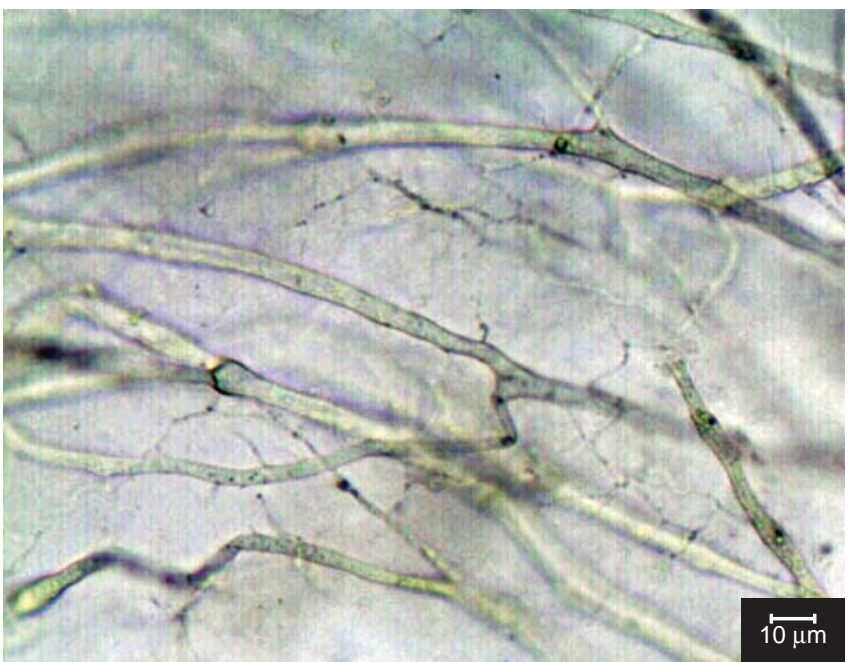

Figura 42. Polychytrium aggregatum. Rizomicélio em meio de cultura.

Figure 42. Polychytrium aggregatum. Rhizomycelium in culture medium.

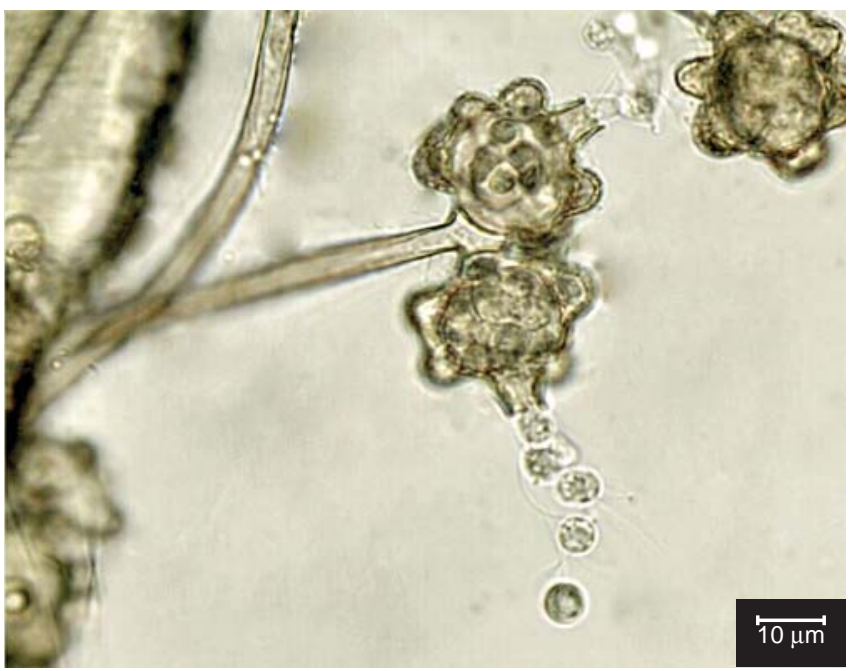

Figura 43. Polychytrium aggregatum. Liberação de zoósporos dos zoosporângios.

Figure 43. Polychytrium aggregatum. Zoosporangia discharging.

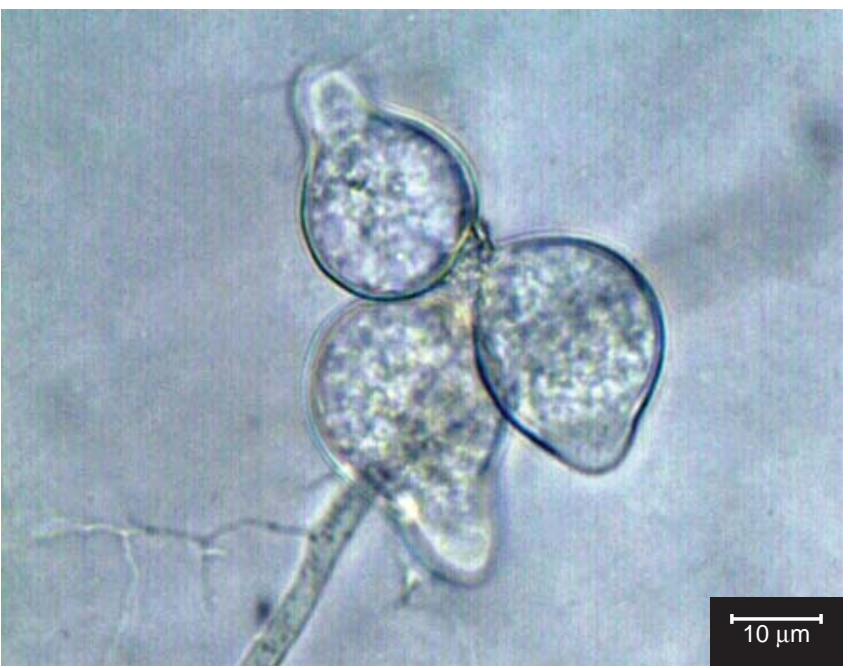

Figura 44. Polychytrium aggregatum. Formação de zoosporângios em meio de cultura.

Figure 44. Polychytrium aggregatum. Zoosporangia in culture medium.

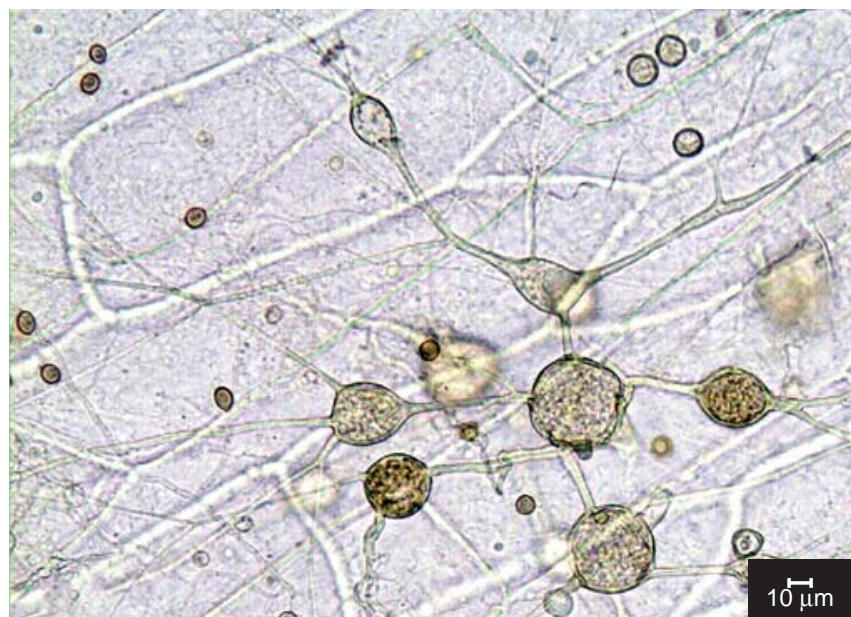

FIgura 45. Septochytrium marilandicum. Talo policêntrico em epiderme de cebola.

Figure 45. Septochytrium marilandicum. Polycentric thallus in onion skin.

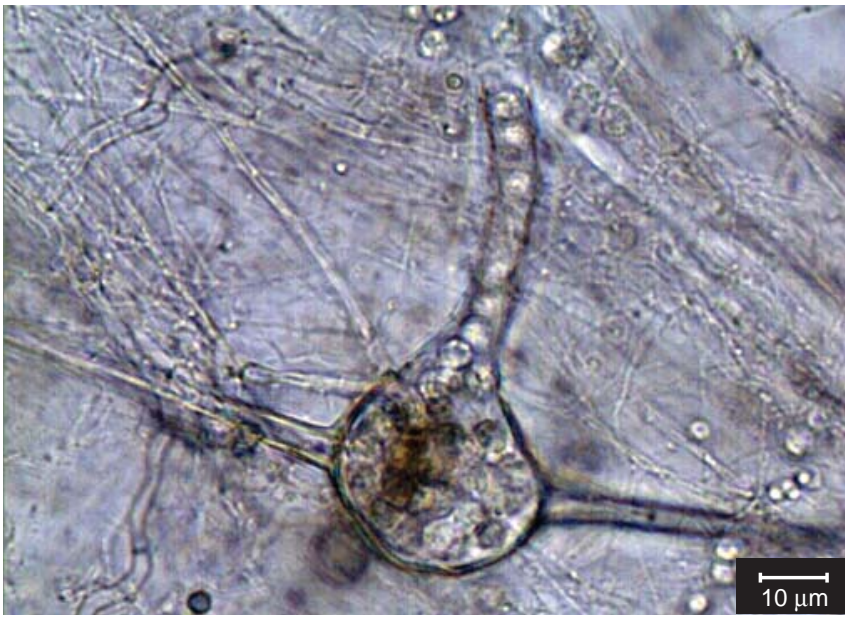

Figura 46. Septochytrium marilandicum. Zoósporos dentro e fora do zoosporângio.

Figure 46. Septochytrium marilandicum. Zoospores in and out of zoosporangia.

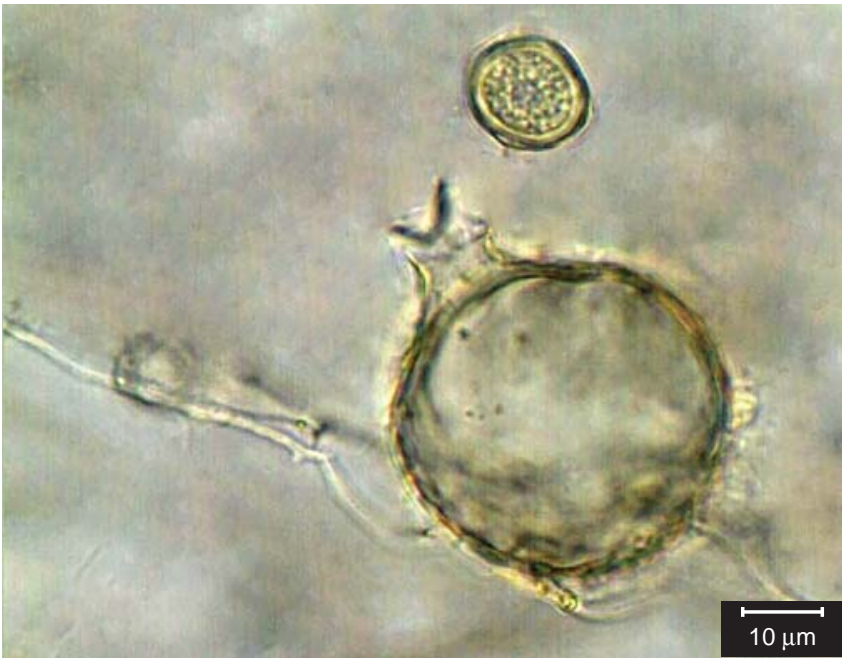

Figura 47. Septochytrium marilandicum. Zoosporângio vazio com opérculo ao lado e esporo de resistência.

Figure 47. Septochytrium marilandicum. Empty zoosporangium with operculum and resting spore. 


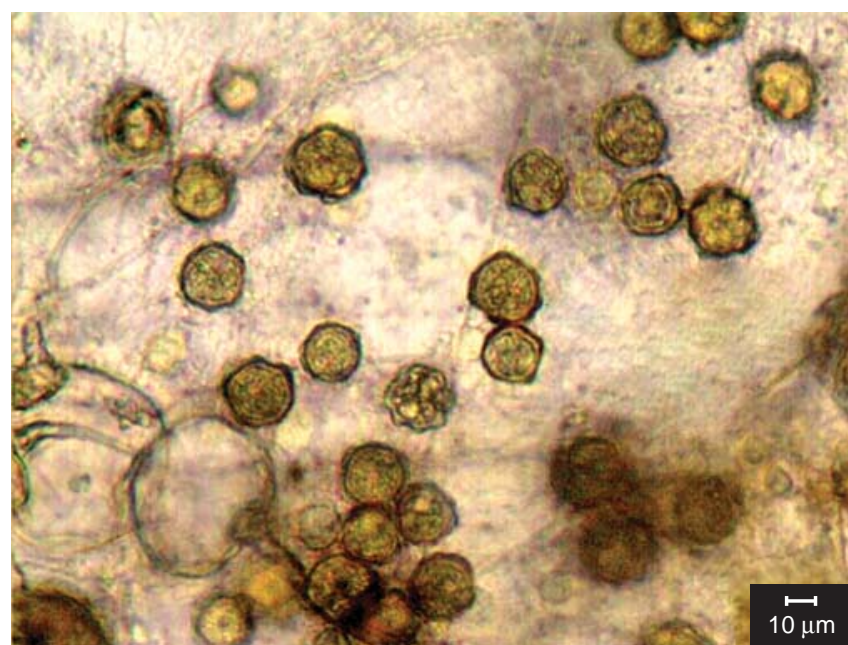

Figura 48. Septochytrium marilandicum. Detalhe dos esporos de resistência. Figure 48. Septochytrium marilandicum. Detail of resting spores.

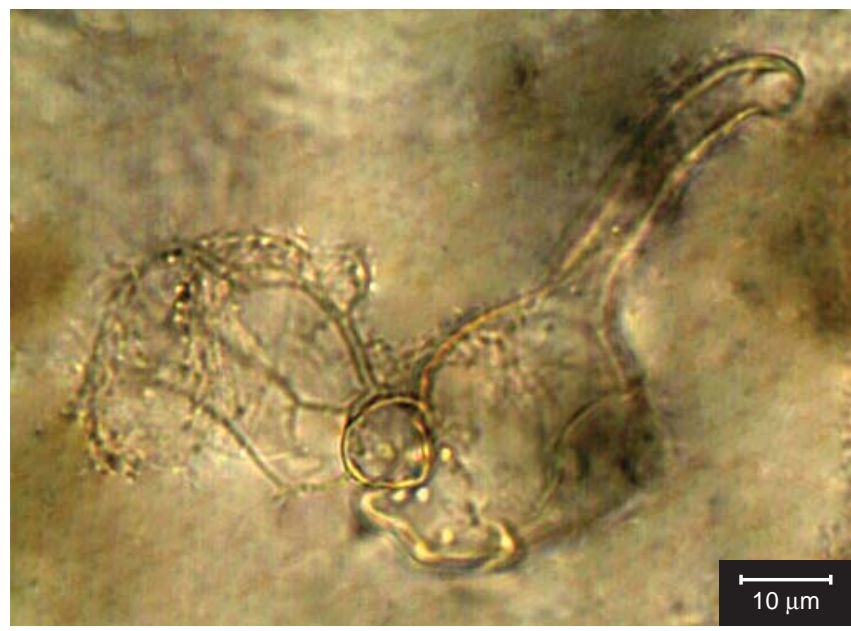

Figura 49. Diplophlyctis asteroidea. Zoosporângio apofisado com tubo de liberação.

Figure 49. Diplophlyctis asteroidea. Apophysate zoosporangium with discharge tube.

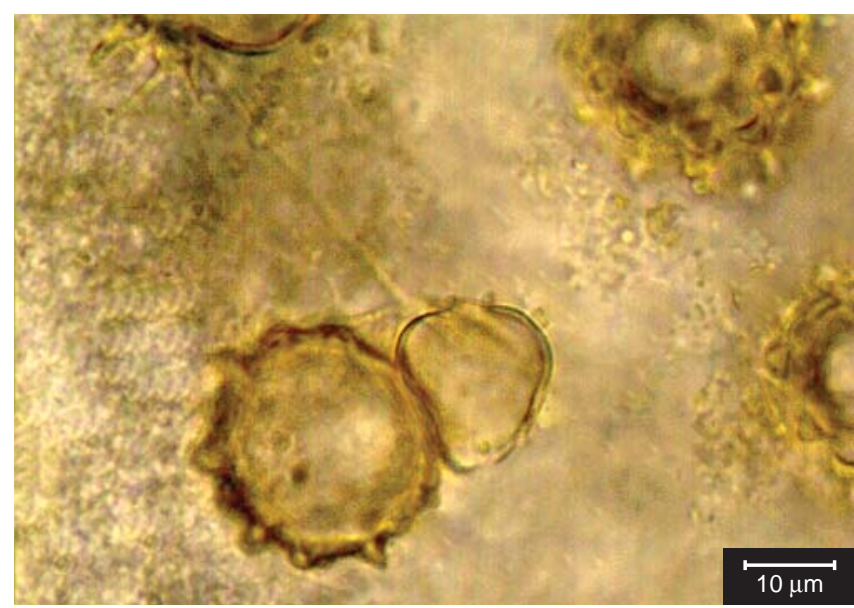

Figura 50. Diplophlyctis sarcoptoides. Zoosporângio com apófise em substrato quitinoso.

Figure 50. Diplophlyctis sarcoptoides. Apophysate zoosporangium in chitinous substrate.

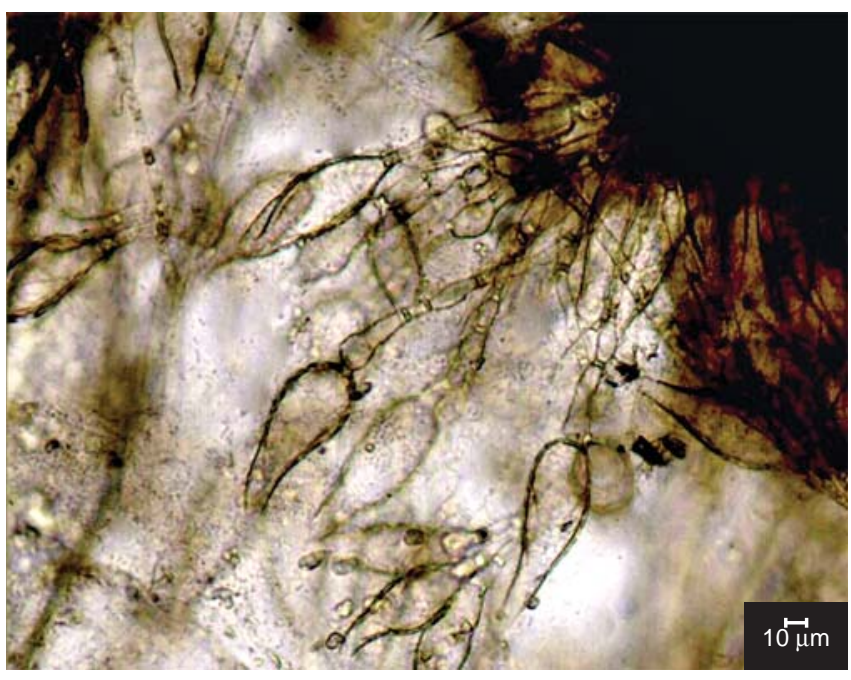

Figura 51. Gonapodya prolifera. Aspecto geral do talo.

Figure 51. Gonapodya prolifera. General aspect of the thallus.

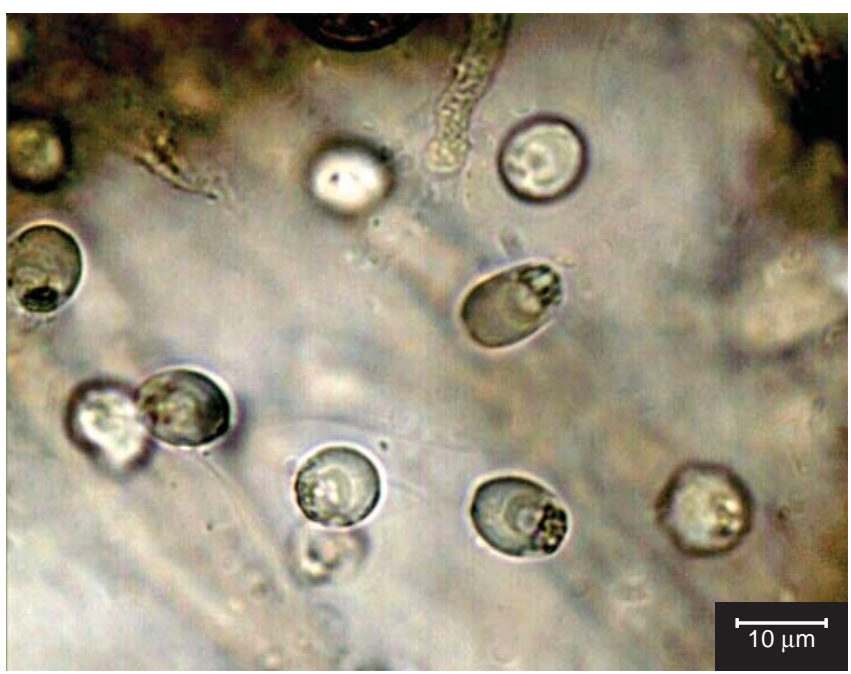

Figura 52. Gonapodya prolifera. Zoósporos.

Figure 52. Gonapodya prolifera. Zoospores.

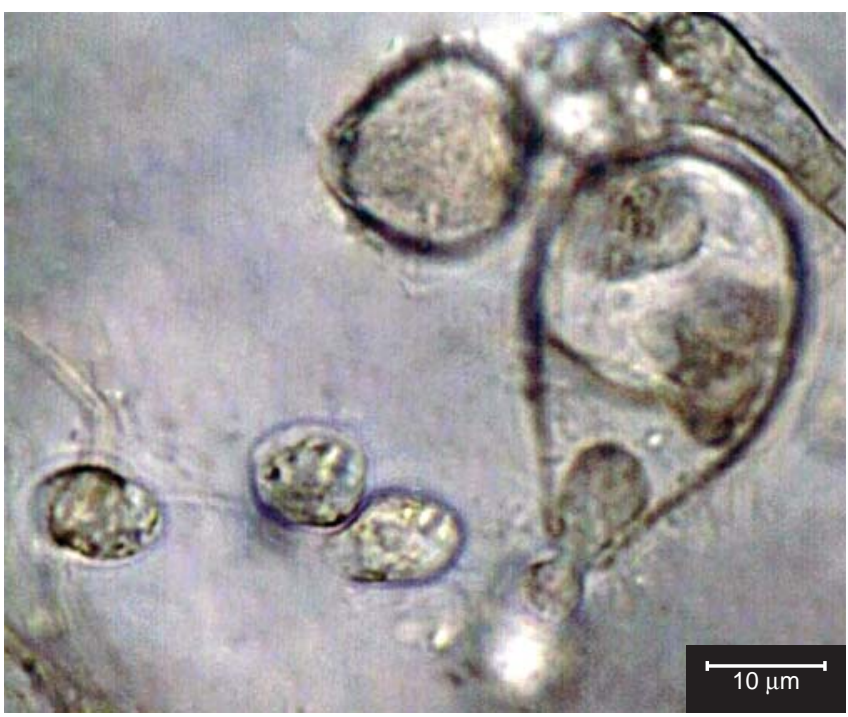

Figura 53. Gonapodya prolifera. Gametângio feminino.

Figure 53. Gonapodya prolifera. Female gametangium. 


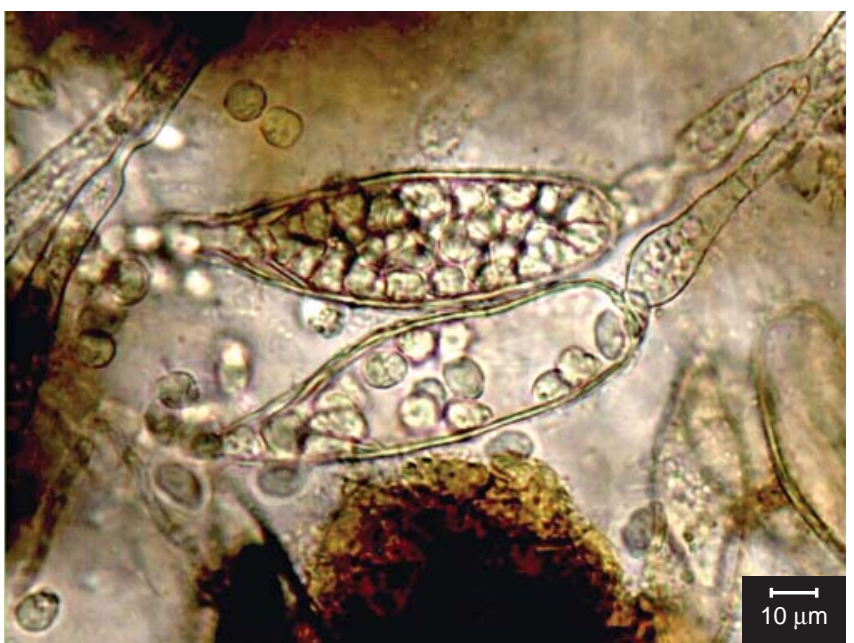

Figura 54. Gonapodya prolifera. Gametângio masculino.

Figure 54. Gonapodya prolifera. Male gametangium.

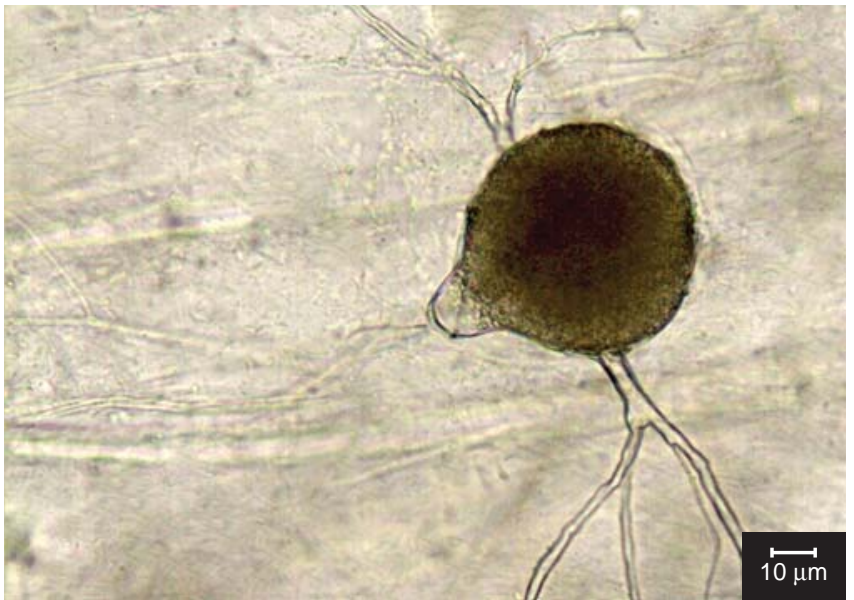

Figura 55. Karlingia granulata. Aspecto geral do zoosporângio.

Figure 55. Karlingia granulata. Zoosporangium.

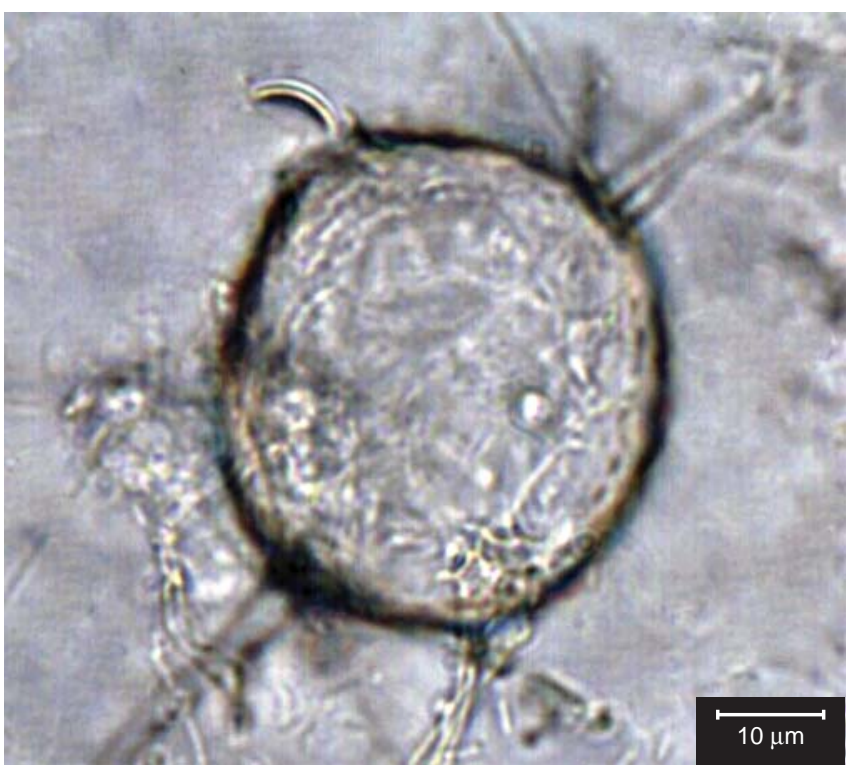

Figura 56. Karlingia granulata. Zoosporângio vazio com opérculo ao lado.

Figure 56. Karlingia granulata. Empty zoosporangium with the operculum beside.

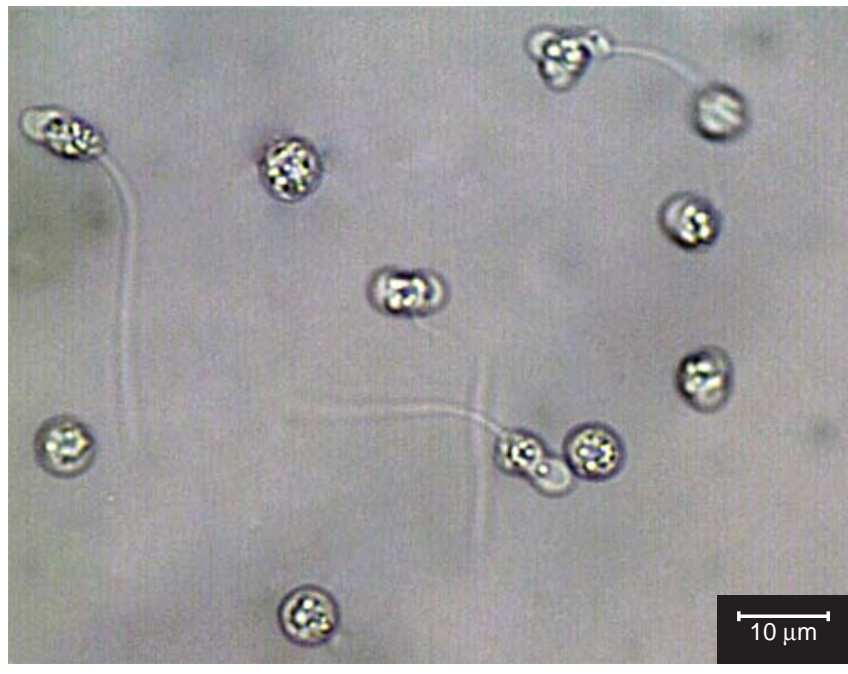

Figura 57. Karlingia granulata. Zoósporos.

Figure 57. Karlingia granulata. Zoospores.

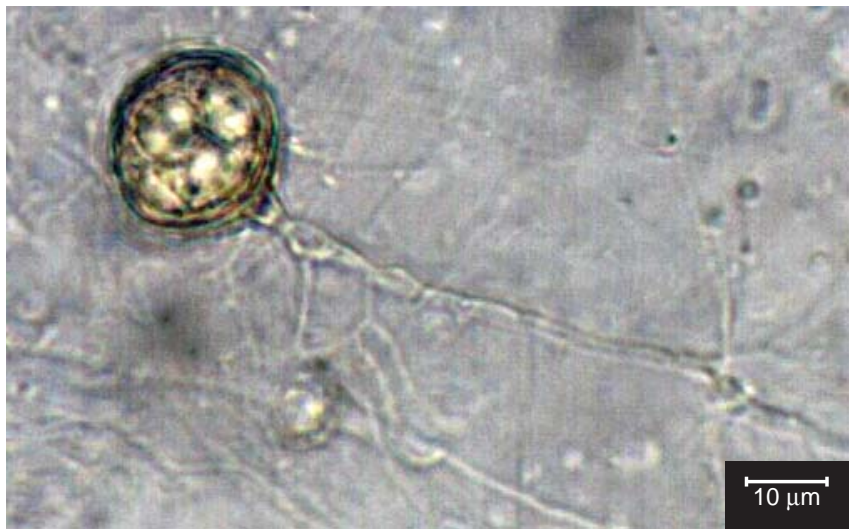

Figura 58. Karlingia granulata. Esporo de resistência.

Figure 58. Karlingia granulata. Resting spore.

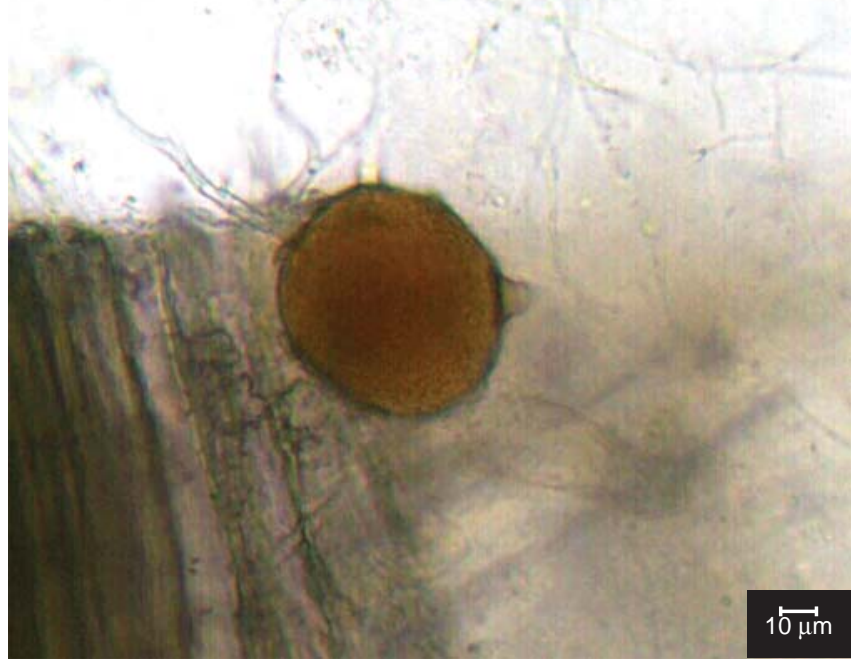

Figura 59. Karlingia rosea. Zoosporângio em palha de milho. Figure 59. Karlingia rosea. Zoosporangium in corn straw. 


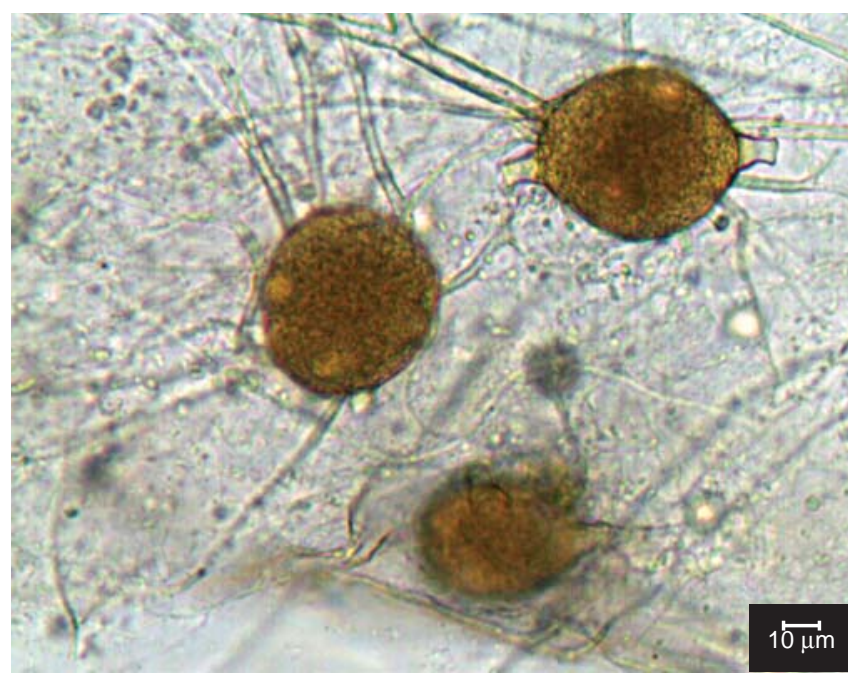

Figura 60. Karlingia rosea. Zoosporângios em epiderme de cebola.

Figure 60. Karlingia rosea. Zoosporangia in onion skin.

\section{Referências Bibliográficas}

AJELLO, L. 1942. Polychytrium, a new cladochytriaceous genus. Mycologia $34: 442-451$.

AJELLO, L. 1945. Phlyctochytrium aureliae parasitized by Rhizophydium chytriophagum. Mycologia 37:109-119.

AJELLO, L. 1948. A cytological and nutrition study of Polychytrium aggregatum. I. Citology. Am. J. Bot. 35:1-12.

ALEXOPOUlOS, C.J., MIMS, C.W. \& BLACKWELL, M.B. 1996. Introductory Mycology. $4^{\text {th }}$ ed. John Wiley \& Sons, New York.

ANTUNES, M.F.R., NINOMYIA, A. \& SCHOENLEIN-CRUSIUS, I.H. 1993. Efeitos da queimada sobre a micota de solo de Mata Atlântica, na "Reserva Biológica de Paranapiacaba", SP. Hoehnea 20:1-8.

BARR, D.J.S. 1990. Phylum Chytridiomycota. In Handbook of Protoctista (Margulis, L., Corliss, J.O., Melkonian, M. \& Chapman, D.J., eds.). Boston: Jones and Bartlett Publishers. p. 454-466.

BARR, D.J.S. 1992. Evolution and kingdoms of organisms from the perspective of a mycologist. Mycologia 84:1-11.

BARR, D.J.S. 2001. Chytridiomycota. In The Mycota - Systematics and Evolution (McLaughlin, D.J., McLaughlin, E.G. \& Lemke, P. A., eds.). v. 7, Part A, p.93-112.

BOOTH, T. 1979. Strategies for study of fungi in marine and marine influenced ecosystems. Rev. Microbiol. 10:123-138.

CANTER, H.M. 1949. Studies on British chytrids. VII. Phlyctochytrium mucronatum n. sp. Trans. Br. Mycol. Soc. 32:236-240.

CARNAVAL, A.C.O.Q., TOLEDO, L.F., HADDAD, C.F.B. \& BRITTO, F.B. 2005. Chytrid fungus infects high-altitude stream-dwelling Hylodes magalhaesi (Leptodactylidae) in the Brazilian Atlantic rainforest. Froglog $70: 3$.

DE VUONO, Y.S., DOMINGOS, M. \& LOPES, M.I.M.S. 1989. Decomposição de serapilheira e liberação de nutrientes na floresta da Reserva Biológica de Paranapiacaba, sujeito aos poluentes atmosféricos de Cubatão, São Paulo, Brasil. Hoehnea 16:179-188.

DOGMA JUNIOR, I.J. 1974a. Studies on chitinophylic Siphonaria, Diplophlyctis and Rizoclosmatium, Chytridiales. III. Nephochytrium complicatus Wiloughby: another Diplophlyctis with a sexual phase. Nova Hedwigia 25:143-159.

DOGMA JUNIOR, I.J. 1974b. Developmental and taxonomic studies on rhizophlyctoid fungi, Chytridiales. IV. Karlingia granulata, Karlingia spinosa and Karlingiomyces dubius. Nova Hedwigia 25:91-105.

DOGMA JUNIOR, I.J. 1976. Studies on chitinophilic Siphonaria, Diplophlyctis and Rhizoclosmatium, Chytridiales. V. Diplophlyctis

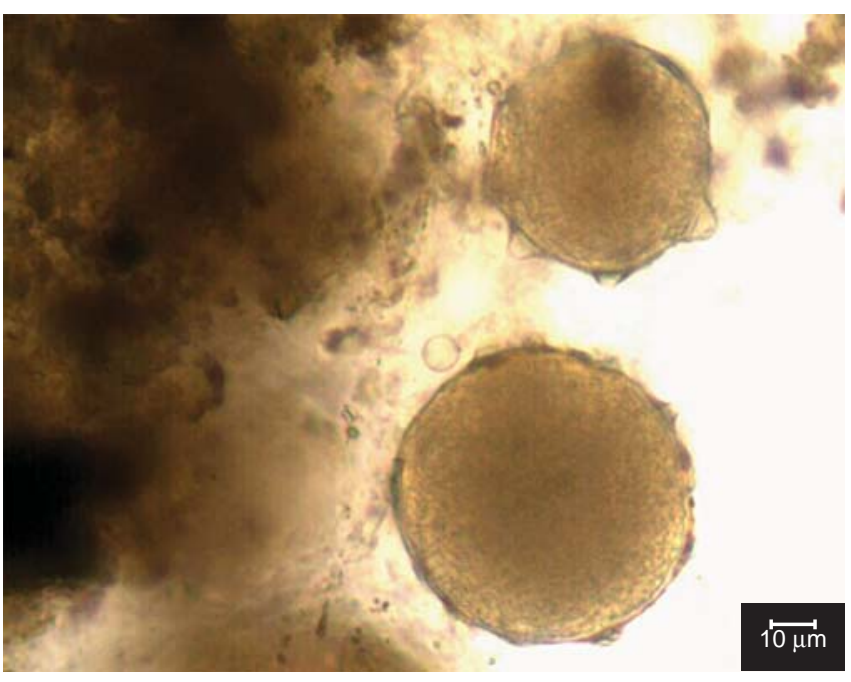

Figura 61. Karlingia rosea. Detalhe dos zoosporângios.

Figure 61 Karlingia rosea. Detail of zoosporangia.

asteroidea, a new species with asexual resting spores. Trans. Br. Mycol. Soc. 67:255-264.

DOMINGOS, M. 1987. Aspectos da ciclagem de nutrientes na Reserva Biológica de Paranapiacaba (São Paulo), sujeita aos poluentes aéreos do complexo industrial de Cubatão. Dissertação de Mestrado, Universidade de São Paulo, São Paulo.

FAY, D.J. 1947. Chytriomyces spinosus nov. sp. Mycologia 39:152-157.

HANSON, A.M. 1944. Three new saprophytic chytrids. Torreya 44:30-33.

HANSON, A.M. 1945. A morphological developmental, and cytological study of four saprophytic chytrids. II. Rhizophydium coronum. Am. J. Bot. 32:479-487.

HAWKSWORTH, D.L.. KIRK, P.M., SUTTON, B.C. \& PEGLER, D.M. 1995. Ainsworth \& Bisby's Dictionary of the Fungi. 8th ed. International Mycological Institute, Egham.

KARLING, J.S. 1944. Brazilian chytrids. II New species of Rhizidium. Am. J. Bot. 31:254-261.

KARLING, J.S. 1945a. Brazilian chytrids. VI. Rhopalophlyctis and Chytriomyces, two new chitinophilic operculate genera. Am. J. Bot. 32:362-369.

KARLING, J.S. 1945b. Brazilian chytrids. V. Nowakowskiella macrospora $\mathrm{n}$. sp., and other polycentric species. Am. J. Bot. 32:29-35.

KARLING, J.S. 1945c. Brazilian chytrids. VII. Observations relative to sexuality in two new species of Siphonaria. Am. J. Bot. 32:580-587.

KARLING, J.S. 1946. Keratinophilic Chytrids. I. Rhizophydium keratinophilum n.sp., a saprophyte isolated on human hair, and its parasite, Phlyctidium mycetophagum n. sp. Am. J. Bot. 33:751-757.

KARLING, J.S. 1947a. New species of Chytriomyces. Bull. Torrey Bot. Club 74:334-344.

KARLING, J.S. 1947b. Brazilian chytrids. X. New species with sunken opercula. Mycologia 39:56-70.

KARLING, J.S. 1951. Cladochytrium setigerum sp. nov. and Septochytrium marilandicum sp. nov. from Maryland. Bull. Torrey Bot. Club 78:3843.

KARLING, J.S. 1964. Indian chytrids. IV. Nowakowskiella multispora sp. nov. and other polycentric species. Sydowia 17:314-319.

KARLING, J.S. 1965. Catenophlyctis, a new genus of the Catenariaceae. Am. J. Bot. 52:133-138.

KARLING, J.S. 1967. Some zoosporic fungi of New Zealand. Sydowia 20:74-84.

KARLING, J.S. 1968. Zoosporic fungi of Oceania. III. Monocentric chytrids. Arch. Mikrobiol. 61:112-127. 
KARLING, J.S. 1977. Chytridiomycetarum Iconographia. J. Cramer, Vaduz.

KIRK, P. M., CANNON, P. F., DAVID, J. C. \& STALPERS, J. A. 2001. Ainsworth \& Bisby`s Dictionary of the Fungi. 9th ed. CABI Bioscience, Wallingford.

KONNO, K. 1972. Studies of Japanese lower aquatic Phycomycetes. Sci. Rep. Tokyo Kyoiku Daigaku 14:227-292.

MILANEZ, A.I. 1974. Notes on the genus Septosperma Whiffen ex Seymour. Rickia 6:63-70.

MILANEZ, A. I. 1984a. Fungos zoospóricos do estado de São Paulo. II. Chytridiomycetes da Região Oeste. Rickia 11:115-127.

MILANEZ, A.I. 1984b. Distribuição geográfica de Karlingia rosea (de Bary $\&$ Woronin) Johanson no Brasil. In Anais do $4^{\circ}$ Congresso da Sociedade Botânica de São Paulo, Rio de Janeiro, p.73-76.

MILANEZ, A.I. 1989. Fungos de águas continentais. In Técnicas de coleta preservação e herborização de material botânico. (O. Fidalgo \& V.L.R. Bononi, coords.). Série Documentos, Instituto de Botânica, São Paulo. p. 17-20.

MILANEZ, A.I. \& TRUFEM, S.F.B. 1981. Ficomicetos em frutos submersos do Parque Estadual das Fontes do Ipiranga, São Paulo. Rickia 9:7-15.

MILANEZ, A.I. \& TRUFEM, S.F.B. 1984. Fungos zoospóricos em frutos submersos do Parque Estadual das Fontes do Ipiranga, São Paulo. II. Rickia 11:77-84.

MILANEZ, A.I., PIRES-ZOTTARELLI, C.L.A. \& SCHOENLEINCRUSIUS, I.H. 1994a. Fungos aquáticos da região de Mata Atlântica no estado de São Paulo. III Simpósio de Ecossistemas da Costa Brasileira, ACIESP. p. 142-149.

MILANEZ, A.I., PIRES-ZOTTARELLI, C.L.A. \& SCHOENLEIN-CRUSIUS, I.H. 1994b. Criptógamos do Parque Estadual das Fontes do Ipiranga, São Paulo, SP. Fungos, 1: Monoblepharidales. Hoehnea 21:157-161.

MILANEZ, A.I., PIRES-ZOTTARELLI, C.L.A., SCHOENLEIN-CRUSIUS, I.H. \& LOHMANN, L.G. 2003. Criptógamos do Parque Estadual das Fontes do Ipiranga, São Paulo, SP. Fungos, 8: Blastocladiales. Hoehnea 30:21-29.

NASCIMENTO, C. A. 2007. Diversidade de Chytridiomycota do Parque Estadual da Serra da Cantareira, Estado de São Paulo. Dissertação de Mestrado. Instituto de Botânica de São Paulo, São Paulo.

PIRES-ZOTTARELLI, C.L.A. 1990 Levantamento dos fungos zoospóricos da Represa do Lobo ("Broa"), São Carlos, SP. Dissertação de Mestrado. Universidade Estadual Paulista, Rio Claro.

PIRES-ZOTTARELLI, C.L.A. 1999. Fungos zoospóricos dos Vales dos Rios Moji e Pilões, Região de Cubatão, São Paulo SP. Tese de Doutorado. Universidade Estadual Paulista, Rio Claro.

PIRES-ZOTTARELLI, C.L.A. \& MILANEZ, A.I. 1993. Fungos zoospóricos da "Represa do Lobo" ("Broa"). Novas citações para o Brasil. Revista Brasil. Bot. 16:205-220.

PIRES-ZOTTARELLI, C.L.A., SCHOENLEIN-CRUSIUS, I.H. \& MILANEZ, A.I. 1993. Quantitative estimation of zoosporic fungi and aquatic Hyphomycetes on leaves submerged in a stream in the atlantic rainforest, in the state of São Paulo, Brazil. Rev. Microbiol. 24:192-197.
PIRES-ZOTTARELLI, C.L.A., MILANEZ, A.I., SCHOENLEIN-CRUSIUS, I.H. \& LOHMANN, L.G. 1996. Criptógamos do Parque Estadual das Fontes do Ipiranga, São Paulo, SP. Fungos, 6: Chytridiales. Hoehnea 23:77-90.

PIRES-ZOTTARELLI, C.L.A, GOMES, A.L. \& NASCIMENTO, C.A. 2007. Entophlyctis luteolus in the Brazilian Atlantic Rainforest. Mycotaxon 99:207-210.

ROCHA, M. \& PIRES-ZOTTARELLI, C.L.A. 2002. Chytridiomycota e Oomycota da Represa do Guarapiranga, São Paulo, SP. Acta bot. bras. 16:287-309.

ROGERS, A.L., MILANEZ, A.I. \& BENEKE, E.S. 1970. Additional aquatic fungi from São Paulo State. Rickia 5:93-110.

SCHOENLEIN-CRUSIUS, I.H. 1993. Sucessão fúngica em folhas de Alchornea triplinervia (Spreng.) M. Arg. em ambientes aquático e terrestre, na Mata Atlântica, Reserva Biológica do Alto da Serra de Paranapiacaba, Santo André, SP. Tese de Doutorado. Universidade Estadual Paulista, Rio Claro.

SCHOENLEIN-CRUSIUS, I.H. \& MILANEZ, A.I. 1996. Diversity of aquatic fungi in Brazilian ecosystems. In Biodiversity in Brazil - A first approach (Bicudo, C.E.B. \& Menezes, N.A., eds). São Paulo, CNPq. p. 31-48.

SCHOENLEIN-CRUSIUS, I.H. \& MILANEZ, A.I. 1998. Fungos zoospóricos (Mastigomycotina) da mata atlântica da "Reserva Biológica de Paranapiacaba", município de Santo André, SP. Revista Brasil. Bot. 2:177-181.

SCHOENLEIN-CRUSIUS, I.H., PIRES-ZOTTARELLI, C.L.A. \& MILANEZ, A.I. 1992. Aquatic fungi in leaves submerged in a stream in the Atlantic rainforest. Rev. Microbiol. 23:167-171.

SCHOENLEIN-CRUSIUS, I.H., PIRES-ZOTTARELLI, C.L.A., MILANEZ, A.I. \& HUMPHREYS, R.D. 1999. Interaction between the mineral content and the occurrence number of aquatic fungi in leaves submerged in a stream in the Atlantic rainforest, São Paulo, Brazil. Revista Brasil. Bot. 22:133-139.

SCHOENLEIN-CRUSIUS, I.H., MILANEZ, A.I., TRUFEM, S.F.B., PIRES-ZOTTARELLI, C.L.A., GRANDI, R.A.P., SANTOS, M.L. \& GIUSTRA, K.C. 2006. Microscopic fungi in the Atlantic Rainforest in Cubatão, São Paulo, Brazil. Braz. J. Microbiol. 37:244-252.

SEYMOUR, R.L. 1971. Studies on mycoparasitic chytrids. I. The genus Septosperma. Mycologia 63:83-93.

SILVA, M. I. L. 2002. Micobiota de água e de solo das margens de igarapés situados na área de mata do campus da Universidade do Amazonas, Manaus, AM. Tese de Doutorado. Universidade de São Paulo, São Paulo.

SPARROW JR., F.K. 1957. A further contribution to the Phycomycete flora of Great Britain. Trans. Br. Mycol. Soc. 40:523-535.

SPARROW JR., F.K. 1960. Aquatic Phycomycetes. $2^{\text {a }}$ ed. University of Michigan Press. Ann Arbor.

WILLOUGHBY, L.G. 1964. A study of the distribution of some lower fungi in soil. Nova Hedwigia 7:133-150. 